Ann. Abeille, I962, 5 (I), 5-58.

\title{
BAU UND FUNKTION DES PERIPHEREN NERVENSYSTEMS AN DEN FORTPFLANZUNGSORGANEN DER DROHNEN (*)
}

\author{
F. RUTTNER \\ Bundesanstalt für Bienenkunde, Wien, Aussenstelle Lunz am See, \\ und \\ 1. Zoologisches Institut der Universität Wien
}

\section{EINLEITUNG}

Die morphologische Untersuchung des Sensoriums der Arthropoden hat infolge der bedeutungsvollen Eirgebnisse auf dem Gebiete der Sinnesphysiologie und Ethologie eine besondere Aktualität erlangt, wobei dem bisher am besten untersuchten Objekt, der Honigbiene, eine hervorragende Rolle zukommt. Es sei hier nur an die Feststellung der Perzeption des polarisierten Lichtes erinnert, die durch den Bau der Ommatidien verständlich wird (v. FRISCH I949, AuTRUM und STUMPF I950), von Hygrorezeptoren in den Antennen (KUWABARA und TUKEDA I956) und von Schweresinnesorganen an Thorax und Abdomen (LINDAUER und NEDEL I959).

Die vorliegende Untersuchung wurde durch Studien über den Paarungsvorgang bei der Honigbiene veranlasst, die gezeigt hatten, dass die beobachteten, in ganz bestimmter Weise miteinander koordinierten Vorgänge einen differenzierten nervösen Apparat zur Voraussetzung haben müssen (RUTTNER I957). Das Schwergewicht wurde auf die Untersuchung der histologischen Feinstruktur der nervösen Endapparate gelegt; die segmentale Zuordnung der einzelnen Nerven sowie die Endigungen an den weiblichen Fortpllanzungsorganen werden an anderer Stelle behandelt (RUTTTNER I96I).

\section{I. - MATERIAI UND METHODIK}

Der Fragestellung entsprechend, wurden vor allem die Geschlechtstiere, Königinnen (o९) und Drohnen $\left(\delta^{\top}\right)$, untersucht, die in dem Zuchtbetrieb der Bundesanstalt für Bienenkunde (Wien) in Lunz am See den ganzen Sommer über in genügender Anzahl zur Verfügung standen. Die sehr umfangreichen Vorversuche wurden an Arbeitsbienen durchgeführt.

Von vorneherein schien klar, dass eine befriedigende Behandlung des Themas nur dann zu erreichen war, wenn es gelang, eine selektive Färbung der nervösen Gewebselemente zu erzielen. Um alle dem peripheren Nervensystem angehörigen Strukturen aufzu finden, musste das Präparat in toto gefärbt werden ; es kam also nur eine vitale oder supravitale Färbemethode in Frage.

(i) Herrn Prof. Karl v. Friscrt in dankbarer Verehrung zu seinem 75. Geburtstag gewidmet. 


\section{A. VERSUCHE MIT SUPRAVITALER METHYLENBLAUF ÄRBUNG}

An Bienenorganen, in physiologischer Kochsalzlösung präpariert, sind etwa noch eine halbe Stunde lang Lebensäusserungen wahrzunehmen (Kontraktionen der Muskulatur von Darm, Malpighischen Gefässen, Ovarien und Stachelapparat, Pulsation des Herzschlauches). Alle Versuche, ein solches supravitales Präparat mit einer Methylenblaulösung nach Ehrlich $(0,5-0,05$ p. Ioo Methylenblau in einer physiologischen $\mathrm{NaCl}$ - Lösung) oder nach Schabadasch (Zusätze von Glukose, brenztraubensaurem Natrium, Magnesiumchlorid oder Resorcin und Finstellung des $\mathrm{pH}$ auf einen bestimmten Wert) zu färben, führten zu unbefriedigenden Resultaten. Da sich immer auch andere Gewebe diffus mitfärbten, liess sich keine wirklich selektive Nervenfärbung erzielen. Wahrscheinlich sind manche Fehlinterpretierungen früherer Autoren — auf die noch zurückzukommen sein wird - - eine Folge der Anwendung dieser Methode.

\section{B. VERSUCHE MIT VITAIER METHYLENBLAUF ÄRBUNG}

Schliesslich führte eine sehr einfache Überlegung zum Erfolg : Der Ausbau der MethylenblauMethode erfolgte ursprünglich an Wirbeltieren. Man geht dort so vor, dass man das zu untersuchende Organ am lebenden, narkotisierten Tier mit der Farblösung durchströmt, indem man sie in die zuführende Arterie injiziert und gleichzeitig durch Oeffnen der abführenden Vene für Abfluss sorgt. Die benötigte Farbstoffmenge ist relativ gross; so sind zur Darstellung der Nerven in der Magenwand der Katze 2,5 l Methylenblaulösung erforderlich. Da offenbar das Nervengewebe wirbelloser Tiere dieselbe Affinität zu Methylenblau besitzt, stand zu erwarten, dass auch bei ihnen mit einer im Prinzip gleichartigen Methode ähnliche Ergebnisse zu erzielen sind; es musste also ein Weg gefunden werden, eine Farblösung im lebenden, möglichst wenig verletzten Tier kreisen zu lassen.

\section{Injektion einer Methylenblaulösung}

Eine der oben genannten oder eine stärker konzentrierte Methylenblaulösung wurde mit Hilfe einer feinen Injektionskanüle in die Leibeshöhle injiziert. Es zeigte sich jedoch, dass es angesichts der geringen Flïssigkeitsmenge, die der Insektenkörper zusätzlich aufnehmen kann, nicht möglich ist, die erforderliche Farbstoffkonzentration in der Hämolymphe zu erzielen. Versuche, durch Schaffung eines Abflusses eine Durchströmung zu erreichen, misslangen.

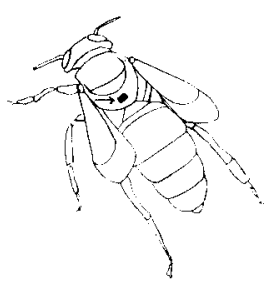

Abb. I. -- Operationsstelle am Propodaeum der $q$ sur Einbringung von Methylenblaukristalien (fiir due Darstellung der Nerven im Abdomen).

FIC. I. -- Ia fleche indique la place du propodeum oit se fait ches la reine

l'iniroduction de cristaux de bleu de méthylène pour la mise en évidence des nerts de l'abdomen.

\section{Implantation von Methylenblau-Substanz}

a) Methylenblau allein

Mit einer geschliffenen Nadel wird in das propodeale Tergum der narkotisierten $q$ eine kleine Offnung geschnitten (Abb. I). In diese wird eine kleine Menge (etwa eine Lanzettenspitze) von Methylenblau-Kristallen eingeführt, die sich in der Hämolymphe rasch lösen. Der ausgeschnittene Chitinlappen wird in die Oeffnung wieder eingefügt und die Wundstelle mit einem Tropfen Gummilack verschlossen (Methode nach FYG I 943). Die Verteilung des Farbstoffes kann auch bei dunkel gefärbten Tieren an der Färbung der Intersegmentalmembranen gut verfolgt werden. So behandelte Tiere leben ohne erkennbare Beeinträchtigung mehrere Tage lang (Bienen- 우 und $\sigma^{\star}{ }^{\star}$ lassen sich unter Laborbedingungen auch sonst nicht wesentlich länger halten). Die Präparation erfolgt I/2$24 \mathrm{~h}$ nach der Färbung (später blasst sie wieder ab). Wichtig ist, dass der Farbstoff nicht in denselben 
Körperabschnitt eingebracht wird, in dem die Nervendarstellung erfolgen soll, da sonst keine gleichmässige Färbung eintritt.

Ergebnis : Bei gelungener Färbung überaus selektive Darstellung der peripheren Nerven bis in ihre feinsten Verzweigungen.

Aber diese Methode ist ebenso launenhaft, wie die Methylenblaufärbung an Arthropoden allgemein geschildert wird; von Io Präparaten gelingen höchstens 2 oder 3. Das NS konnte ebensogut selektiv gefärbt wie selektiv nicht gefärbt sein - offenbar ganz abhängig vom jeweiligen Stoffwechselzustand. Für ein nur in begrenzter Zahl verfügbares Objekt wie eine Bienen $q$ war das Verfahren in dieser Form also nicht brauchbar.

\section{b) Methylenblau-Substanz mit Zusatz von Puffer - und Glukoselösungen}

Das Einbringen der Methylenblaukristalle erfolgt wie bei a. Nur wird vorher so viel als möglich von der aus der Wunde austretenden Hämolymphe abgesaugt. Nach mindestens teilweiser Auflösung des Farbstoffes werden in die Skelettöffnung $2-3$ Tropfen einer der Lösungen nach Schabadasch eingetropft (Puffer, bzw. reduzierende Substanzen ; RoveIS I948, § 1944). Ärt und Konzentration dieser Zusätze muss man für jedes Objekt empirisch feststellen. In umfangreichen Testserien (da nicht einmal $q$ und $\sigma^{z}$ dasselbe Optimum zeigen) brachte der Zusatz folgender Lösungen bei der Biene die besten und verlässlichsten Resultate :

o Phosphatpuffer n. Sörensen, pH $=6,0$,

$\sigma^{*}$ (und auch Arbeitsbienen) Honiglösung 20 p. 100 mit einem (natürlichen) $\mathrm{pH}$ von 4,5 (an Stelle der von Schabadasch angegebenen, hier aber weniger günstigen (Glukose).

Im allgemeinen kann gesagt werden, dass im sauren Bereich die Endverzweigungen, im neutralen oder leicht alkalischen die Ganglien und grossen Nervenstämme besser Farbe annehmen.

Im Gegensatz zu reinem Methylenblau wird der Zusatz dieser Lösungen von den Tieren schlecht vertragen. Es genügt aber eine Färbedauer von lo - 20 Min., eine längere Uberlebenszeit ist also nicht erforderlich. Aus diesem Grunde kann auch auf einen Wundverschluss verzichtet werden. Die rasche Verteilung des Farbstoffes muss meist durch geeignete Massnahmen (passive Pumpbewegungen mit dem Abdomen) gefördert werden.

Diese Färbemethode gelingt bei noch voll vitalen Tieren so gut wie immer. Tiere, die durch längere Gefangenschaft o. dgl. gelitten haben, sind weniger geeignet. Modifikationen durch $\ddot{\text { Änderung }}$ der eingebrachten Farbstoffmenge sind möglich, sie werden vor allem durch Lage und Art des darzustellenden Gewebes bestimmt. Zur Darstellung von Nervenendigungen am Darm oder an den Ovarien z.B. darf man nur schwach färben, während Endigungen weit in der Peripherie mehr Farbstoff und eine längere Färbedauer verlangen. Andererseits sind ganz allgemein diese peripheren subdermalen oder epithelialen Nervenelemente am leichtesten darstellbar.

Eine distinkte Färbung der Nervenendigungen in einer ungefärbten Skelettmuskulatur oder im Drüsengewebe ist ein Zeichen von grösserer Spezifität. Das Optimum an spezifischer Nervenfärbung ist dann erreicht, wenn auch die netzförmige viscerale Muskulatur, die eine bemerkenswerte Affinität zu Methylenblau besitzt, ungefärbt bleibt (Die eigenartig schraubig gewundenen Muskelbänder auf den Malpighi-Gefässen aber sind für gewöhnlich gerade dann distinkt gefärbt, wenn die Nervenfärbung sehr gut gelungen ist; bei Uberfärbung nimmt die ganze Wandung, einschliesslich des Epithels, Farbe an ). Auch an den lateralen Ovidukten bleiben die Muskelfasern höchstens stellenweise gänzlich ungefärbt. Doch bereitet dieser Umstand kaum ernsthafte Schwierigkeiten, da die Nervenfasern einen anderen (mehr violetten) Farbton annehmen als die blauen Muskelfasern und gegebenenfalls eine Untersuchung bei stärkerer Vergrösserung sofort jeden Zweifel behebt.

Periphere Nerven - und Sinneszellen mit ihren Fortsätzen nehmen die Farbe sehr stark an. In gut gelungenen Präparaten bleiben nicht nur Bindegewebe und Epithel, sondern auch das Neurilemm ungefärbt, sodass ein sehr klares Bild auch der zartesten Zellfortsätze des Nervengewebes entsteht. Weniger günstig scheinen die Resultate an den Ganglien des Bauchmarkes zu sein ; der Farbstoff dringt vielfach schlecht durch die Bindegewebshülle, einzelne Ganglienzellen der Randzone sind ïberfärbt, andere wieder ungefärbt. Allerdings wurde die Methode bisher ausschliesslich auf die Darstellung des peripheren NS abgestimmt.

Nur anhangsweise sei erwähnt, dass auch Versuche mit Verfütterung von Methylenblau gemacht wurden. Dabei zeigte sich wieder, dass die Substanz selbst (Methylenblau ZnCl-frei, feinst "Bayer ») keine toxische Wirkung ausübt. Bei Präparierung einen bis mehrere Tage nach Beginn der Fütterung war der Darm und manchmal stellenweise auch die Muskulatur gefärbt, eine Nervenfärbung jedoch war in keinem Falle festzustellen.

\section{c. 一 FIXIERUNG DER FÄRBUNG}

Nach gleichmässiger Verteilung des gelösten Farbstoffes im Abdomen lässt man ihn etwa lo Min. einwirken. Dann wird das Abdomen geöffnet und die Färbung zunächst durch Übergiessen mit einer 5 p. Ioo igen Ammoniummolybdatlösung fixiert. 
Dadurch wird aber nur die Färbung, nicht aber das Gewebe fixiert und auch erstere beginnt nach etwa $24 \mathrm{~h}$ diffus zu werden. Die zur Fixierung gebräuchliche Ammoniumpikrat-Gelatine, die von Schabadasch angegebenen Gemische sowie verschiedene andere geprüfte Substanzen führten zu Farbumschlag, Zerstörung feiner Strukturen oder zu un’̧enügender Gewebsfixierung. Schliesslich haben sich folgende Methoden der Aufbewahrung von mit Ammoniummolybdat fixierten Methylenblaupräparaten bewährt

\section{Aufberwahrung der Präparate in toto}

Rasches Entwässern in der Alkoholreihe, Uebertragen von Alk. absol. in Terpineol. In Terpineol bleibt das Gewebe so weich, dass ein weiteres Präparieren möglich ist, soferne im Frischzustand wenigstens die Organe freigelegt worden waren. Präparate, die jetzt seit 3 Jahren in Terpineol liegen, zeigen nicht die Spur einer Entfärbung.

Statt in Terpineol kann man das Präparat auch in flüssigem Euparal aufbewahren. Das hat den Vorteil, dass die Alkoholbehandlung abgekürzt und aus Alkohol 96 p. 1oo direkt in Euparal übertragen werden kann.

Manches weist darauf hin, dass Nachfixierung mit Goldchiorid, Osmiumtetroxyd oder Chloralhydrat auch eine Aufbewahrung in wässriger Lösungen, wi€ Formol oder Formolgemischen, möglich ist. Solche Präparate lassen sich auch noch nach längerer Zeit ausgezeichnet präparieren. Die bisherigen Ergebnisse sind aber noch nicht ganz eindeutig und verlässlich und müssten nochmals überprüft werden.

\section{Einschlusspräparate}

Alkoholreihe - Einbetten in Euparal oder Caedax (Kanadabalsam ist zu vermeiden, da dieser Säuren enthält und die Färbung angreift). Man kann aber auch in Terpineol einbetten und das Deckglas mit Harz oder Lack umranden.

\section{Anfertigung von Schnitten}

Das gefärbte, mit Ammoniummolybdat fixierte Präparat wird über Alkohol rasch in Methylbenzoat gebracht. Orientierung des ja meist sehr kleinen Objekts auf einem weichen, in Terpineol aufbewahrten Celloidinblock, Härten mit Chloroform, Benzol, Paraffin (RomeIs § 440). Evt. Gegenfärbung der Schnitte mit Säurefuchsin.

Zum Vergleich wurden noch Silberimprägnationen (nach Bodian, in der Modifikation von Power) und Zellfärbungen an Schnittpräparaten (Haematoxylin Heidenhain und van Gieson) durchgeführt.

Die Honigbiene bietet für die Untersuchung nervöser Endapparate sehr günstige Bedingungen, weil die Körperdecke - besonders am Abdomen - dünn, wenig sklerosiert und (z.B. an den Sterniten) wenig pigmentiert ist und daher Totalpräparate, die nach der beschriebenen Weise eingebettete wurden, noch bei stärkster Vergrösserung klare Bilder ergeben. Verwendet man noch dazu helle Rassen - etwa Apis mellifica ligustica - , deren Pigmentgehalt durch Einkreuzung der Mutation "cordovan" noch weiter herabgesetzt ist, so werden die subdermal gelegenen Strukturen des Nervensystems einwandfrei ausgeleuchtet und sogar am unpräparierten Tier von aussen sichtbar.

Sämtliche Mikroaufnahmen wurden - soferne nicht anders angegeben — von Präparaten hergestellt, die nach der oben dargelegten Methylenblau - Methode angefertigt worden sind.

\section{II. - DAS HAUTNERVENSYSTEM DES ABDOMENS}

\section{A. - DIE SENSILIEN}

Das Abdomen der Honigbiene ist bei beiden Kasten der Weibchen und beim $\sigma^{\top}$ von einem dichten Haarpelz bedeckt. Die einzelnen Sklerite tragen jedoch nur in ihrem rückwärtigen Abschnitt Haare, während ihr vorderer Anteil - im wesentlichen im Bereich des eng anliegenden freien Abschnittes der Intersegmentalmembran - unbehaart bleibt (Abb.2). Das Haarfeld bedeckt I $/ 2-3 / 4$ der Breite der Sternite und Tergite ; nur der erste, zur Gänze freiliegende Abdominalring ist an seiner ganzen Aussenfläche behaart. Auf dem 2. - 5. Sternit der Arbeiterin beschränkt die ausgedehnte unbehaar- 
te Wachsdrüsenfläche ((Wachsspiegel») das Haarfeld auf I/3 der Sternitbreite. Im Bereich des Haarfeldes befinden sich neben einfachen Haaren verschiedener Stärke und Form (siehe GOETZE I940) zahlreiche Sinneshaare, die von typischen bipolaren Sinnesnervenzellen (SNZ) innerviert werden (Abb.3). Neben diesen Haarsensillen sind in wechselnder Zahl Sensillen ohne Anhang vorhanden, bei denen der periphere

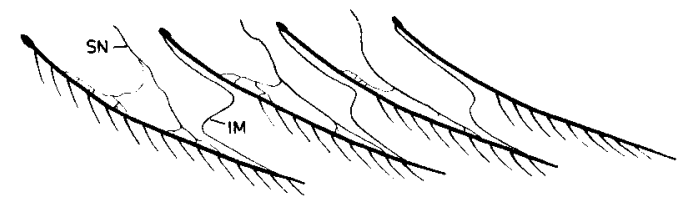

Abb. 2. - Sternite mit Intersegmentalmembran (IM) und sensiblen Nerven (SN).

FIG. 2. - Sternite avec membrane intersegmentaire $(I M)$ et nerfs sensitifs $(S . N$.).

Fortsatz einer SNZ an einer sehr dünnen Membran endigt, durch die eine kreisrunde Öffnung in der Exocuticula plan verschlossen wird (Membransensillen). Im ganzen konnten an der Oberfläche des Abdomens der Honigbiene drei verschiedene Typen von Sensillen festgestellt werden :

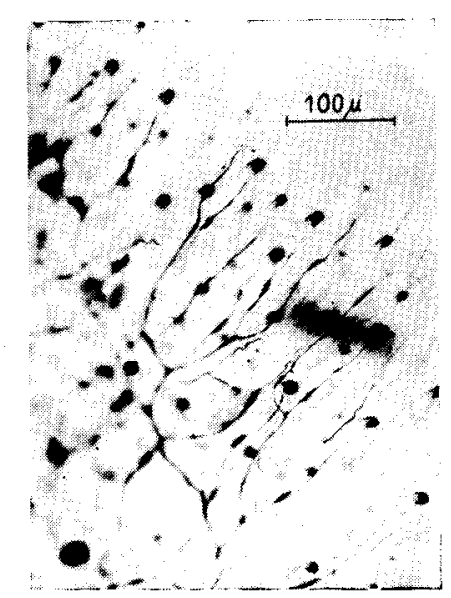

Albb. 3. - Sensillen mit bipolaren Sinnesnervenzellen; , kaudaler Rand eines Tergits.

FrG. 3. - Sensilles avec cellules nerveuses sensorielles bipolaives; bord postérieur d'un tergite de $․$

\section{Sensilla trichodea}

\section{a) Mononeuronale Sensillen}

Es handelt sich um typische Haarsensillen, die mit einer spindelförmigen SNZ verbunden sind. Das Sinneshaar ist mit seiner meist kolbig aufgetriebenen oder gebogenen Basis mittels einer Membran im Hohlraum einer chitinös umwulsteten Öffnung in der Cuticula eingelenkt (Abb.4 und 5). Die Öffnung in der Cuticula wird basal durch eine zweite Membran verschlossen, durch welche der Fortsatz der SNZ hindurchtritt. Dieser endigt mit einer kommaförmigen, am Ende sehr feinen spitze am Innenrand der basalen Höhlung des Haares. 


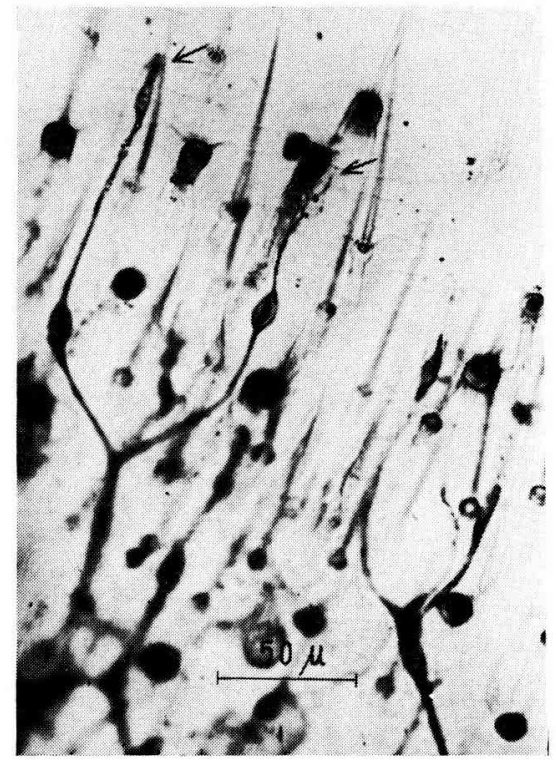

Abb. 4 , - Sensilla trichodea und S. basiplana $(\downarrow)$. P, I. Tergit.

FıG. 4. - Sensilla trichodea et sensilla basiplana $(\downarrow)$. ๆ, 1er tergite.

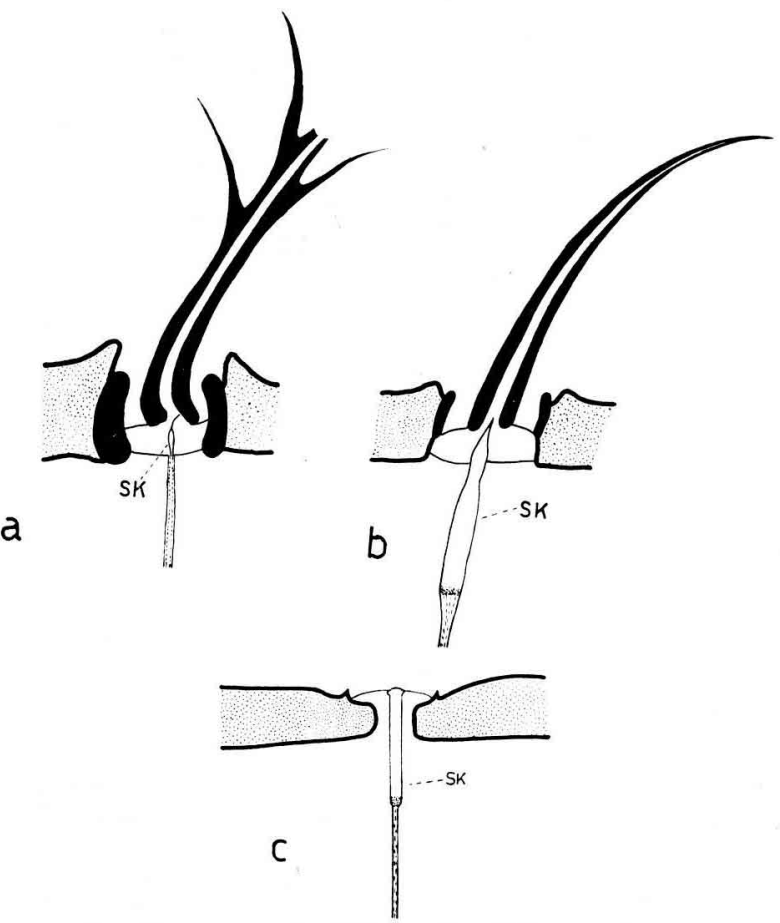

Abb. 5. - Sensillentypen an den Skleriten des Abdomens. a) mononeuronales, b) polyneuronales Sensillum trichodeum, c) Sensillum basiplanum. Sk Sinneskörper.

FIG. 5. - Différents types de sensilles des sclérites de l'abdomen. a) Sensille trichoïde mononeuronale b) polyneuronale - c) Sensillum basiplanum - Sk, corpuscule sensoriel. 
Die Länge des peripheren Fortsatzes der SNZ kann besonders am freien Hinterrand der Sklerite sehr beträchtlich sein. Dort wird durch Anlagerung und Verdikkung der Intersegmentalmembran des vorhergehenden Segmentes eine Tasche gebildet, in deren Hohlraum sich der später zu besprechende Nervenplexus, Tracheen, Haemolymphe und Epithelien befinden (Abb.2). Gegen den Rand zu verschmelzen die dorsale und die ventrale Wand der Tasche miteinander und es bleiben nur schmale

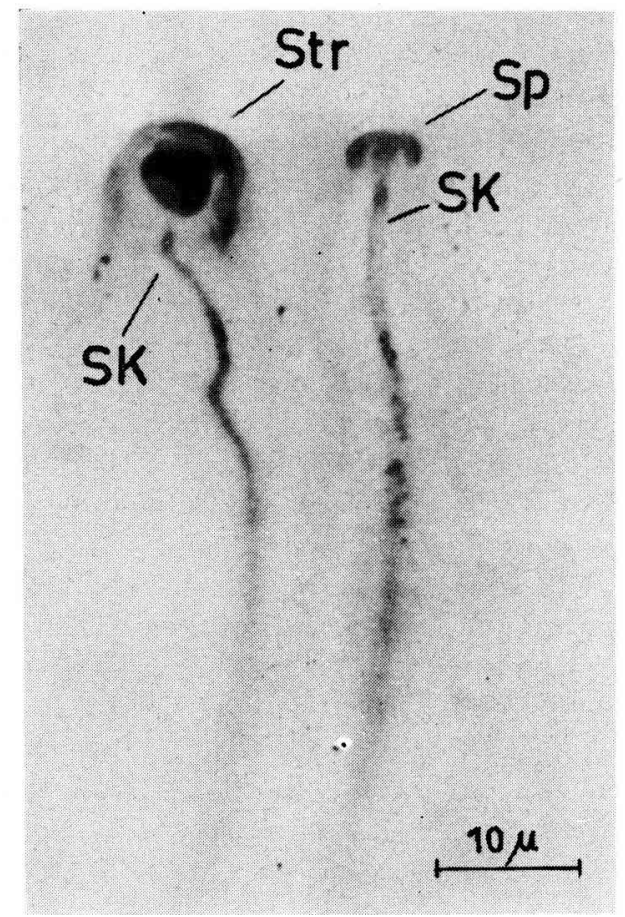

Abb. 6. - Sensillum irichodeum $(S l r)$ und S. basiplanum $(S p)$ vom Sternit einer. Der periphere Fortsatzeiner bipolaren Sinnesnervenzelie zieht durch eine Membranzur Basis des Haares des Sensillum irichodeum, wo er mittels Sinnesköpers (Sk) am Rande der zentralen Höhlung ansetzt.

FIG. 6. - Sensille trichoide (Str) et sensille basiplane (St) sur un slernite d'ouvrière. I. fo fore périphérique d'une cellule nerveuse sensorielle bipolaire atteint a travers une membrane la base du poil de la sensille trichoide rit elle s'applique au moyen du corpuscule sensitif $(S k)$ au bord de la cavité centrale.

Kanäle offen, durch die die einzelnen Nervenfortsätze zu den terminalen Sensillen ziehen (Abb. 3, 4, 6, 8). Die Struktur des peripheren Fortsatzes der SNZ bleibt von der Zelle an bis zum Durchtritt durch die Endocuticula unverändert (abgesehen von gelegentlichen Verdickungen). Nur der terminale Sinneskörper nimmt bei Methylenblaufärbung im Gegensatz zu den ubrigen Abschnitten ein homogenes, hyalines Aussehen an (nach WEBER I933 besteht er aus einer chitinartigen Substanz). Metaterminale Strukturen, wie sie MEYER I955 als feine Fibrillen in Netzform beschrieben hat, konnten nicht dargestellt werden. Die Spitze des rezeptorischen Fortsatzes erscheint immer glatt und deutlich begrenzt. 
b) Polyneuronale Sensillen

Diese Sensillen stehen nicht mit einer, sondern mit vier, eng zu einer Gruppe zusammengeschlossenen SNZ in Verbindung. Sensillen derselben Art wurden von SCHNEIDER und KAISSIING (I957) von der Antenne von Bombvx mori beschrieben (Abb.8 der zitierten Arbeit). Die Sinnesfortsätze der vier SNZ ziehen, zu einem einheitlichen Strang vereinigt, zu einem gemeinsamen Sinneskörper von durchschnittlich I2 Länge, der in das Lumen der Borste hineinzuführen (also nicht an ihrer Basis anzusetzen) scheint (Abb. 5b). Dieser relativ lange Sinneskörper hebt sich durch seine diffuse, helle Färbung im Methylenblau-Präparat sehr deutlich von den Fortsätzen zu den anderen Sensillen ab.

Die Sinneshaare der polyneuronalen Sensillen unterscheiden sich in charakteristischer Weise von denen der mononeuronalen. Während letztere lang, dünn und \pm gefiedert sind, erscheinen die von mehreren Neuronen versorgten Sinneshaare stachelartig-kräftig, stärker pigmentiert und ungefiedert. Die schlanke Basis ist in der flach eingesenkten Pore der Cuticula von einem breiteren Membranring umgeben, der sich - wieder im Gegensatz zum Fiederhaar - mit Methylenblau etwas anfärbt. Es ist also eine ganze Anzahl sehr deutlicher Interschiede zwischen diesen beiden Sensillentypen vorhanden. - GoETZE (In36) unterscheidet beim langen "Überhaar " auf der Dorsalseite des Abdomens der Arbeiterin Fiederhaare und Stichelhaare. Letztere sind aber im Spitzenabschnitt gezähnt, während die Stichelhaare der z11sammengesetzten Sensillen immer vollständig glatt sind.

Es ist wichtig, darauf hinzuweisen, dass polyneuronale Sensillen nur auf den Sterniten von Arbeiterinnen und in ganz vereinzelten Fällen auf den Sterniten von $\sigma^{x} \sigma^{x}$ gefunden wurden, niemals aber an Tergiten, oder an Sterniten von $\not Q$. Bei der Arbeitsbiene liegen sie regelmässig in der 2. oder 3. Sensillenteihe (vom kaudalen Rand des Haarfeldes gezählt).

\section{Sensilla membranacea}

\section{a) Sensilla basiplana.}

Diese Endapparate werden an der freien Körperoberfläche des Abdomens stets nur von einer einzigen SNZ versorgt. Ihr peripherer Fortsatz ist von dem der mononeuronalen Sensilla trichodea nicht zu unterscheiden. Die Endigung erfolgt mittels eines schwach tingierbaren Sinneskörpers mit oft kaum merklicher terminaler Anschwellung unmittelbar an der sehr dünnen Verschlussmembran der wulstlosen Öff̈nung in der Cuticula (Abb. 5c). An bestimmten Stellen jedoch - z. B. am durch Chitinleisten verstärkten Vorderrand des Haarfeldes - ist der in einer oft gewundenen Höhlung gelegene Endabschnitt der Sinnesfortsätze plump verdickt und sehr chromophil (Abb. 7). Ob dieser Typ auch funktionell eine Sonderstellung einnimmt, ist nicht bekannt.

Die Abschlussmembran der hier beschriebenen Sensillen liegt plan und völlig frei (also nicht versenkt) am Grunde einer flachen Delle der Cuticula als Abschluss einer kreisrunden Pore. Deren Ränder sind wie gestanzt und mit scharfen Zacken versehen (Abb. 5c, 8). Dieser Sensillentyp lässt sich von dem Sensillum basiconicum ableiten, wenn man sich den flach aufsitzenden Membrankegel durch eine plane Membran ersetzt denkt. In beiden Fällen endigt der Sinnesfortsatz im Zentrum der Membrati. 


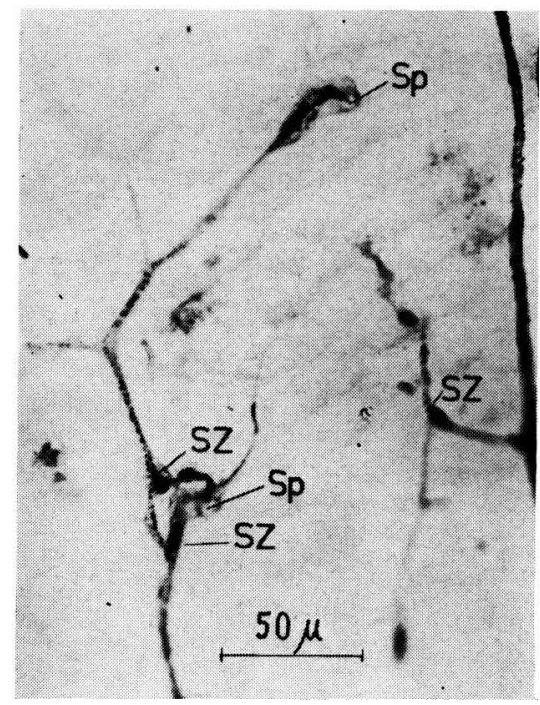

Abb. 7. - Sensilla basiplana $(S p)$ von der verdicklen kranialen Region des 3. Sternils einer 9 . Sinnesnevenzellen (SZ) mit plumpem Sinnesfortsatz, der in einer Höhlung der Cuticula gelegen ist.

FIG. 7. - Sensille basiplane $(S p)$ de la région crániale épaissie du 3 e sternite d'une reine.

Cellule nerveuse sensorielle $(S:)$ avec fibre sensorielle épaisse située dans une cavité de la cuicule.

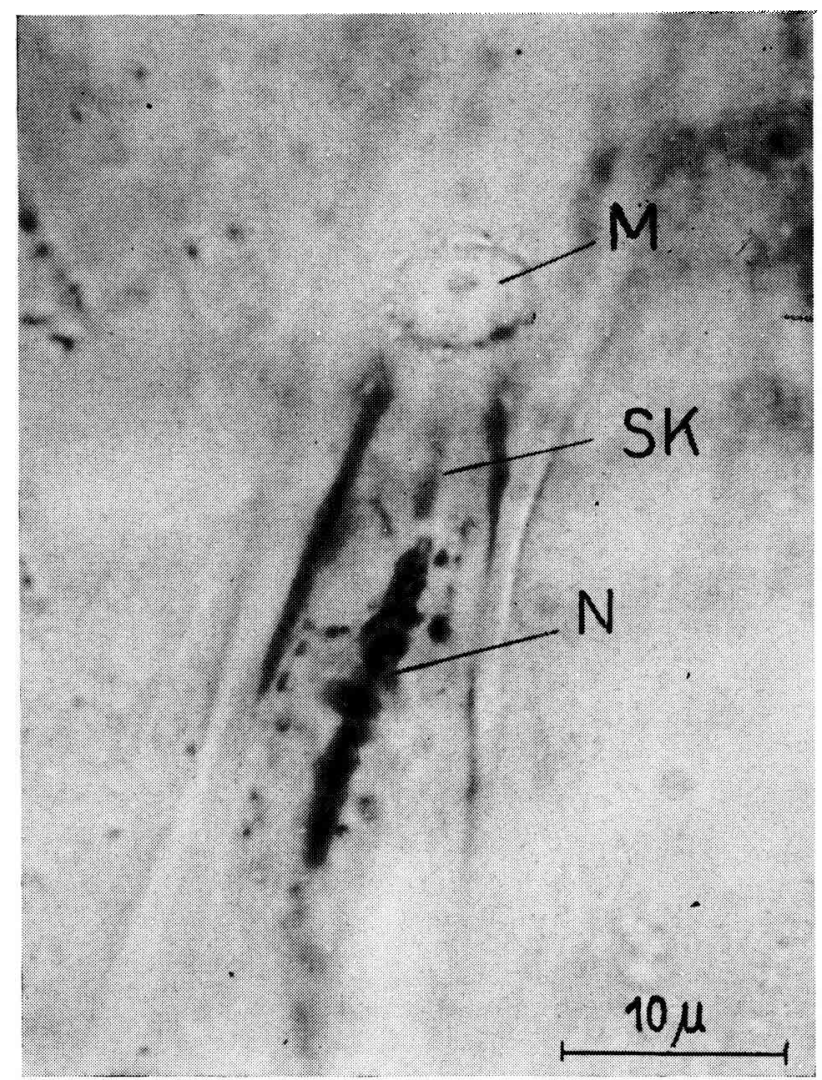

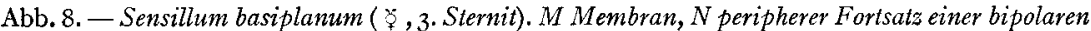
Sinnesnervenzelle (in einem Kanal zwischen den beiden verschmolzenen Blättern der Epidermis), Sk Sinneskörper

FIG. 8. - Sensille basiplane ( $\zeta, 3^{\circ}$ sternite). $M$, membrane, $N$, fibre périphérique d'une cellule nerveuse sensorielle (dans un canal enire les deux feuillets soudés de l'épiderme), $-S k$, corpuscule sensoriel. 
Dass es sich bei den Sensilla basiplana um Chemorezeptoren handelt, wie man nach ihrem Bau vermuten könnte, ist nach ihrer Verteilung an der Körperoberfläche und ihrer grossen Zahl wenig wahrscheinlich. Möglicherweise sind sie Organe des Temperatursinnes, der ja bei der Honigbiene ganz besonders fein entwickelt ist.

b) Sensilla campanitormia.

Ganz vereinzelt an den Skleriten von Arbeitsbienen.

Über besondere Typen von Chemorezeptoren auf der Analplatte wird weiter unten zu berichten sein.

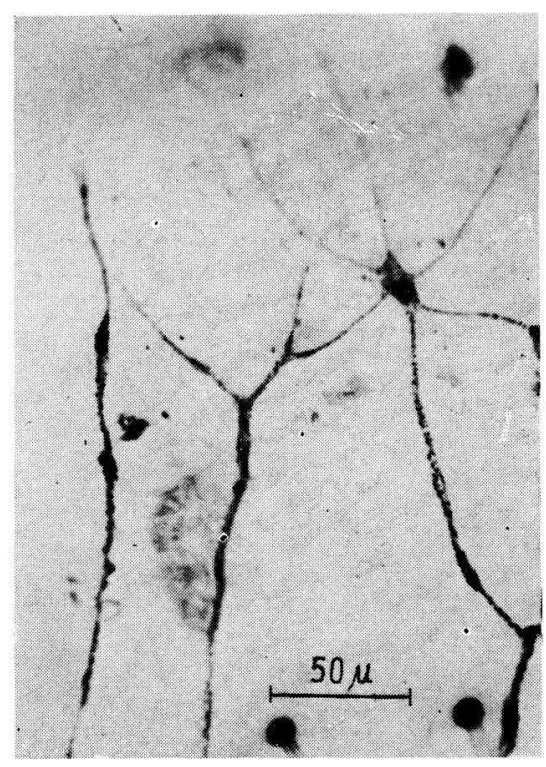

Abb. 9. - Multipolare Nervenzelle (Typ II) mit treien Endigungen (P, 3. Sternit).

FIG. 9. - Cellule nerveuse multipolaire (Type II) ayec terminaisons libres ( $9,3^{\mathrm{e}}$ sternite)

\section{Die Verteilung der Sensillen am Abdomen}

Es lässt sich eine deutliche Häufung der Sensillen am Hinterrand der Sklerite feststellen. Vergleichszählungen in je einem Gesichtsfeld $\left(=0,2 \mathrm{~mm}^{2}\right)$ vom 3. Sternit einer $q$ ergaben im Durchschnitt :

\begin{tabular}{|c|c|c|c|}
\hline 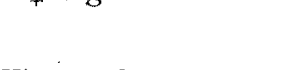 & Sens, trichodea & Sens. basiplana & $\begin{array}{l}\text { Haare (nicht } \\
\text { innerviert) }\end{array}$ \\
\hline Hinterrand . . . . . . . & 35 & 21 & 70 \\
\hline Mitte & 15 & 5 & 165 \\
\hline
\end{tabular}

Die polyneuronalen Haarsensillen auf den Sterniten der Arbeiterinnen befinden sich, wie erwähnt, ausschliesslich am Hinterrand. Ihr zahlenmässiges Verhältnis zu den übrigen Sensillen wurde in einem beliebigen Abschnitt wie folgt ermittelt :

Sensilla trichodea (mononeuronal), 88

Sensilla trichodea (polyneuronal), I2

Sensilla basiplana, $\quad 38$

Die Genitalregion des $\sigma^{x}$ fällt durch ihren Besatz mit Sensillen ganz aus dem Rahmen der ïbrigen Regionen heraus und wird weiter unten getrennt besprochen. 


\section{B. - FREIE NERVENENDIGUNGEN}

Der unbehaarte vordere Abschnitt der Sklerite ist - wemn auch schütterer ebenfalls mit rezeptorischen Endigungen versehen. Am Rande zum Haarfeld befinden sich, wie erwähnt, zahlreiche Membransensillen mit plumpen Endfortsätzen. Ausserdem sind multipolare Nervenzellen vorhanden (Typ II nach der Einteilung von ZAWARZIN I9I2; Abb. 9), die ihre frei endigenden Fortsätze bis gegen die Antecosta zu entsenden. Diese Zellen können von grosser Regelmässigkeit sein. Die Wachsdrüsenregion bei der Arbeitsbiene ist nur spärlich durch freie Endigungen innerviert, die sich zwischen die Drüsenzellen einsenken. Ganz vereinzelt sind solche Multipolare mit freien Endigungen auch im Bereich des Haarfeldes anzutreffen. Freie Findigungen, die nicht mit Zellen in der Peripherie in Verdindung stehen -- von MEYER (1955) bei Blatta beschrieben - sind nicht vorhanden.

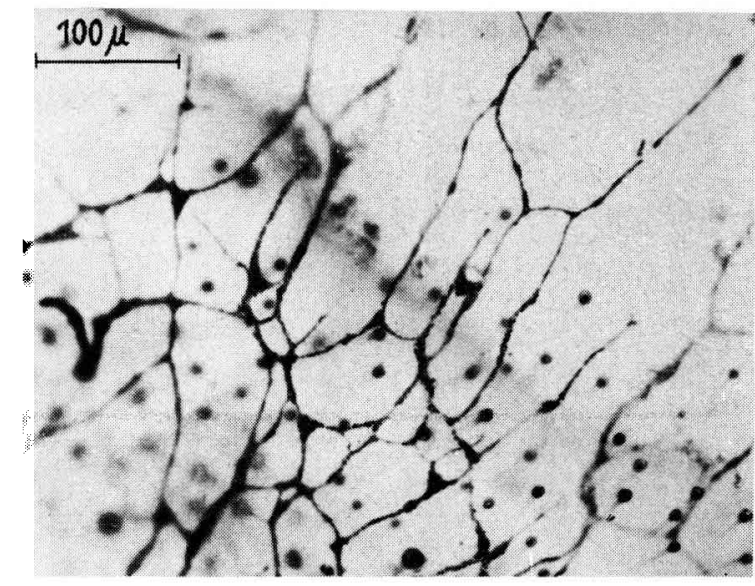

ibb. ro. - Suldermaler Plexus (9, 3. Sternit).

Iir. 10. - Plexus suddermitice ( 9 , 3e sternite).

C. - DER SUHDERMALE PLEXUS

$\mathrm{Zu}$ den rezeptorischen Organen - Sensillen und freie Nervenendigungen -- tritt ein nervöser Apparat, dessen Struktur eine weitgehende Differenzierung gegenüber dem Zustand bei niederen Arthropoden erkennen lässt. Verfolgt man die Fortsätze der bipolaren SNZ in zentraler Richtung, so zeigt sich neben der erwarteten bündelweisen Vereinigung der Axone zu grösseren Ästen und Stämmen ein vielfach sehr kompliziertes Netz von Nervenbahnen, das den gesamten Mittelteil des Sklerits subdermal ïberzieht (Abb. ro. u I I). Gespeist wird dieses Netz durch Aste der sensiblen Segmentnerven, gegen den Rand des Sklerits zu löst es sich in die zentripedalen Fortsätze der bipolaren, bzw. multipolaren SNZ auf (Abb. II).

Analysiert man diesen Nervenplexus näher, so lassen sich folgende Bestandteile, die an seinem Aufbau beteiligt sind, feststellen :

I. Neuriten der SNZ - die oft auf sehr verschlungenem Wege - streckenweise auch rückläufig und sich in mannigfacher Weise verflechtend - die Segmentnerven 
erreichen. Sie lassen sich besonders in silberimprägnierten Präparaten oft über weite Strecken verfolgen.

2. Multipolare Nervenzellen und deren Fortsätze - die mit den rezeptorischen

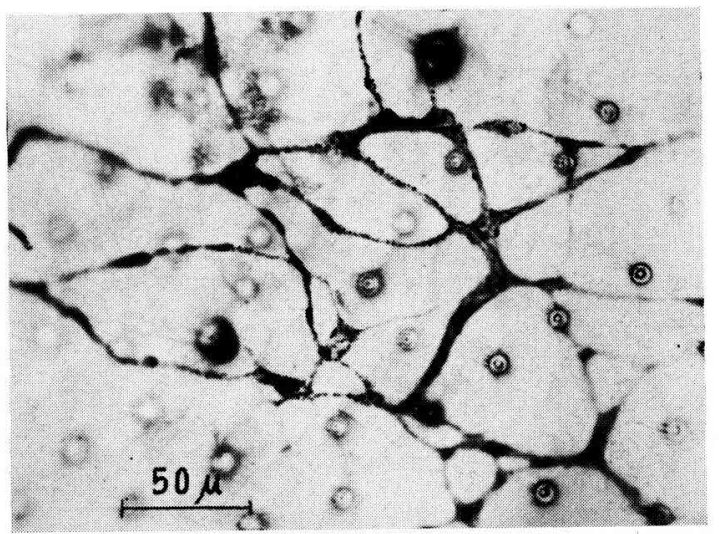

Abb. I . - Subdermaler Plexus mit multipolaren Nervenzellen und 2 Sensilla trichodea; dazurischen Haare ohne Innervation (, 3. Sternit).

FIG. II. - Plexus subdermique avec cellules nerveuses multipolaires et deux sensilles trichoides: on voit également des poils sans innervation (q, $3^{\mathbf{e}}$ sternite).

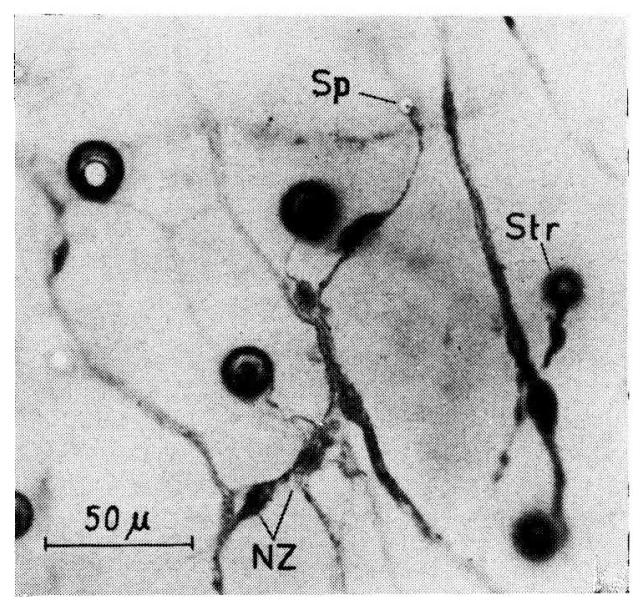

Abb. 12. - Subdermaler Plexus mit Nevenzellen und zahlreichen verbindenden Fibrillen.

Sp Sens. basiplanum, Str Sens. trichodeum (\$, Deckplatte). NZ Nervenzellen.

FIG. I2. - Plexus subdermique avec cellules nerveuses, et nombreuses fibrilles associatives.

$S p$, Sensille basiplane - Str, sensille trichoïde (J, valves péniales) - NZ, cellules nerveuses.

Nervenbahnen in vielfacher Verbindung stehen (Abb. I2). Der Prototyp dieser Multipolaren sind pyramidenförmige Zellen, in der Gabelung eines Nerven gelegen, deren Plasma mit den durchziehenden Fasern enge Verbindung aufnimmt (Abb. I3 $\mathbf{u}$. I4). Häufig entsenden diese Zellen auch Fortsätze zu anderen Faserzügen, sodass alle Übergänge von der tripolaren zur multipolaren Form vorhanden sind. WIGGIESWORTH (I953) hat diesen Zelltyp schon bei Arthropoden beschrieben, aber die Vermutung 


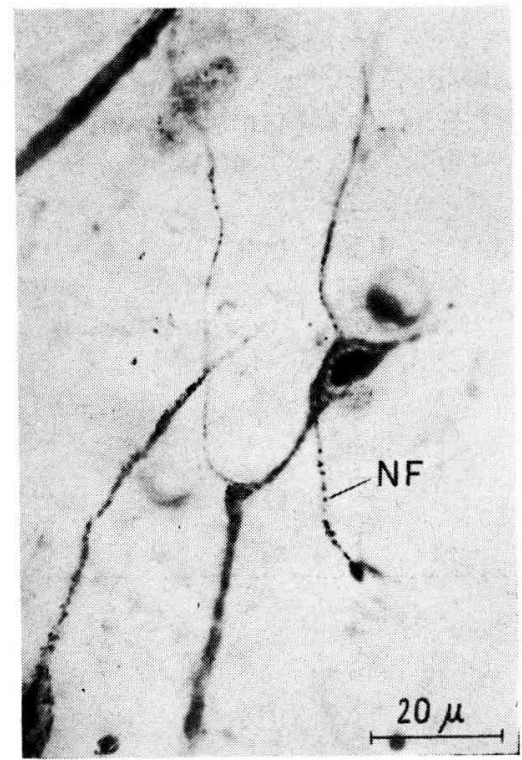

Abb. I 3. - "Tripolare "Nerienselle mit hindurchsiehender Neurofibrille (NF).

Fig. I.3. - Cellule nerieuse "tripolaire" anec neurofibrille $(M F)$ passant au travers.

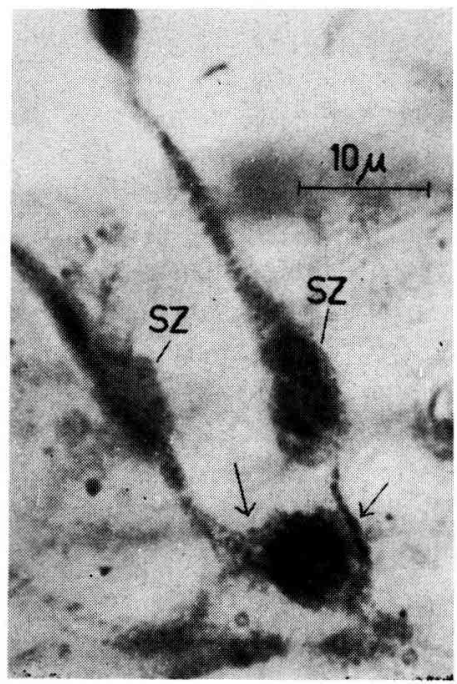

Abb. I4. - Neuriten zweeier bipolarer Sinnesnervenzellen (SZ) durch breite neuroplasmatische Brücken $(\downarrow)$ mit dem Perikaryon einer assosiativen Zelle verbunden $\left(\delta^{*}, 7\right.$. Sternit $)$.

I'IG. I4. - Neurites de deux cellules nerveuses sensorielles bipolaires $(S Z)$ reliées par de larges ponts neuroplasmatiques $(\downarrow)$ au péricarvon d'une cellule associative $\left(\widehat{ }, \mathrm{\gamma}^{\mathrm{e}}\right.$ sternite $)$.

Annales de l'Abeille. - 1962. 
geäussert, es könnte sich um modifizierte Neurilemmzellen handeln. I)emgegenüiber konnte MEYER (I955) den Nachweis erbringen, dass solche trianguläre Zellen unter der Epidermis von Blatta nervöser Art sind und dass sie ihre Fortsätze in benachbarte Nervenbahnen entsenden. Ich kann die Befunde MEYERs für Apis nachdrücklich bestätigen. In den vorliegenden Präparaten bleibt das Neurilemm - sowohl das der perizellulären Kapseln wie das um die Nervenbahnen — gänzlich ungefärbt, während sich distinkt gefärbte, aus dem Perikaryon der Multipolaren kommende Fasern in Nervenstränge oder Zellen der Umgebung verfolgen lassen (Abb. I2).

Häufig stehen Triangel-bzw. multipolare Zellen nicht durch Fasern, sondern durch breite protoplasmatische Fortsätze miteinander in Verbindung. Liegen mehrere solcher Zellen hintereinander, so entstehen rosenkranzartige Zellketten, die auch im Nervenplexus innerer Organe - z.B. an den Schleimdrïsen des $\sigma^{x-\cdots}$ gefunden werden.

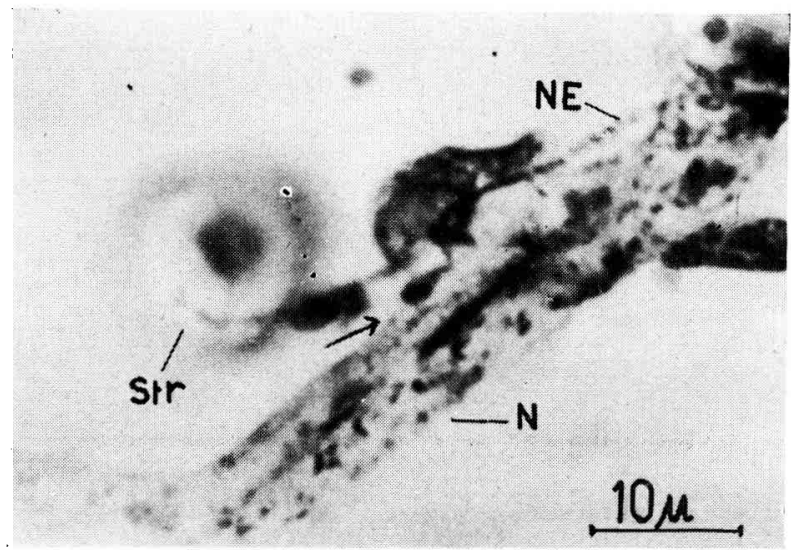

Abb. I 5. - Bipolare Sinnesnernenselle mit knopjartiger Endignng $(\downarrow)$ an Ven $(X)$. NE Neurit, Str.Sensillam trichodem. (o, l)echplatte).

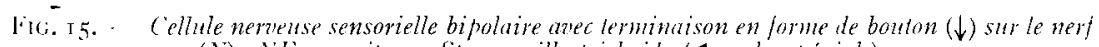
$(\mathrm{N})$. WE, newrite - Sir, sensille bichoile $(\tilde{\sigma}$, valse péniale).

3. Nervenfasern unbekannter Herkunft - die auch in bipolare SNZ eintreten, und diese in manchen Fällen durchziehen (Abb. I3), aber in anderen Fällen mit dem neuroplasmatischen Reticulum zu verschmelzen scheinen. Es kann deshalb oftmals Zweifel darüber aufkommen, ob es sich bei den SNZ wirklich immer um streng bipolare Zellen handelt. Als solche erscheinen bei der Biene vor allem die SNZ der Peripherie des Plexus und die SNZ in Silberpräparaten (mit ihrer weniger spezifischen und feinen Strukturdarstellung). I)ie im Bereich des Plexus gelegenen SNZ sind sehr oft eng mit einem Nervenast verbunden, dessen Fasern teilweise durch das Zellplasma hindurch ziehen — oder aber unter Lockerung ihrer Struktur in enge Verbindung zu diesem treten. Es ist dann oft unmöglich festzustellen, ob es sich um Fasern ein€s fremden Neurons aus dem $Z$ NS oder aus Multipolaren oder un Fortsätze der SNZ selbst handelt (Abb.22). Die Frage, ob ubipolare "SNZ ausser den Neuriten noch weitere Fasern in den Plexus entsenden können, muss deshalb offen gelassen werden. Sicher erscheint mir lediglich, dass "bipolare) SNZ sowohl untereinander wie mit Nervenbahnen durch neuroplasmatische Fortsätze in Verbindung treten können. Abb. I5 
zeigt eine mit einem Nervenast eng verbunde "Bipolare ", die mit knopfförmigen Plasmafortstzen dem an dieser Stelle verdickten Nerven anliegt. Auch einzelne Nervenfasern können mit ähnlichen Verdickungen an stärkeren Ästen enden (Abb. I6).

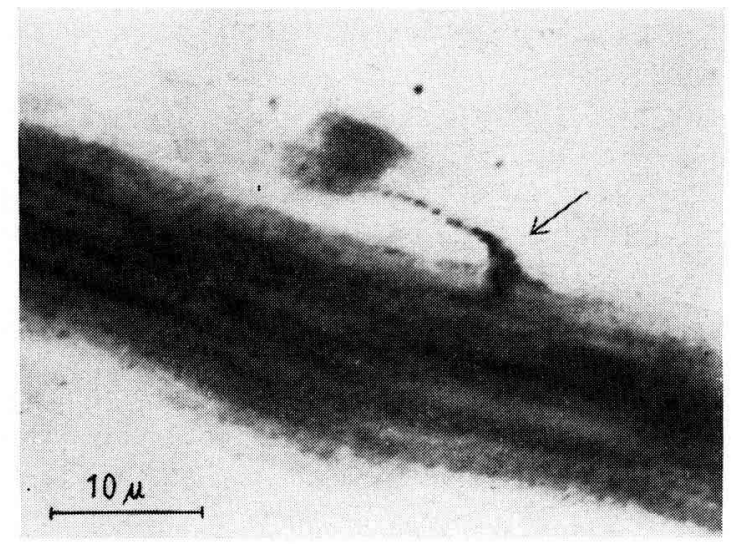

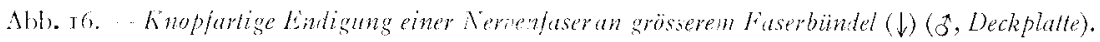

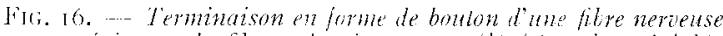

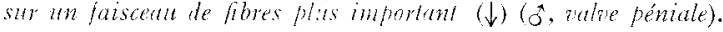

DISKUSSIOX ZU KAIITTI, II

Fs erhebt sich hier natiurlich die Frage, welche Strukturen des Nervensystems mit der vitalen Methylenblaufärbung eigentlich dargestellt werden. Die Diskussion unl die terminalen bzw. metaterminalen nervösen Apparate, um die Struktur und Verbindung der Neurofibrillen, das endozelluläre Reticulum usw. lassen erkennen, wie seht die jeweiligen Interpretationen der Befunde von der jeweiligen Technik abhängen (vergl. die zusammenfassenden Besprechungen von SPATZ (I952), MEYER (I955), KIRSCHF (I960)). Insbesondere sollte man sich darüber klar werden, wie weit die dargestellten Strukturen präexistent sind und wie weit es sich lediglich um Aquivalentbilder, bzw. Artefakte, oder $11 \mathrm{~m}$ Darstellung von Elementen aus anderen Gewebssystemen handelt. Ich muss MFye darin beipflichten, dass auch die vitale (bzw. supravirale) Methylenblaufärbung ungeachtet ihrer unerreichten Selektivität zu Artefaktbildungen neigt. Als Folge der Einwirkung des Farbstoffes und mehr noch der reduzierenden und osmotisch wirksamen Substanzen und der Fixierung kommt es zu Entmischungsvorgängen und Schädigungen des Plasmakolloids, die vielfach zur Verklumpung und Verklebung der Neurofibrillen führen. Disse erscheinen bei der angewendeten Methodik bei genügend starker Vergrösserung als Reihe von Punkten oder Knoten ( (Varikositäten »), die im Fibrillenverband zum Zusammenfliessen zu grösseren Klumpen neigen. Fine Verstärkung mögen diese Artefaktbildungen im vorliegenden Fall noch dadurch erfahren haben, dass aus äusseren Gründen die Objekte statt in frischem Zustand erst als fixierte und eingebettete Präparate verarbeitet werden konnten.

Immerhin lassen gerade diese Erscheinungen viel eher einen Schluss auf die physikalische Beschaffenheit der Fibrillen in vivo zu als die "Telegraphendrähte " der 
Silberimprägnationen. Sind demnach auch die Aufschlïsse ïber den Fibrillenverlauf und die Verknüpfung der Neurone untereinander nur lückenhaft, so können doch folgende für die Zielsetzung der vorliegenden Untersuchung wesentlichen Feststellungen über die Struktur des subdermalen Nervenplexus getroffen werden :

I. Die Axone der SNZ ziehen nicht isoliert zum ZNS, sondern sie stehen untereinander in Verbindung.

2. Die Verkniipfung der zentripetalen Neurone erfolgt durch assoziative multipolare Ganglienzellen oder durch plasmatischen Kontakt der SNZ mit Ganglienzellen, bzw. mit intraplasmatisch verlaufenden Fasern.

Die SNZ sowie die Ganglienzelle besitzt im Methylenblaupräparat ein intensiv gefärbtes Gerïst, das um den Kern Verdichtungen aufweist und durch radiäre Balken - besonders in runden Zellen - eine Radspeichenstruktur annimmit (Abb. 15, 25). Die gleich gefärbten Zellfortsätze nehmen aus diesem Gerüst ihren Ursprung. Das Neuroplasma wird häufig von aus anderen Zellen stammenden Fasern durchzogen, die hier in einem Teil der Fälle eine Auflockerung ihrer Struktur und eine enge Verbindung mit dem endozellulären Gerüst erkennen lassen (Abb. 14). Bei aller Vorsicht in der Interpretation, die bei der Radspeichenstruktur im Neuroplasma - zumindest im Sinne einer Vergröberung - und bei deren Verschmelzung mit der durchziehenden Faser die Annahme von Artefaktbildungen nahelegt, kann doch die Auflockerung der Faser nicht in diesem Sinne gedeutet werden. Man muss in ihr ebenso eine Kontaktherstellung erblicken wie in der Verbindung zwischen Fasern oder Zellen mittels plasmatischer Fortsätze. Gelegentlich liegen Nerven- bzw. Sinneszellen in Gruppen beisammen, von einer gemeinsamen Kapsel umschlossen (Abb. 23). Auch zwischen diesen Zellen lassen sich plasmatische Briicken nachweisen.

Der subdermale Nervenplexus steht durch kräftige Nervenäste mit den zugehörigen Abdominalganglien in Verbindung. Einzelne seiner Abschnitte aber hängen trotz ihres beträchtlichen Volumens nur mittels verhältnismässig feiner Verbindungen mit den Hauptstänmen zusammen. Wir sehen hier also eine bemerkenswerte Abweichung von dem iiblichen Schema der baum- oder strauchförmigen Verzweigung des peripheren Nervensystems bei den Arthropoden. Auf Grund seiner charakteristischen Merkmale - Volumenzunahme in der Peripherie und Besitz eigener assoziativer Flemente - ist man berechtigt, von einem Nervensystem zu sprechen, das man wegen seiner Verbindung mit rezeptorischen Endapparaten in der Körperdecke am besten als Hautnervensystem bezeichnet. Man wird ihm eine gewisse Eigenfunktion, zumindest im Sinne einer Integration der aufgenommenen Reize, kaum absprechen können. Funktionen, die bei einfach gebauten Arthropoden im ZNS erfolgen, sind hier also $z$.T in die Peripherie verlegt.

Aus dem Gesagten ergibt sich, dass jedes Segnent seinen eigenen subdermalen Plexus besitzt, Sternum und Tergum getrennt. Die Geflechte der linken und rechten Seite jedes Segments gehen ineinander über. 1)ie Ausbildung des Plexus ist nicht in allen Abschnitten gleich. Am stärksten ist er an dem Skleritring ausgebildet, der den kranialen Abschluss des Abdomens bildet (2. abdomimales Segment). Ein reiches, girlandenartiges Geflecht findet sich rings um die Stigmata. Eigenartig und ihrer funktionellen Deutung harrend, sind die Kastenunterschiede : Die Königin besitzt auf sämtlichen abdominalen Segmenten einen wesentlich reicher entwickelten Nervenplexus als die Arbeitsbiene, bei der sich der Grossteil der sensiblen Fasern in einfacher Weise ramifiziert, bei geringerer Netzbildung und Finschaltung von nur wenigen 
assoziativen Zellen. Andererseits sind bei der Arbeitsbiene auf der Bauchseite, wie oben erwähnt, die zusammengesetzten Stichelhaarsensillen vorhanden, die der Königin fehlen. Über die Bedeutung dieser Kastenunterschiede sind vorderhand nur Vermutungen auf Grund der funktionellen Beanspruchung der rezeptorischen Apparate möglich : Die Wahrnehmung der Zellgrösse bei der Eiablage durch die Königin, welche der Ablage befruchteter oder unbefruchteter Fier vorangehen muss, und die Wahrnehmung der Beladung des Haarkleides der Arbeitsbiene bei der Sammeltätigkeit. Klarer liegt die Bedeutung des spezifisch modifizierten rezeptorischeiı Systems in der Genitalregion des $\sigma^{x}$ zutage (s. nächster Abschnitt).

Zum Vergleich wurde die Innervation der Körperdecke bei einigen anderen sozialen Hymenopteren untersucht. Bei Bombus- $\sigma^{x} \sigma^{x}$ sind die Verhältnisse ganz ähnlich wie bei Apis, es ist ein gut entwickelter, zellreicher Plexus unter den abdominalen skleriten vorhanden, der mit Haarsensillen in Verbindung steht. Bei Vespa- $\sigma^{r} \sigma^{r}$ hingegen vereinigen sich unter den schwach behaarten Skleriten die zentripetalen Fortsätze der SNZ ohne wesentliche Plexusbildung zu den sensiblen Segmentnerven.

Uber die Verhältnisse bei andern Arthropoden liegen widersprechende Angaben vor. TONNER (I933-I935) hat bei zahlreichen Formen (Crustaceen, Hexapoden) ein subdermal gelegenes " Hautnervensystem " beschrieben, das aus einer Schicht multipolarer, netzartig miteinander verbundener Nervenzellen und einem darunter gelegenen Fasernetz bestehen und das mit dem ZNS verbunden sein soll. Über eine Verbindung mit Sensillen wird nichts berichtet. Auf grund von Ausschaltungsversuchen bei Astacus wird diesem "Hautnervensystem » die Funktion einer 'Tonusregulation der Seklettmuskulatur zugeschrieben. Die Erregung der Muskulatur durch zentrifugale Fasern solle nur möglich sein bei gleichzeitigem Finströmen von Erregungen aus der Peripherie, eben aus dem "Hautnervensystem ".

Die Befunde TONNERs wurden seither nicht bestätigt. Insbesondere hat AI,ExANDROWICZ (I957) dessen Angaben auf Grund eingehender Untersuchung des peripheren Nervensystems mariner Crustaceen mittels vitaler Methylenblaumethode einer kritischen Prifung unterzogen und die Existenz eines Hautnervensystems bei diesen Formen verneint. Erschwert wird die Beurteilung durch die mangelhafte Qualität der Abbildungen in den Arbeiten Tonners, aber in einigen Fällen erscheint die Interpretation AlexANDROWICz', dass es sich bei den dargestellten Zellelementen nicht um Nerven-, sondern um ein Netz von Bindegewebszellen handelt, sehr wahrscheinlich. In anderen Fällen, so bei den abgebildeten multipolaren Zellen unter der Gelenkhaut von Squilla mantis, sind zweifelsohne multipolare Nervenzellen des Typus II dargestellt, die ja bei allen Arthropoden in diesen Regionen vorkommen und sehr häufig miteinander in Verbindung stehen. In eigenen Untersuchungen an marinen Crustaceen (Leander, Callianxssa, Squilla) an der Zoologischen Station Neapel (1) konnte in Übereinstimmung mit ALEXANDROwICz im subdermalen Bereich keinerlei Plexusbildung beobachtet werden. Die Neuriten der bi-oder multipolaren SNZ vereinigen sich hier geradlinig und ohne $Z$ wischenschaltung assoziativer Zellen in der Peripherie zu Nervenstämmen.

Hingegen scheint das von MEYER (1955) kurz erwähnte subdermale Nervennetz bei Lasius flaws mit dem hier bei Apis und Bombus gefundenen identisch zu sein,

(ז) Für die Überlassung eines Arbeitsplatzes bin ich Herm Dr. Peter DorrkN und für die Ermöglichung des Aufenthaltes dem Bundesministerium für Unterricht (Wien) zu aufrichtigem Dank verpflichtet. 
da er dessen Aufbau aus den zentripetalen Fortsätzen der Bipolaren beschreibt. lịn Hautnervensystem scheint aber keineswegs bei allen Insekten vorhanden zu sein. In allen bischer beobachteten Fällen bildet es jedoch kein in sich geschlossenes System im Sinne Tonners, sondern einen integrierenden Bestandteil peripherer sensibler Leitungsbahnen, die durch eine Vermehrung assoziativer Elemente eine höhere Stufe differenzierter Struktur- und Leistungsformen erreichen.

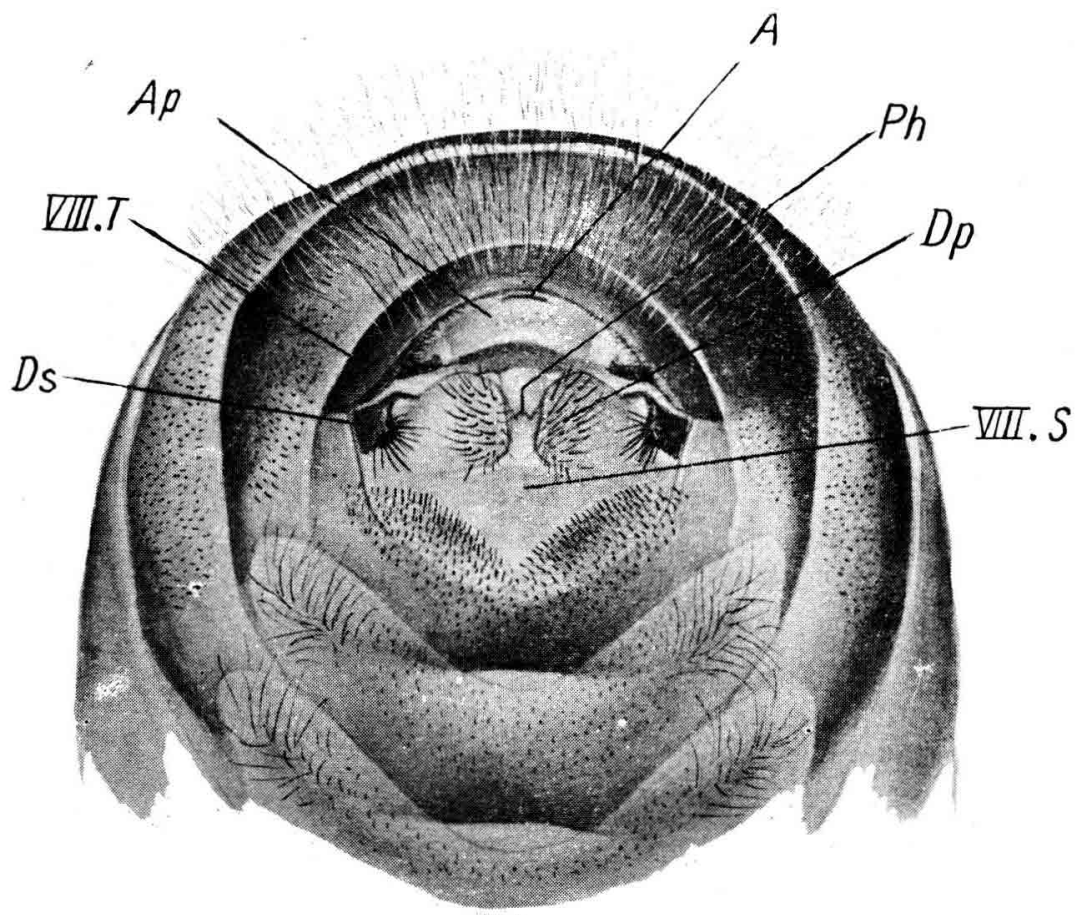

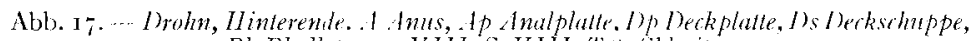
Ph Phallotrma, VIII.S, VIII. T's. Sklerit.

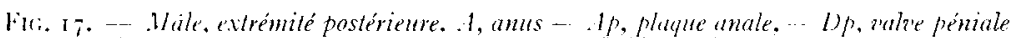
ISS, platues puramérales - Ph, phallotrème. VIII.S, VIII. T, ge sclévite.

\section{III. -- DAS GENITAIE SINNESFEII DES DROHNEN}

Die Bauchschuppen der terminalen Segmente des $\sigma^{x}$ zeigen weitgehende Umbildungen. Es hängt dies mit der der Honigbiene eigentiimlichen, weitgehenden Reduktion des äusseren Kopulationsapparates zusammen, dessen Funktion von einem kompliziert gebauten, membranösen Endophallus übernommen wird. Zwei ovale, mit zahlreichen kräftigen Borsten versehene Chitinplatten (Deckplatten nach ZANDFR I948) zu beiden Seiten der äusseren Geschlechtsöffnung, also der Einstülpungsstelle des Endophallus (Phallotrema), sind nach Sropgrass (I94I) aus den lateralen Skleriten des - rückgebildeten - Aedeagus hervorgegangen (" penis valves"; Abb. r7, I8). Das kranial anschliessende 8 . Sternit ist stark reduziert und sowohl mit 
den Deckplatten, wie mit dem 7. Sternit fest verwachsen, so dass der ventrale Abschluss des Abdomens des $\sigma^{7}$ durch eine zusammenhängende grosse Platte gebildet wird (Abb. I8).

Die der Deckplatte lateral aufliegende, sehr kräftige Chitinschuppe (Deckschuppe nach ZANDER, Abb. I8, DS) entspricht der Lamina parameralis und ihre dunkel pigmentierte, ein Borstenbüschel tragende mediale Ecke der Paramere. Ein kräftiger Chitinfortsatz der Deckplatte (Aedeagal-Apodem, Abb. I8, APA) reicht unter die Deckschuppe hinein und ist mit dieser durch zwei fächerförmige Muskeln verbunden

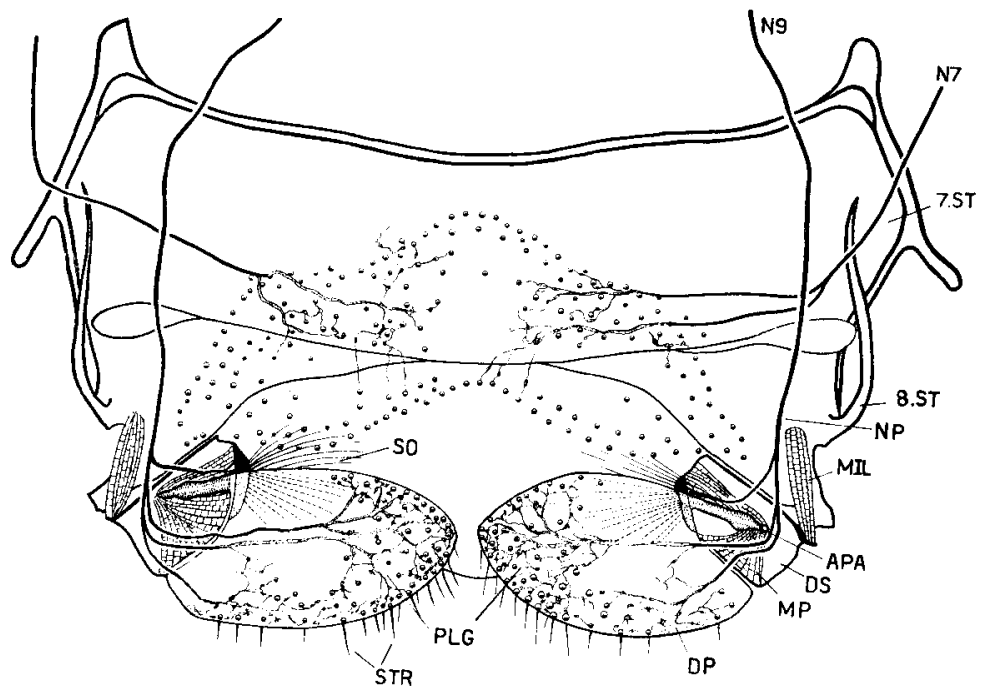

Abb. r8. - Die drei kaudalen Sternile des o. APA Aedeagal-Apodem, Dp Deckplatte, DS Deckschuppe, MP Musculus parameralis, MIL Intersegmentalmuskel zum 8. Sternum (8. St), NP Nervus parameralis, N7, N9 7. und 9. Segmentnerv, PLG Deckplatten-Plexus, SO Sinneshaare des parameralen Sinnesorgans, Sir Sensilla trichodea.

Fig. IS. - Les trois sternites terminaux du mâle - APA, Apodène cedagal, Dp. valves péniales. DS, plaques paranérales

$M P$, muscle paraméral - MIL, muscle intersegmentaire du $8^{\mathrm{e}}$ sternite $(8 . S t)$, NP, nert paraméral No $\%$, No 9 , Nerls des $7 \mathrm{e}$ el ge segments. - PLG, Plexus des valves piniales - SO, poils sensoriels de l'organe sensoriel paraméral, - - STR, sensilles Trichoides.

(Musc. paramerales, MP). Ein drittes, sehr schlankes Muskelbündel zieht von dem Apodem zum kaudalen Pol der Schleimdrüse (Musc. tensor glandulae mucosae, Abb. 52). Durch einen weiteren Muskel ist die Parameralplatte mit dem 8. Sternit verbunden (MIL).

GOETZE und SCHMIDT (I942) haben in dem röhrenförmigen Aedeagal-Apodem eine Drüse beschrieben, deren als Duftstoff wirksames Sekret durch das Borstenbüschel an der Paramere verteilt wiirde ("Duftpinsel "). Die Abgabe des Sekrets, das in einer bläschenförmigen Auftreibung an der Spitze des Apodems gespeichert werde, könne durch die aussen ansetzende Parameral-Muskulatur reguliert werden. Die genannten Autoren haben deshalb für die Lamina parameralis - sie spielt in der Rassensystematik der Honigbiene eine gewisse Rolle - die Bezeichnung " Duftschuppe "vorgeschlagen. 
Eine nähere Untersuchung erweist jedoch diesen Fortsatz der Deckplatte als einfaches Apodem, also einen als Muskelansatz dienenden Chitinzapfen. Drüsenzellen sind in seiner Höhlung nicht vorhanden. Über die Funktion des Borstenbüschels und der ebenfalls reich mit kräftigen Borsten besetzten Deckplatte geben die Innervationsverhältnisse Aufschluss : Ein langer dünner Nerv zieht, als 2. Ast des zusammengesetzten Terminalnerven vom letzten. Abdominalganglion kommend, zur Lamina parameralis (9. SN). Unterwegs gibt er einen Ast an den Musc. tensor glandulae mucosae ab. In der Gegend der Deckschuppe teilt er sich in zwei Äste. Der proximale Ast endet unter dem Haarbüschel der Paramere, der distale nach Abgabe von Asten an die Parameralmuskulatur in der subdermalen Schicht der Leckplatte (Abb. I8).

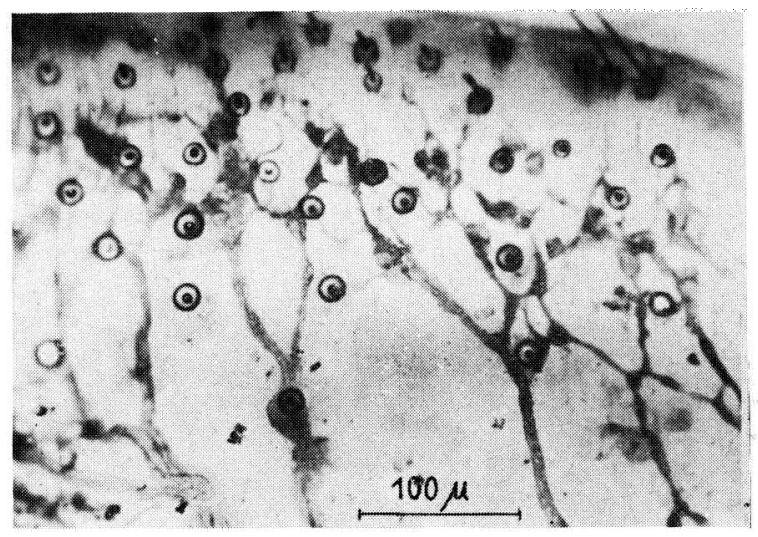

Abb. I9. - Deckplatten-Plexus (med. Kand) mil zahleichen Vervenzellen und Sensilla trichndea.

FIG. I9. - Plexus des valves péniales (milieu du bord) avec nombreuses cellules nerieuses et sensilles trichoides.

\section{A. - DER DECKPLATTEN-PIFXUS}

Der Deckplattennerv teilt sich in zwei bis drei Äste, die subdermal unter der Deckplatte ihren bisher kreisrunden Querschnitt verlieren und als breite flache Bänder zum medialen Rand der Deckplatte ziehen. Dort befinden sich dicht aneinandergereiht zahlreiche einfache Stichelhaarsensillen mit bipolaren SNZ (Abb. I8, I9, $20,2 \mathrm{I}$ ), welche das Phallotrema umgeben. Haare ohne Innervation sind nicht vorhanden. Zwischen den Haarsensillen liegen in geringer Zahl Sensilla basiplana (Abb. 23), ausserdem sind im basalen schwach behaarten Bereich der Platte rezeptorische multipolare Nervenzellen mit freien Erdigungen vorhanden (Abb. 20).

Zwischen den zentripetad verlaufenden Faserzügen sind feine Fasern vorhanden, die als lockermaschiges Nez mit multipolaren Nervenzellen in Verbindung stehen und in grössere Nervenstämme oder in das Neuroplasma von SNZ eintreten. Der Aufbau des Plexus aus Zellen und sich vielfach ïberkreuzenden und verzweigenden Faserzügen wird auf Abb. 2I deutlich. Es sind auch hier "bipolare "SNZ vorhanden, die nach verschiedener Richtungen Fibrillen abgeben. Sollte es sich lediglich um hindurchziehende Fasern handeln - was, wie gesagt, auf Grund der Methylenblaupräparate nicht eindeutig entschieden werden kann -, so scheinen sie doch im Bereiche des Perikaryons weitgehend ihre Individualität $z u$ verlieren $(A b b, 22)$. Stellenweise liegen 
" bipolare " SNZ, die durch Plasmastränge oder Fibrillen miteinander in Verbindung stehen, in Nestern beisammen (Abb. 23). Auch Kontakte zwischen SNZ und Fibrillen

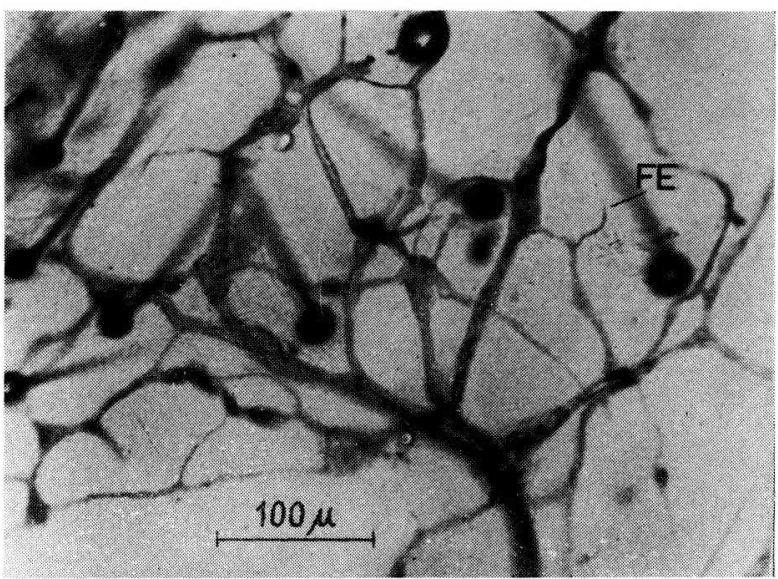

Abb. 2o. - Deckplatlen-Plexus (kaudaler Rand) mit Sensillen. HE Freie Vevervenendigung.

FiG. 20. - Plexus des zalves péniales (bord poslérieur) avec sensilles. FE, terminaisons nerveuses libres.

anderer Neurone, bzw. von Fibrillen untereinander, sind zu beobachten (Abb. I5, I6). Grundsätzlich ist der Aufbau des Deckplatten-Plexus also gleich wie beim subder-

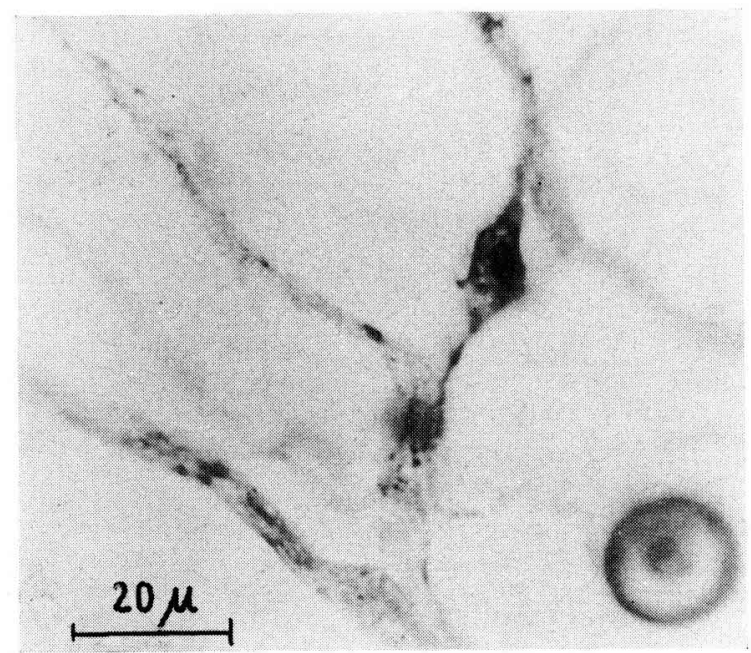

Abb. 2r.... Fibrillengeflecht und Nervenzellen aus dem Deckplatten-Plexus.

FIG. 2I. - Entrelacement de fubrilles et cellules nerveuses du plexus de values péniales.

malen Plexus der übrigen Somite, mit dem Unterschied, dass auf den Deckplatten die Sensillen und damit auch die Sinneszellen wesentlich dichter stehen. Besonders entlang der medialen Spitze der Deckplatte liegen die SNZ in enger Berührung dicht aneinander. Die SNZ sind hier relativ gross und mehr oder weniger rund. Bei kreisrunden SNZ 
riicken nicht selten die Abgangsstellen von Neurit und Sinnesfortsatz an denselben Pol, sodass Formen entstehen, die " pseudounipolaren " NZ ähneln (Abb. 24). Der Sinnesfortsatz der SNZ ist deutlich anders strukturiert als der Neurit, und zwar so-

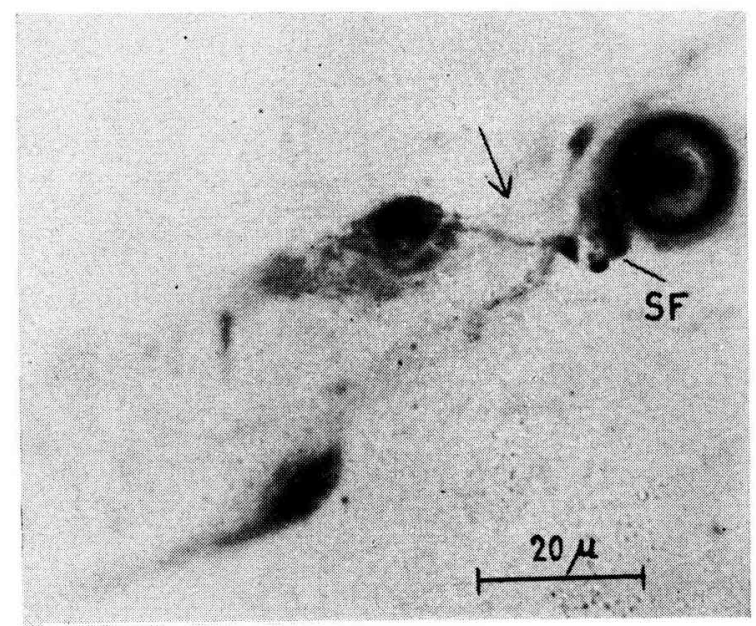

Abb. 22. - "Bipolare" Sinnesnervenzelle, die ausser einem Sinnesfortsalz (SF) zu einem Sensillum trichodeum aus ihrem Perikaryon noch zwei feine Fibrillen abgibt $(\downarrow)$.

Fís. 22. - Cellule nerveuse sensorielle "bipolaire "qui émet, en dehors d'une fibre sensorielle (Sl") allant d une sensille trichoïde, deux fines fibrilles partant de son péricaryon.

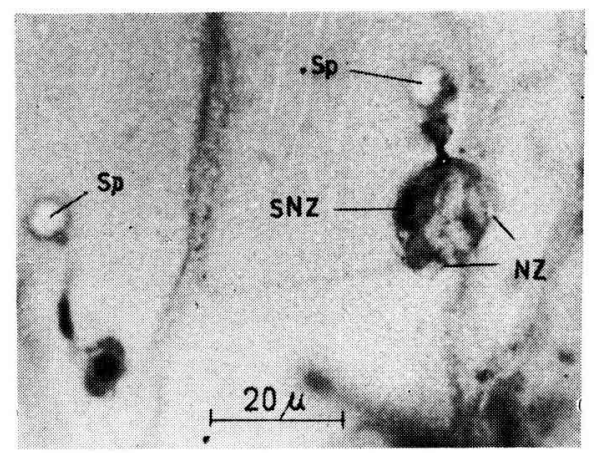

Abb. 23. - "Zellnest" mit gemeinsamer Kapsel. Sinnesnervenzelle (SNZ) mit Sinnesfortsatz zu Sensillum basiplanum $(S p)$, dansben und in enger Verbindung mit ihr noch zwei weitere Nervenzellen $(N Z)$

FIG. 23. - "Nid cellulaire" avec capsule commune. Cellule nerveuse sensorielle (SNZ) avec deux fibres sensorielles vers une sensille basiplane. A côté, et en étroite relation avec elle deux autres cellules nerveuses (NZ).

wohl im Methylenblau- wie im Silberpräparat : Während der Neurit das Bild eines kompakten, monofibrillären Axons gibt, ist der Sinnesfortsatz aufgelockert, mit gitterartiger Struktur (Abb. 24, 25).

\section{B. - DAS PARAMERAI,-GANGLION}

Die immer dunkel pigmentierte mediale Ecke der Deckschuppe ist nach innen umgeschlagen, sodass eine Chitinduplikatur mit kräftigen Wänden entsteht. Entlang 


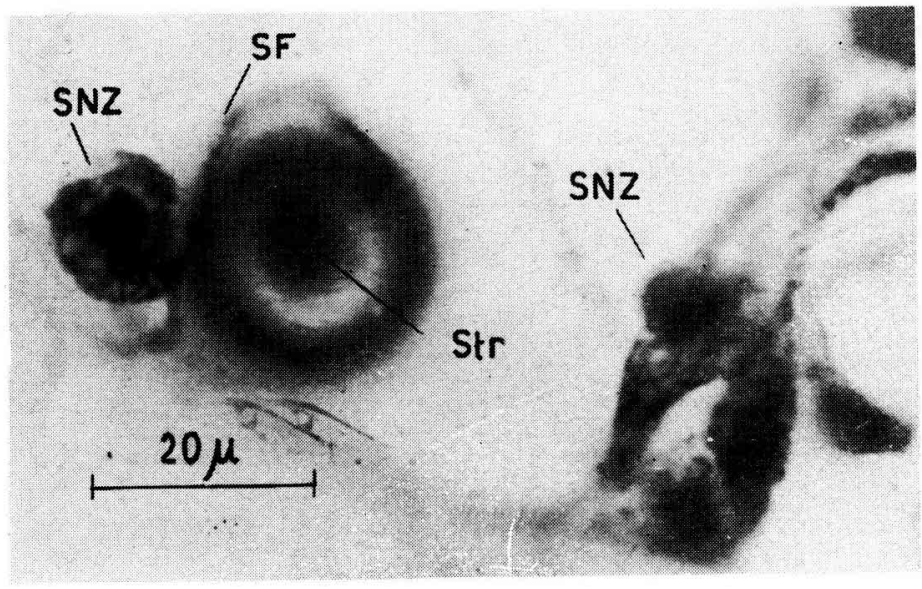

Abb. 24. - "Pseudounipolare "Sinnesnervenselle (SNZ) mit gitterförmiq sirukturierten Sinnesfortsatz $(S F)$ zu Sensillum trichodeum $(S t r)$.

Fig. 24. -- Cellule nerveuse sensorielle "pseudo-unipolaire" (SNZ) avec fibre sensorielle (SI) struciuree en forme de grillage vers une sensille trichoidde $(S t r)$.

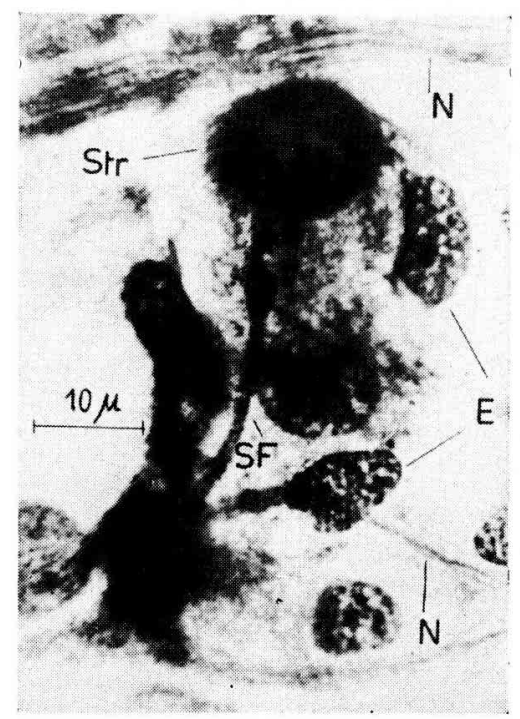

Abb. 25. - Der Sinnestortsatz (SF) zu einem Sensillum trichodeum (Str) ist deutlich anders strukturiert als die zentripetad verlaufenden Fasern $(N)$.

E Kerne von Epythelzellen. Silberimprägnation nach Bodian-Power.

FIG. 25. - La fibre sensorielle (SF) vers une sensille trichoide (Str) est nettement différente dans sa structure des fibres centripètes $(N)$. $E$, Noyaux des cellules épithéliales - Imprégnation argentique de BodianPower. 
der Kante sind die langen Borsten $(0,3-0,7 \mathrm{~mm})$ nach der typischen Art der Haarsensillen in die hier sehr kräftige Cuticula eingelassen. An der Basis jeder einzelnen Borste setzt der Sinnesfortsatz von SNZ an, die im Innern der Chitintasche liegen (Abb. 26, 27). Es handelt sich einerseits um längliche, vielfach kommaförmig gebogene bipolare Zellen, andererseits um multipolare Nervenzellen, die - vorwiegend zentripetal von den SNZ gelegen - durch zahlreiche Ausläufer untereinander und mit den SNZ in Verbindung stehen. In manchen Fällen werden aber Haarsensilleli nicht von einem Fortsatz einer bipolaren Zelle, sondern einer multipolaren NZ innerviert. Auf Grund der sonst zu beobachtenden Verhältnisse kann es sich aber

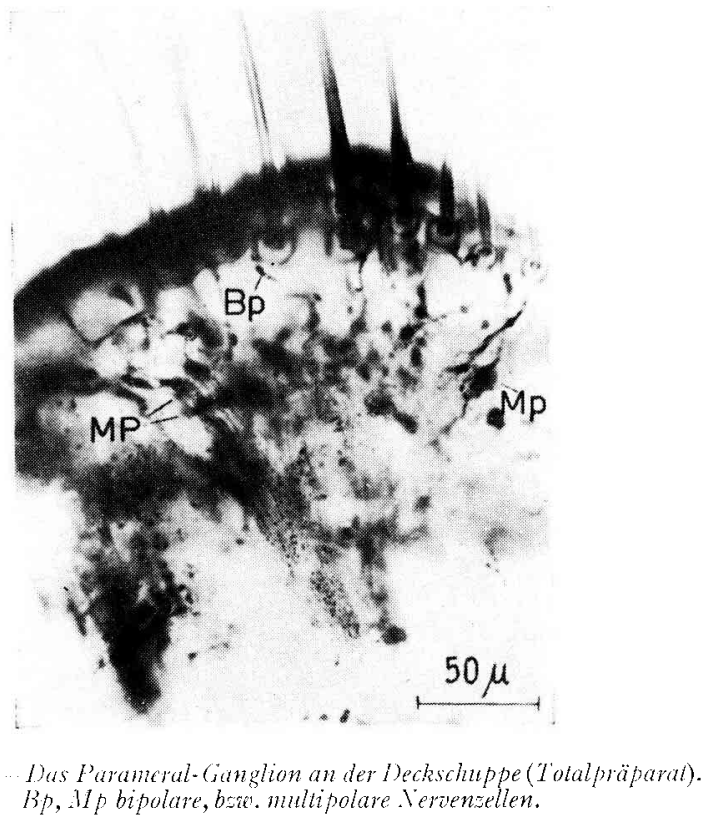

Fu. 26. - Le ganglion paraméral de la plaque paranérale (Préparation in toto). Bp, $.1 p$, cellules nemenses respectionent bipolatres el mullipolaires.

durchaus nur scheinbar um einen Fortsatz dieser Zelle, in Wirklichkeit aber um den peripheren Fortsatz einer bipolaren Zelle handeln, der durch die multipolare hindurchzieht.

Es liegt hier also ein peripheres Ganglion mit zwei Zelltypen vor. Die Zellen liegen in Nestern zusammen, die durch Bindegewebssepten voneinander getrennt sind (Abb. 27). Der Aufbau des Ganglions lässt sich ohne Schwierigkeiten von der Struktur des flächenhaft ausgebreiteten subdermalen Plexus unter den Somiten ableiten. Nur tritt hier, infolge der andern räumlichen Anordnung, das Fasergeflecht zurück, während die assoziativen Ganglienzellen stark vermehrt sind.

Die Parameren haben bei der Honigbiene infolge der starken Reduktion an Grösse und Muskulatur ihre Funktion als Klammerorgan verloren, sie sind aber zu einem hochentwickelten Sinnesorgan geworden, das dank der Länge seiner Borsten auf 
taktile Reize sehr empfindlich ansprechen kann. Gemeinsam mit den Deckplatten und mit den Sensillen am 7 . Sternum bilden sie als funktionelle Einheit ein genitales Sinnesfeld, das sicherlich für die Kopula von Bedeutung ist.

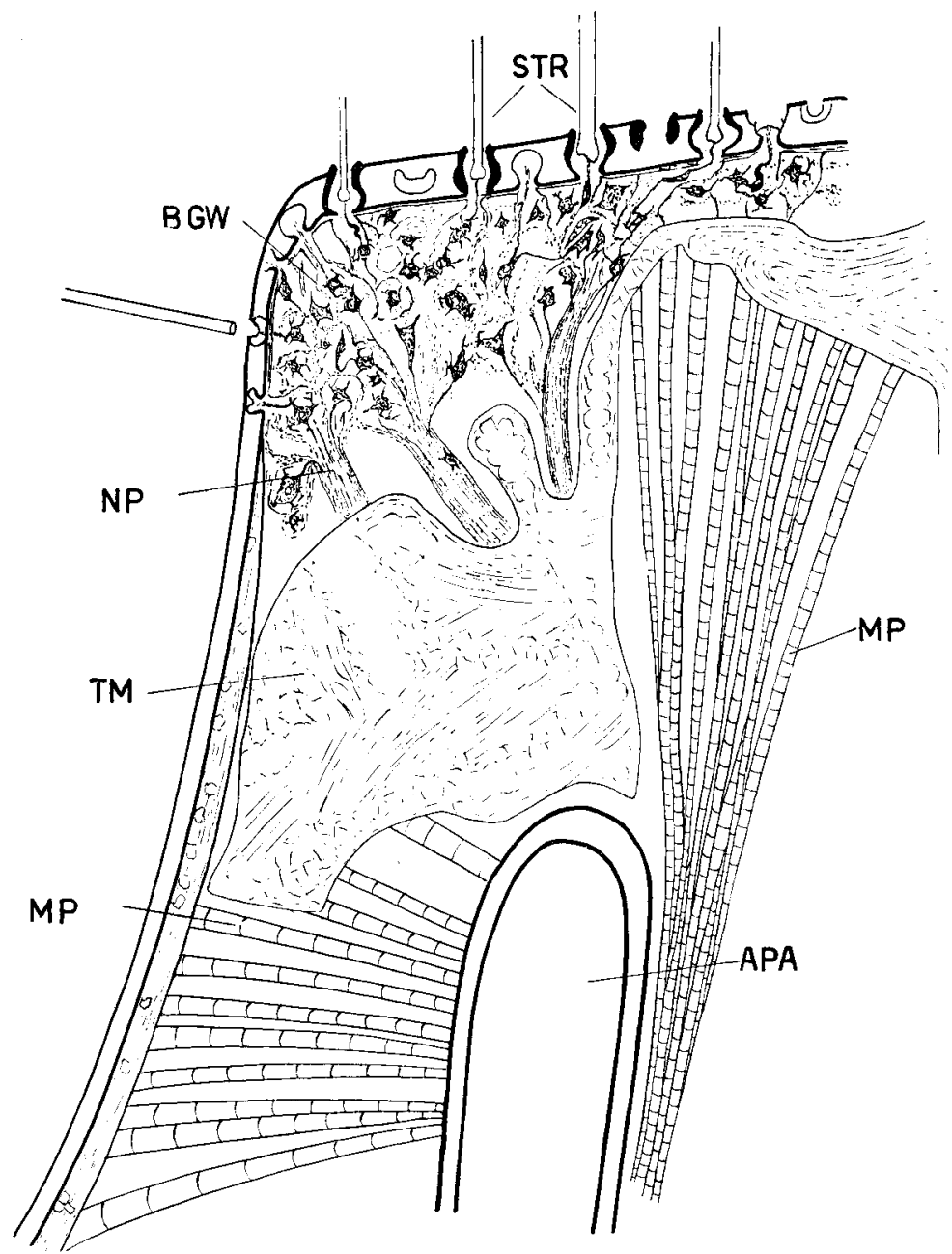

Abb. 27. - Schnitt durch die Deckschuppe und das Parameral-Ganglion( schematisch). APA Aedeagal-Apodem, $B G W$ Bindegewebs-Septen um Nervenzellen, MP Parameral-Muskulatur, NP Zweig des ParameralNerven, Str Sensilla trichodea, TM Trachealmembran.

Fig. 27. - Coupe a travers la plaque paramérale et le ganglion paraméral (schéma) APA-Apodème aedeagal - BGW, tissu conjonctif entourant les cellules nerveuses - MP, musculature paramérale $-N P$,

branche du nerf paraméral — Str, sensille trichoide - TM, membrane trachéenne.

\section{C. - SINNESORGANE AM ECTOPHALI,US ANDERER HYMENOPTEREN}

$$
\text { I. Vespa }
$$

Bei Vespa bilden die beiden mit einer dicken Cuticula versehenen Laminae paramerales (bzw. Parameren) eine sehr kräftige Zange, deren Backen von starken Muskeln bewegt werden (Abb. 28). Im Zentrum befindet sich der Aedeagus, dessen Late- 
ralsklerite (homolog der I)eckplatte beim Drohn) an der Spitze ein kleines Haarbiischel tragen. Zwischen Paramere und Aedeagus liegt die Volsella mit zwei zarten,
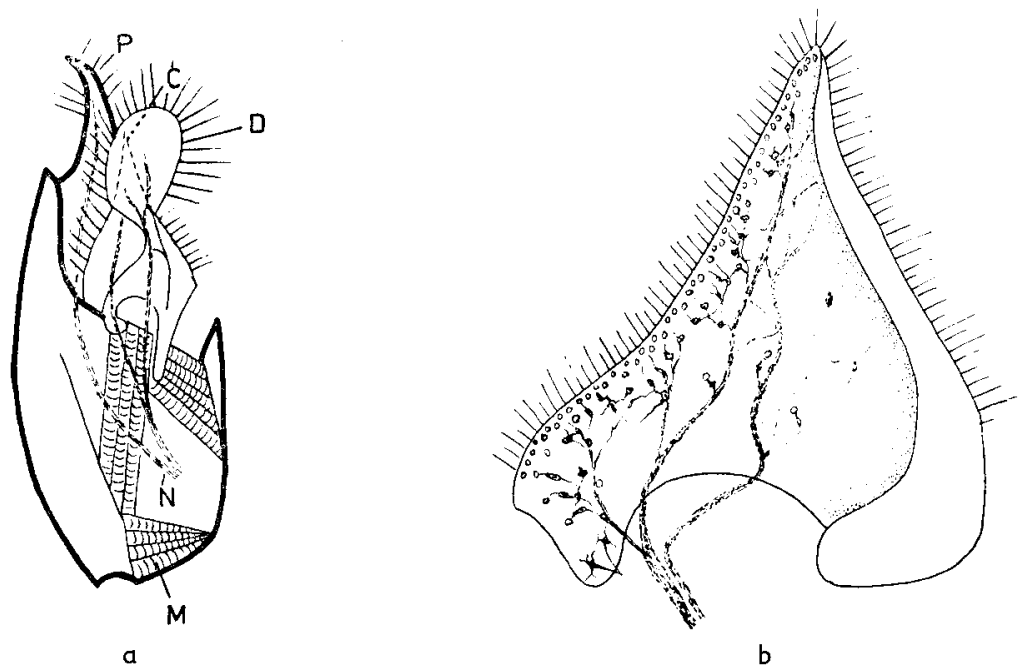

a

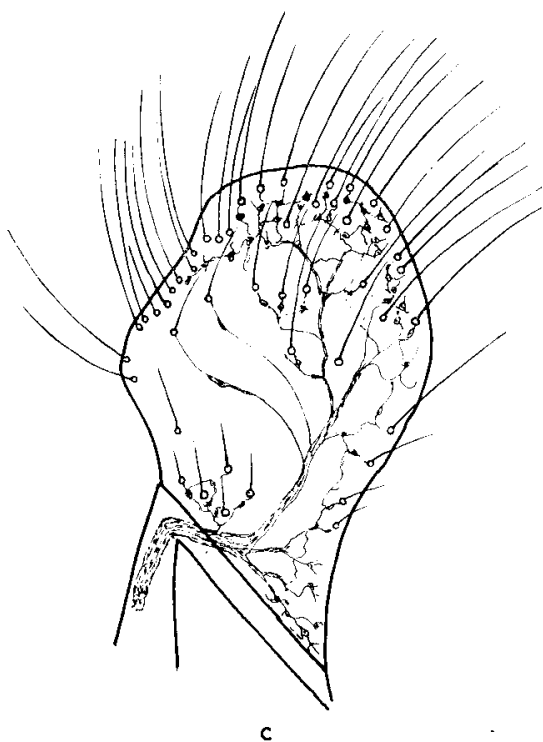

c

Abl. 28 -- Sklevile des Eciophallus von Vespa a). P Paramere, C D Cuspis und Digitus der Volsella $M$ Muskulatur, $N$ Nerv. b). Cuspis volsellaris, c). Digitus volsellaris mit Plexus und Sensillen (Stark vereinfacht).

Fig. 28. -- Sclérite de l'ectophallus de "Vespa.". a) P, paramère - CD, Cuspis et digilus de la Volsella -- M, musculature - $N$, nerf. b) Cuspis volsellaris. c) Digitus volsellaris avec plexus et sensilles (trés simplifié).

stark behaarten Blättern (Digitus und Cuspis). Alle genannten Sklerite geben kräftigen afferenten Nervenbahnen ihren Ursprung. An der Spitze der Paramere befinden sich zwar nur relativ spärlich Sensilla trichodea. Aber die beiden Blätter der Volsella enthalten subdermal ein dichtes Geflecht von Nerven mit multipolaren und 
bipolaren Nervenzellen. Die Sinnesfortsätze der letzteren ziehen zur Basis der langen weichen Haare (Abb. 28, b, c). Auch das Haarbüschel an der Spitze der Aedeagalsklerite erweist sich als ein Sensillenfeld. Die Volsella besitzt nach ihrer Struktur und Iage sicher keine mechanische Funktion, sie ist als reines Sinnesorgan aufzufassen.

\section{Bombus}

Die Parameralplatten von Bombus sind noch kräftiger entwickelt als die von Vespa. Ihre oft bizarren Chitinfortsätze bilden ein wichtiges taxonomisches Kriterium. Es sind kräftige Haarsensillen in grosser Zahl vorhanden, die sich bei verschiedenen Formen ( $z$. B. hei B. hortorum, Abb 29) medial zu einem Sensillenfeld anordnen. Aus dem darunter gelegenen, dichten und zellreichen Nervengeflecht ziehen einige Nervenäste zentripetad.

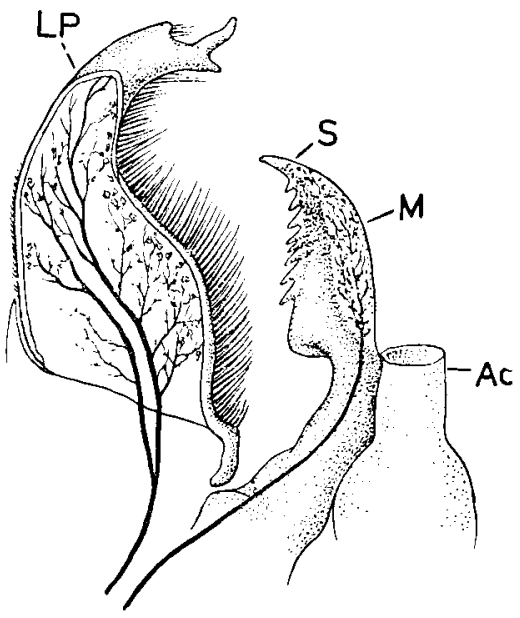

Abb. 20. - Sklerte des Ectophallus zin Bombus hortorum.

As Ledeagus, LP Lamina parameralis mit Plexus, $S$ Sagitta nit Sinnesmembran $(M)$.

Fic. 29. - Sclérite de l'eclophallus ie Bombus hoitorum. Ac, Aedeagus

- LP, I.amina parameralis arec plexus - S, Sagitla arec membrane sensonelle $(M)$.

I ie ebenfalls sehr variablen Aedeagalsklerite (Sagittae) bilden mit einer harten, oftınals gezähnten Chitinleiste ein Widerlager für die Sinneshaare an der Medialseite der Parameren. Sehr eigenartig ist ein Sinnesfeld an der medialen, dem membranösen I'nis zugewandten Seite der Sagitta : Hier ist die Epidermis zu einer dünnen, durchsichtigen Membran umgewandelt. Sie ist dicht mit Membransensillen und - in geringerer Zah1 - mit Sensilla trichodea mit sehr kurzen, zarten Haaren bedeckt. In Bereiche der Sensillengruppen ist die Cuticula etwas verdickt und pigmentiert; bei schwacher Vergrösserung erscheint deshalb die durchsichtige Epidermis übersät mit unregelmässigen, bernsteinfarbenen Flecken. Auch am ungefärbten Präparat erkennt man subdermal einen dicht verzweigten Plexus mit den SNZ. An der lateralen Seite der Sagitta sind ebenfalls Haar-11nd Membransensillen vorhanden ; enge Kanäle, welche die sehr dicke Cuticula durchsetzen, stellen die Verbindung mit dem Plexus her.

Auch an der Aussenseite der Lamina parameralis ist die Cuticula in einem schmalen Segment zu einer sensillentragenden Membran umgebildet. 


\section{I). - DIE ANAIPIATTEE}

Wegen ihrer engen topographischen Beziehungen zur Genitalregion soll noch das terminale Sklerit des Abdomens, die nach Sxopgrass (I94I) als reduziertes Io. Sternit aufzufassende Analplatte (Abb. I7, Ap.) besprochen werden. Es ist dies eine

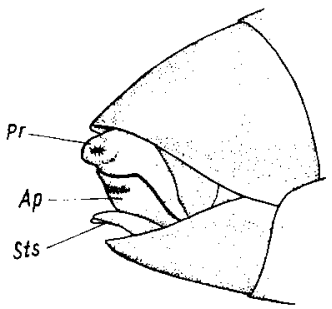

Abb. 30. - Hinterende einer Arbeitsbiene. Ap Analplatte, I'r Procliger (rorgestïlpt), Sts Slachelscheide.

Fri. zo. - Extrémité postériéure d'une Abeille outrière. Ap, plaque anale

- Pr, proctiger (sorti) — Sts, fourreal de l'aiglitlon.

schildförmige, wenig sklerotisierte Platte, die in die Intersegmentalmembran zwischen Analöfnung und Stachelapparat (beziehungsweise beim $\sigma^{*}$ zwischen jener und der Deckplatte) eingelagert ist; sie bildet die basale Wand des Proctiger (= termi-

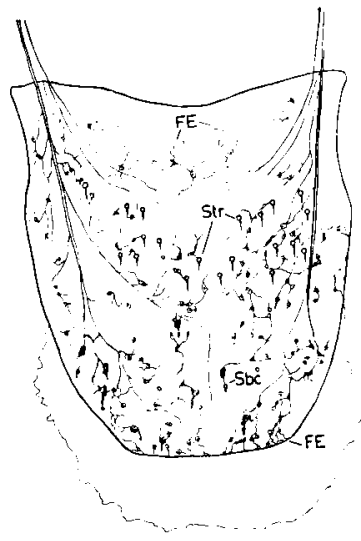

Abb. 3r. - Inalplatle mit Sensillen und Plexus (schematisch).

IF Freie Nervenendigungen, Sbc Sensillum basiconicum, Str Sensillum trichodeum.

FIC. 3I. - Plaque anale avec sensilles et plexus (schéma). FE, lerminaisons neveruses libre's -. Sbe, Sensillum basiconicum - Str, Sensillum trichodeum.

nales anustragendes Segment - SxodgRASS 1956). Ihr kaudaler Rand begrenzt ventral die Analöffnung; eine an diesem ansetzende Membran geht in die Intima des Rectums ïber.

In Ruhestellung steht die Analplatte senkrecht zur Körperachse. Ihr Hinterrand wird von der Intersegmentalmembran des 8 . Tergits ïberdeckt, sodass sie die Analöffnt1ng vollkommen verschliesst. Bei Entleerung der Kotblase klappt die Platte 
um und schiebt sich löffelartig mit der Analöffnung zwischen den terminalen Skleriten hervor (Abb. 30).

Im Rahmen der vorliegenden Untersuchung wurde die Aufmerksamkeit dadurch auf diese Platte gelenkt, dass sich ein relativ kräftiger Nerv, der als medialster (also letzter) Ast vom terminalen Bauchganglion oder vom gemeinsamen Endnerv abzweigt, an ihr endigt. Im subdermalen Bereich der Analplatte ist ein reich entwickelter Nervenplexus vorhanden (Abb. 3r), der sich in seinem Aufbau gut mit dem der Deckplatte vergleichen lässt, jedoch nach der Art der mit ihm verbundenen Sensillen sich deutlich von diesem unterscheidet. An der Analplatte sind die folgenden rezeptorischen Endapparate vorhanden :

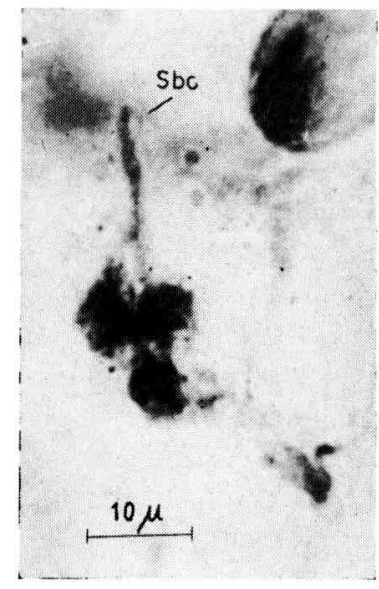

Abb. 32.- Gruppevon Sinnesnervensellen mit peripherem

Fortsatz zu Sensillum basiconicum $(S b c)$. Analplatte.

Fic. 32. - Groupe de cellules nerveuses sensorielles avec fibre périphérique vers une sensulle basiconique. $(S b c)-$ Plaque anale.

I. Sensilla trichodea mit einer bipolaren SNZ

a) mit kräftigen Haaren (jederseits 6-I5)

b) mit zarten Haaren ("Riechhaare")

2. Sensilla basiconica mit 2-4 SNZ, die einen gemeinsamen, plumpen Sinnesfortsatz mit einem feinen Endfilament bis in die Spitze des Riechkegels entsenden (Abb. 32). Diese Kegelsensillen sind am kaudalen Rand der Platte in grosser Zahl vorhanden.

3. Frei an der Cuticula endigende Sinneskörper. I-4 SNZ entsenden einen plumpen, oftmals gewundenen rezeptorischen Fortsatz an die dünne durchsichtige Cuticula, um hier stumpf zu enden. Ob die Cuticula an dieser Stelle verändert ist, konnte nicht festgestellt werden.

4. Multipolare Nervenzellen mit freien Endigungen.

Die Sensillen der Analplatte dienen vermutlich vorwiegend der Chemorezeption. 


\section{E. DISCUSSION ZU KAPITEI, III}

Das genitale Sinnesfeld des $\sigma^{*}$ ist sowohl nach seiner histologischen Struktur wie nach der subdermalen Lage als spezifische I)ifferenzierung des Hautnervensystems am Abdomen der Biene anzusprechen. Auch das Parameralganglion ist strukturell lediglich ein weiterer Schritt in der Konzentration der im subdermalen Plexus schon vorhandenen nervösen Eilemente.

Periphere Ganglien - also nicht bloss Anhäufungen von Sensillen oder SNZ sind bei der Honigbiene meines Wissens noch nicht beschrieben worden. Auch beim Johnstonschen Organ ziehen die Neuriten der Sinneszellen ohne Unterbrechung in das Zentralnervensystem. Es muss aber angenommen werden, dass dieses Ganglion keineswegs das einzige ist; Untersuchungen des peripheren Nervensystems höherer Insekten mit geeigneten Methoden werden sicherlich noch zu mancher Entdeckung führen. LINDAUER und NEDEI. (I959) haben an dem Schweresinnesorgan der Honigbiene in einem Chitinzapfen des Episternums ein dichtes Sensillenfeld beschrieben, dessen bipolare SNZ subdermal in einer geschlossenen Schicht angeordnet sind. Unter diesen SNZ lassen sich auf Abb. 9 und II der zitierten Arbeit Zellen erkennen, die als multipolare Ganglienzellen gedeutet werden könnten und dem ganzen Organ in seinem histologischen Aufbau eine auffällige Ähnlichkeit mit dem Parameralganglion geben. Vielleicht handelt es sich auch hier um ein echtes Ganglion.

JANET (I II) hat in der Antennenbasis der Biene ein "ganglion sensitif tactile" abgebildet; über seinen histologischen Aufbau ist nichts bekannt. Von den Mandibeln der Honigbiene bringt NEDEL. (I959) die Aufnahme eines - allerdings wenig selektiv gefärbten - zellreichen Nervenplexus, der anscheinend ähnlich gebaut ist wie der Deckplattenplexus, bzw. das Parameralganglion.

Die vergleichende Untersuchung an verschiedenen sozialen Hymenopteren (Apis, Bombus, Vespa) hat ergeben, dass die Sklerite des Ectophallus iiberall durch einen reichen Besatz an Sensillen und durch ein differenziertes peripheres Nervensystem ausgezeichnet sind. Auf Grund der Kenntnis der Sinnesorgane an den phallischen Skleriten der hier beschriebenen Formen können Rückschlüsse auf die Verhältnisse auch bei anderen Hymenopteren gezogen werden. Aus der eingehenden Darstellung der männlichen Genitalien der Hymenopteren von SNodGRASS (I94I) geht hervor, dass so gut wie bei allen Formen Sklerite mit stark behaarten und of tmals sehr zarten Partien vorhanden sind, die als Sinnesregionen aufgefasst werden müssen. Sehr hä11fig weisen die Parameren (bzw. Laminae paramerales) oder Teile von ihnen diese Charakteristika auf; wo sie als kräftige Zangen vorwiegend mechanischen Funktionen dienen, wie bei Vespa, sind andere Sklerite (Volsella, Lamina aedeagalis) als spezifische Sinnesorgane ausgebildet. Bei eigens darauf zielenden Untersuchungen lassen sich voraussichtlich auch andere, spezifische Gestaltungen der rezeptorischen Region auffinden, die nicht sogleich als solche zu erkennen waren, wie z. B. die Sensillenfelder an Membranen von Sagitta und Lamina parameralis von Bombus.

Man muss demnach ganz allgemein dem Phallus der Hymenopteren sehr feine rezeptorische Funktionen zuschreiben, die den mechanischen an Bedeutung sicherlich gleichkommen und in manchen Fällen ( $z$.B. bei Apis) auch für sich allein bestehen bleiben. Ihre Kenntnis ist wichtig für das Verständnis der in einer geregelten Folge ablaufenden Vorgänge bei der Copula. 
Eine Lücke in der Erklärung der Funktion der rezeptorischen Organe am Abdomen der Biene bleibt durch die Unsicherheit in der physiologischen Deutung der verschiedenen morphologischen Sensillentypen bestehen. Gewöhnlich wird dickwandigen Sensillen (z. B. Sensilla trichodea) die Fähigkeit zur Aufnahme taktiler Reize zuerkannt; dïnnwandige Sensillen hingegen sollen auf chemische Reize ansprechen. Nur in einigen Fällen konnten bisher bestimmte Sensillentypen experimentell einer bestimmten Funktion zugeordnet werden (z. B. Sensilla trichodea als taktile Rezeptoren an den statischen Organen, LINDAUER und NEDEL (I959) ; dünnwandige Haarsensillen als Chemorezeptoren an den Tarsen verschiedener Dipteren, Hodgson und ROEDER I955).

Gänzlich unmöglich wird eine funktionelle Deutung nach morphologischen Kriterien dann, wenn Sensillen derselben Gruppe, aber verschiedener Struktur im einzelnen, an derselben Körperregion nebeneinander vorkommen ; dies gilt z B. für die monozellulären und polyzellulären Sensilla trichodea an den Sterniten der Arbeitsbienen. Auch über die Funktion der am Abdomen recht zahlreichen Sensilla basiplana mit ihrer sehr dïnnen Verschlussmembran kann nicht das Geringste ausgesagt werden.

\section{IV. - DIE INNERVATION DES MÄNNICHEN GENITAITRAKTES}

\section{A. - ANATOMIE UND Histologie DER GENITALORGANE}

Anatomie und Histologie von Vesicula seminalis und Glandula mucosa wurden von Bishop (I920) eingehend studiert. Beide Bildungen sind nach SNodGrass (I94I) Differenzierungen des Vas deferens und weisen einen identischen histologischen Bau auf : Eine kräftige muskuläre Wand, bestehend aus einer äusseren Schicht von longitudinalen und einer inneren Schicht von zirkulären Muskelfasern, und - als Auskleidung des Lumens - ein Drïsenepithel. Nach aussen ist das Vas deferens von einer lockeren Bindegewebshülle umgeben, die im Bereich der Vesicula seminalis eine beträchtliche Stärke erreicht.

Als Vesicula seminalis wird der flaschenförmig aufgetriebene, mittlere Abschnitt des Vas deterens bezeichnet (Abb. 33). Die Spermatozoen wandern in den ersten Lebenstagen des $\sigma^{\top}$ aus den Testes in diesen Hohlraum ein, wo sie sich mit dem Sekret des Drüsenepithels zur Spermaflüssigkeit vermischen. Nach dem Io. - I5. Lebenstag des ơ sind die entleerten Testes stark geschrumpft (Abb. 33, Ho). Nach unten zu verengt sich das Vas deferens wieder zu einem dünnen, S-förmig gekrümmten Rohr, das sich kaudal mit dem Ausfïhrungsgang der Glandula mucosa vereinigt.

Die paarigen Glandulae mucosae sind biskotenförmige Körper von 4,5-5,0 mm Länge und I,3 - I,4 mm mittlerer Breite, die den dorsocaudalen Teil des Abdomens erfüllen (Abb. 33). Die zweischichtige Muskelwand ist am kranialen Pol am dïnnsten, während sie am kaudalen Pol mächtige Verdickungen mit kompliziertem Faserverlauf aufweist, in die Vas deferens und Ductus ejaculatorius eingebettet sind (Abb.34). Die Vereinigungsstelle dieser beiden Gangsysteme ist so vollständig in die Muskulatur der Glandula mucosa eingebettet, dass die Vesicula seminalis lediglich als Anhang an der weit grösseren Schleimdrïse wirkt.

Ein dicker Muskelwulst von vorwiegend zirkulären Fasern schiebt sich zwischen 


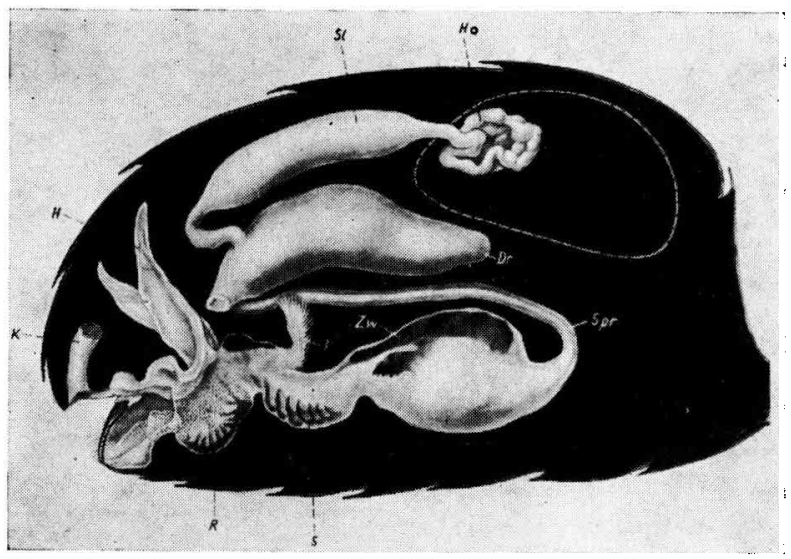

Abb. 33. - Der Genitaltrakt des of in situ (nach Ruttner 1960). Dr Schleimdrüse, F Federanhang, H Hörnchen, Ho Hoden (entleert; gestrichelte Linie: Form und Grösse des noch mit Samen gefüllten Hodens), $K$ Rectum, $R$ Rautenfeld, S Spiralstreif, Spr Ductus ejaculatorius, Sl Vesicula seminalis, Zw Bulbus.

(Mit freundlicher Genehmigung des Ehrenwirth Verlages, München, aus BÏDEL - HEROLD, "Biene und Bienenzucht »).

FıG. 33. - Le Tractus génital du mâle in situ (d'après Rutlner, 1960). Dr, glande à mucus - F, lobe frang, (ou tendeur) - H, cornules - Ho, testicules (vides, la ligne pointillée indique la forme el la taille du testiculé encore plein de sperme $-K$, rectum $-K$, plaque pileuse $-S$, bande spirale $-S p r$, canal éjaculateur $-S l e$ vésicule séminale - Zw, bulbe.

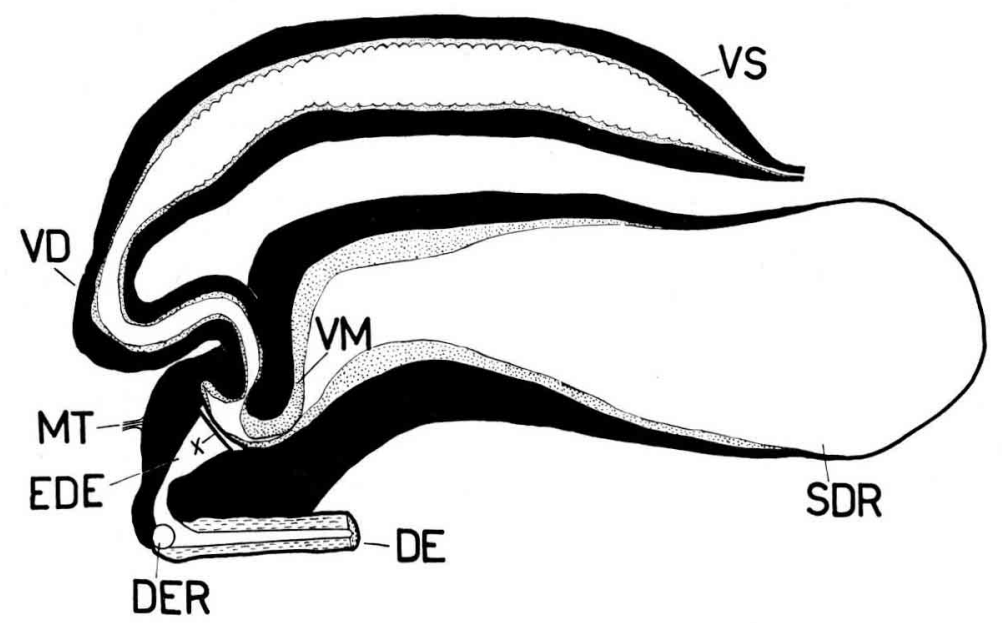

Abb. 34. - Schnitt durch Vas deferens und Glandula mucosa (schematisch; nach Bishop r920). Schwarz: Muskulatur; punktiert : Drüsenepithel (nach Schleimsekretion atrophiert). DE Ductus ejaculatorius, DER Verzweigungsstelle des $D$. ejac., EDE Endabschnitt des D. ejac., MT Ansatzstelle des Musculus tensor gland. muc., SDR Schleimdrïse, VD Vas deferens, VM muskuläres Ventil der Schleimdruse, VS Vesicula seminalis, $x$ Verschlussmenbran

FIG. 34. - Coupe à travers le canal déférent et la glande à mucus.(schéma, d'après Bishop I920). En noir: musculature; pointillé : épithélium glandulaire (atrophié après la sécrétion du mucus) $-D E$, canal éjaculateur - DER, point de ramification du canal éjaculateur $-E D E$, portion terminale du canal éjaculateur $-M T$, point d'application du muscle tenseur de la glande à mucus - SDR, glande à mucus - VD, canal déférent

- V'm, soupape musculaire de la glande à mucus - VS, vésicule séminale. 
die Einmündung von Vas deferens und basalem Abschnitt der Schleimdrüsenhöhlung (Abb. 34, VM.). Diese Struktur ist funktionell von besonderer Bedeutung, da sie ein muskuläres Ventil bildet, das den Ausgang der Schleimdrïse vollständig verschliesst (BISHOP I920).

Das Drüsenepithel der Schleimdrüse besteht beim unreifen $\sigma^{x}$ aus besonders hohen Zylinderzellen, durch welche das freie Lumen auf einen engen zentralen Bereich reduziert wird. Durch holokrine, bzw. merokrine Sekretion erfolgt, vom kranialen Pol der Drüse beginnend, während des Reifungsprozesses eine weitgehende Rückbildung des Epithels. Beim reifen $\sigma^{\nearrow}$ hat sich das nun prall mit Schleim gefuillte Lumen der Glandula mucosa am aufgetriebenen vorderen Pol bis zur Basalmembran des Epithels ausgeweitet.

Ausser dem oben erwähnten Muskelventil ist noch ein zweiter Verschluss der Schleimdrüse, bzw. des Vas deferens vorhanden : Der basale Abschnitt der Höhlung der Glandula mucosa, der das Vas deferens aufnimmt, endet blind, ohne Verbindung mit dem Ductus ejaculatorius. Zwischen dem konusförmig erweiterten Ende des letzteren und dem Lumen der Schleimdrüse ist eine dünne, chitinöse Doppelmembran ausgespannt (Abb. 34, x), die erst bei der Ejakulation zerreisst und den Weg für Sperma und Schleim freigibt.

Am kaudalen Pol der Glandula mucosa, gegentiber der Verschlussmembran des Ductus ejaculatorius, entspringt ein schlankes Muskelbuindel (Abb. 34, 52, MT), das quer durch die Abdominalhöhle zum Aedeagal-Apodem (Deckplatten-Apodem, 9. sternales Sklerit) zieht (Abb. I8, APA). Dieser Musculus tensor glandulae mucosae wird schon von Bishop (I920) und SNODGRAss (I94I) kurz erwähnt, in seiner funktionellen Bedeutung aber nicht berïcksichtigt. Sicherlich dient er nicht lediglich der Fixierung der Schleimdrüsen, wie Brshpop annimmt. Die Verbindung eines drüsigen Organs mit einem Sklerit durch einen Muskel, der nach seiner histologischen Struktur ein typischer Skelettmuskel ist, muss als sehr ungewöhnlich besonders hervorgehoben werden. Seine Kontraktion führt zu einem doppelten Fffekt :

I. Streckung des S-förmig gekrümmten kaudalen Abschnittes des Vas deferens und Erweiterung seines I,umens.

2. Spannung und schliesslich Zerreissung der Abschlussmembran des Ductus ejaculatorius (Vielleicht schon durch den Zug allein, sicher aber durch den zusätzlichen Druck des Spermas).

Damit ist der Weg für das Sperma in der Vesicula seminalis freigeworden ; von der sich kontrahierenden Wandmuskulatur gepresst, strömt es in den Ductus ejaculatorius.

\section{B. 一 DIE EJAKULATION}

Eine wirkungsvolle Besamung der Königin erfolgt nur dann, wenn das Sperma des Drohns quantitativ in die Ovidukte der Königin gelangt. Dazu muss zuerst reines Sperma ejakuliert werden und erst anschliessend der Inhalt der Schleimdrüsen, der das gesamte Sperma aus dem Ductus ejaculatorius und der Vagina in die Ovidukte presst. Jede Störung in dieser zeitlichen Aufeinanderfolge vereitelt die erfolgreiche Samenübertragung.

Es ist erstaunlich, mit welcher Exaktheit nun tatsächlich die Ejakulationen von Sperma und von Schleim miteinander synchronisiert sind. Damit das Sekret der 
Schleimdrüsen anschliessend an das Sperma und zu keinem andern Zeitpunkt ausgepresst wird, muss

I. eine freie Passage von der Vesicula seminalis in den Ductus ejaculatorius vorhanden sein : Kontraktion des Musculus tensor glandulae mucosae ;

2. während der Sperma-Ejakulation die Muskelklappe im unteren Teil der Drüse (Abb. 34, VM.) geschlossen sein; dazı reicht offenbar der Ruhetonus der Muskulatur aus ;

3. dieser Muskelwulst nach Entleeren der Vesicula seminalis retrahiert werden, sodass nun der Ausführungsgang der Schleimdrüse geöffnet wird ;

4. erst in diesem Augenblick eine Kontraktionswelle einsetzen, die vom apikalen Pol beginnend, die Entleerung der Schleimdrüse bewirkt. Jede anders verlaufende Kontraktion - etwa beginnend im kräftigen basalen Abschnitt der Drüse - muss zur Ruptur der relativ dïnnen apikalen Drïsenwand führen.

Diese Verzögerung der Kontraktion der Schleimdriisenmuskulatur ist das Entscheidende an dem ganzen Vorgang.

Den Schlïssel zum Verständnis dieser Vorgänge liefert das Studium der Innervation. Es wurden deshalb die nervösen Endigungen am reproduktiven System des Drohnen und an seinen Hilfsapparaten eingehend untersucht.

\section{C. - DER NERVÖSE, ENDAPPARAT AN GLANDULA MUCOSA UND VAS DEFERENS}

\section{Der 10. Segmentnerv}

Das Bauchmark des $\sigma^{x}$ besteht aus vier Abdominalganglien (bei der $O$ : Ebenfalls vier; bei der Arbeitsbiene : Fünf). Alle Fortpflanzungsorgane werden durch Nerven aus dem kaudalsten (4.) Ganglion versorgt. Dieses - relativ grosse - Ganglion entsendet beim $\sigma^{x}$ nur drei Paare von Nervenstämmen, obwohl es aus einer hochgradigen Konzentration der abdominalen Ganglienkette hervorgegangen ist : Seitlich zwei Nervenpaare, die den 6 . und 7. Segmentnerven entsprechen, und kaudal die beiden dicken "Terminalnerven ", die Fasern aus dem 8 . - I I. Segment enthalten.

Der Terminalnerv teilt sich in mehrere Äste mit folgendem Versorgungsbereich (RUTTNER I961) :

I. Ast : 8. Somit (8. Segmentnerv)

2. Ast : Lamina parameralis (Deckschuppe nach ZANDER)

Aedeagal-Sklerit (Deckplatte nach ZANDFR) samt ihrer Muskulatur, einschliesslich des M. tens. gland. muc. (9. Segmentnerv).

3. Ast : Glandula mucosa, Vesicula seminalis, Rectum (ro. Segmentnerv).

Der ro. Segmentnerv ist der Hauptast des Terminalnerven. Er zieht zum kaudalen Pol der Schleimdriise, wo er sich fingerförmig in mehrere Äste verzweigt (Abb. 35). Einer dieser Äste umgreift die Schleimdrïse lateral, um dann in die Muskulatur einzudringen. Erst bei stark ïberfärbten Präparaten gelingt es, diesen Ast bis z11m Vas deferens zu verfolgen (Abb. 36). Er gibt hier feine Verzweigungen an dessen Muskulatur ab und zieht weiter zur Vesicula seminalis. Die Endigungen an deren Muskulatur konnten bisher leider nicht dargestellt werden, da die dicke schwammige Bindegewebshülle jede Färbung am Totalpräparat vereitelt hat. 
Die übrigen Äste des ro. Segmentnerven verzweigen sich an der Schleimdrüse selbst, die eine ungemein reiche nervöse Versorgung aufweist (Abb.37).

An dem Nervenplexus der Schleimdrüsen lassen sich zwei Schichten abgrenzen, die strukturell deutlich voneinander verschieden sind :

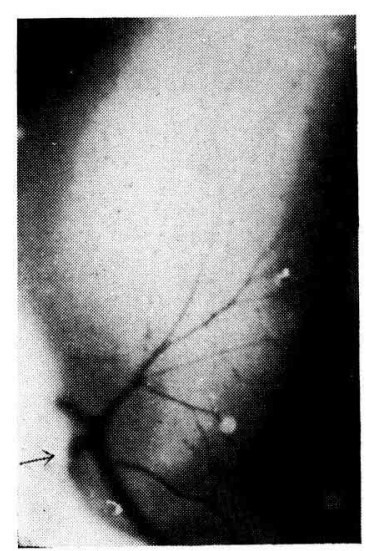

Abb. 35. - Kaudaler Pol der Schleimdrüse mit Verzweigung des to. Segementnerven.

( $\downarrow)$ Ast zum Vas deferens. Vergr. $40 \times$.

FIG.35. - Póle caudal de la glande à mucus avec ramification du nerf du $10^{\mathrm{e}}$ segment $(\downarrow)$. Branche vers le canal déférent. Grossissement $40 \times$.

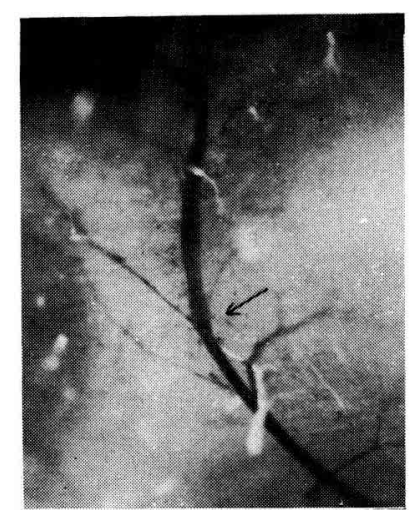

Abb. 36. - Nerv zum Vas deferens nit Zweigen zur Schleindrïsenmuskulatur.

( $\downarrow$ ) Eintrittsstelle in die tieferen Schichten der Schleimdrüsenmuskulatur.Vergr. $80 \times$.

Fig. 36. - Nerf au canal détérent avec rameau vers la musculature de la glande à mucus.

$(\downarrow)$ Point de pénétration dans les couches profondes de la musculature de la glande d mucus. Grossissement $80 \times$

\section{Oberflächlicher Plexus der Glandula mucosa}

Die oberflächlichen Schleimdrüsennerven ziehen \pm paralell und der obersten longitudinalen Muskelschicht anliegend, bis zum kranialen Pol der Drüse. Sie stehen durch zahlreiche Anastomosen miteinander in Verbindung und bilden an der Drïsenkuppe ein gemeinsames Geflecht. Zahlreiche kurze Seitenäste endigen an oder in der äusseren Muskelschicht. Es sind zwei Typen von nervösen Endapparaten vorhanden : 
a) Multipolare Nervenzellen mit freien Endigungen (Abb.38). Es sind relativ grosse Zellen mit zahlreichen Ausläufern, die entweder frei endigen oder mit anderen Zellen dieses Typus oder mit Nervensträngen in Verbindung stehen. Auf diese Weise entsteht an der Oberfläche der Schleimdrüse ein Netz von Nervenzellen und - fasern, das besonders an der Kuppe reich entwickelt ist (Abb. 39). Die multipolaren Nervenzellen besitzen eine gewisse Ähnlichkeit mit den sensorischen Zellen des Typus II nach Zawarzin ; da aber ihre freien Endigungen in engem Kontakt mit oberflächlichen

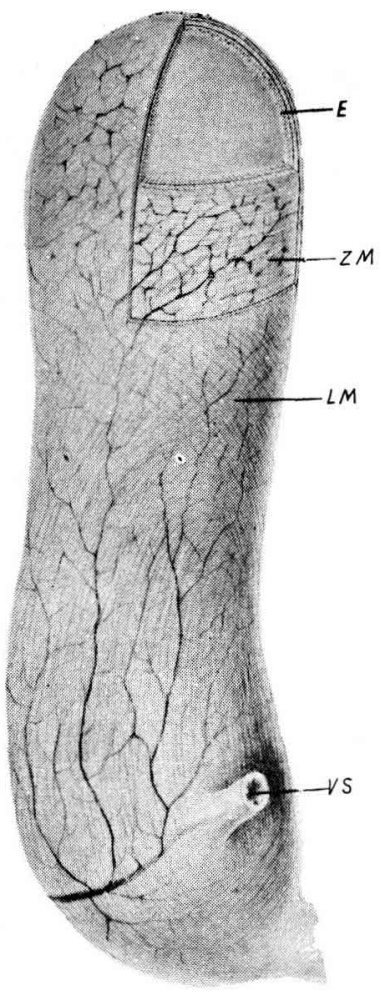

Abb. 37. - Glandula mucosa mit Innervation.

E Drïsenepithel, L.M oberflächliche longitudinale Muskulatur, ZM zirkuläre Muskelschicht, VS Vas deferens.

Fig. 37. - Glande d̀ mucus avec innervation. E, épithélium glandulaire

- L.M, musculature superficielle longitudinale $-Z M$, couche musculaire circulaire $-V S$, canal déférent.

Muskelfasern treten, wage ich nicht zu entscheiden, ob sie eine propriorezeptive oder eine effektorische Funktion besitzen. Dies um so mehr, als sich die knopfförmig aufgetriebenen und gewundenen Endigungen der Fortsätze dieser Zellen strukturell nicht von den Endigungen effektorischer Nervenfasern unterscheiden lassen.

b) Motorische Endigungen (ohne Zellen) an der oberflächlichen Muskelschicht (Abb. 38).

Die motorischen Endigungen an der Skelettmuskulatur der Bienen zeigen dieselbe Struktur wie sie MEYER I955 von der Skelettmuskulatur von Blatta, Carausius und Formica dargestellt hat: Die efferenten Fasern dringen zwischen die Muskelbündel ein und bilden unter dem Sarkolemm Endapparate, die vor allem durch eine 


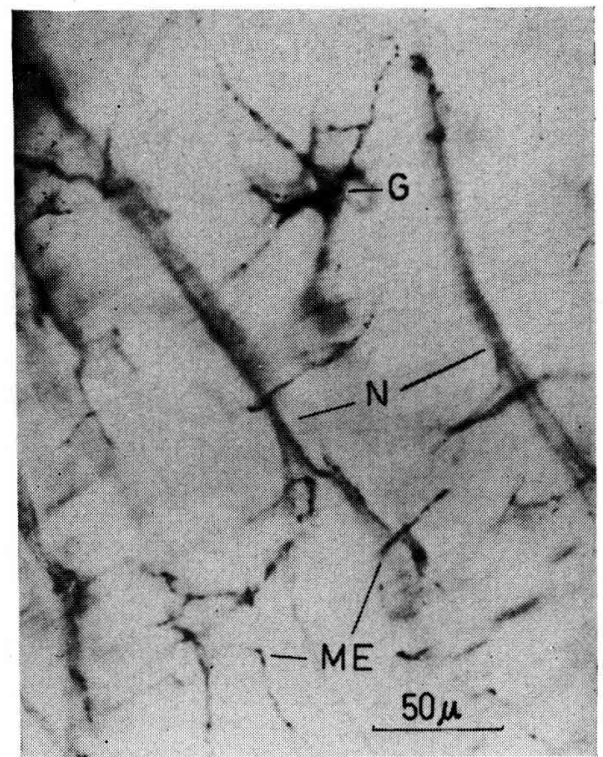

Abb. 38. - Multipolare Ganglienzelle $(G)$ in der oberflächlichen Muskelschicht der Schleimdrüse. $N$ Aeste des Schleimdrüsennerven, ME sarte notorische Endkörper zieischen den (querverlaufenden und durchsichtigen) Muskelfasern.

FIG. 38. - Cellule ganglionaire multipolaire $(G)$ dans la couche musculaire superficielle de la glande d mucus. - $N$, branches du nerf de la glande à mucus - ME, délicates terminaisons motrices entre les fibres musculaires (en travers et transparentes).

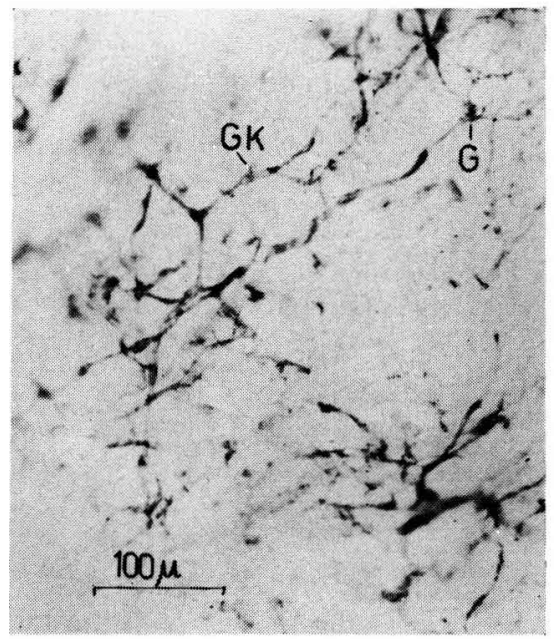

Abb. 39. - Oberflächlicher Plexus an der Kuppe der Schleindrïse. $G K$ Kette von Ganglienzellen, zu einer Nervenbabn vereinigt, $G$ multipolare Ganglienzelle mit terminalen Verzweigungen.

FIG. 39. - Plexus superficiel sur la cupule de la glande à mucus. $G K$, chaîne de cellules ganglionnaires réunies en une voie nerveuse $G$, cellule ganglionnaire multipolaire avec ramifications terminales. 


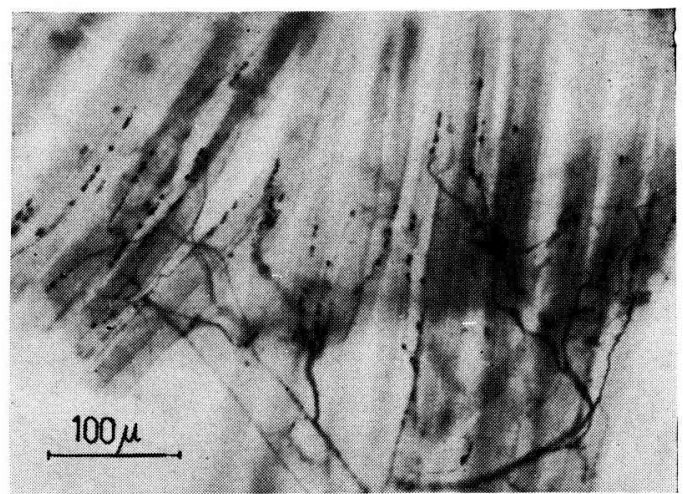

Abb. 40. - Motorische Endigungen an Skelettmuskulatur (Königin, Intersegmentalmuskulalur am Abdomen).

FIG. 40. - Terminaison motrices sur la musculature du squelette.

(Reine, musculature intersegmentaire de l'abdomen).

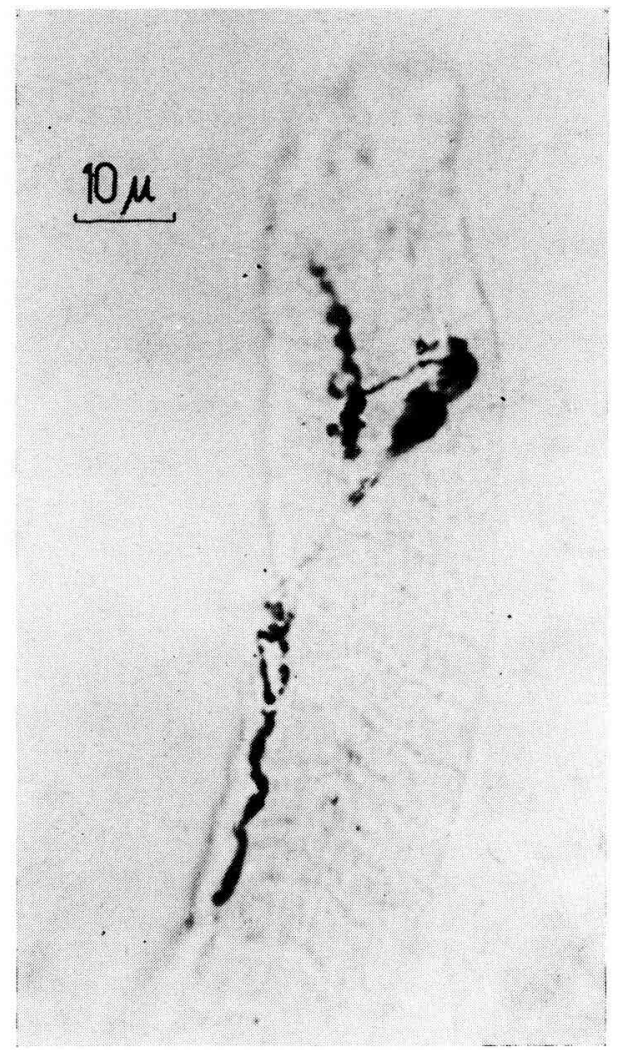

Abb.4I. - Motorische Endkörper an Skelettmuskelfaser.

Fig. 41. - Corpuscule terminal moteur sur fibre de la musculature du squelette. 
Volumszunahme (gegenüber der zugehörigen Nervenfaser) und durch eine besonders starke Chromophilie bei Methylenblaufärbung charakterisiert sind. Ihre Struktur kann sehr verschieden sein : Eine einfache lineare Aneinanderreihung kugeliger Anschwellungen entlang den Myofibrillen (Abb. 40) oder kompakte stabförmige Verdickungen wie an der Muskulatur des Ductus spermaticus der $Q$ (RuTTNER I96I), oder vielfach bizarre, trauben- oder geweihartige Endformationen mit stärkerer oder schwächerer Gliederung (Abb. 4I). Diese Struktureigentiimlichkeiten sind nicht artspezifisch, wie MEYER (I955) annimmt, sondern an demselben Organismus, in verschiedenen Muskelgeweben, nebeneinander anzutreffen, also organ- oder funktionsspezifisch. Die Verbindung Nerv-Muskel an visceralen Organen (Darm, Gift-

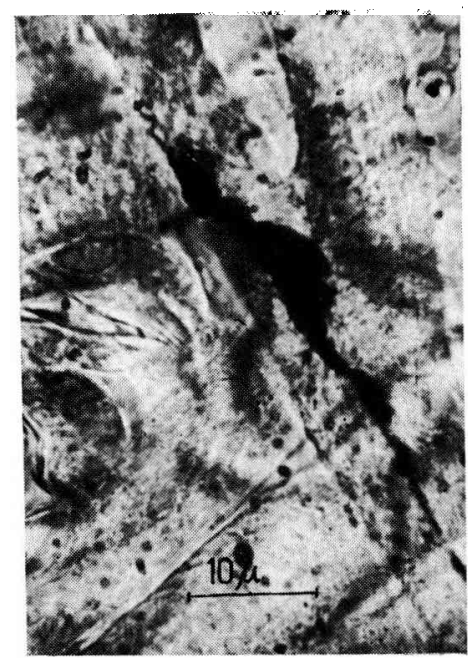

Abb. 42. - Motorische Endigung an visseraler Muskellaser (Rectum).

Fis. 42. - Terminaison motrice sur fibre musculaire viscérale (Rectum).

blase) ist bei der Biene deutlich anders als bei der Skelettmuskulatur: Es legen sich wenig gegliederte plasmatische Anschwellungen der Nervenfaser an das Sarkoplasma (Abb. 42).

Übereinstimmend mit den Befunden von MEYER (I955) an anderen Insekten wurden an der Skelettmuskulatur der Biene nirgends Doyèresche Hügel, also kernhaltige, plasmatische Endplatten gefunden. Die nervösen Endapparate an der Muskulatur sind in jedem Fall terminale Bildungen von Nervenzellen, ohne Beteiligung anderer Ėlemente. Dagegen zeigt das Sarkoplasma an der Stelle der motorischen Endigung häufig eine Anschwellung.

Die motorischen Endigungen in der obersten, longitudinalen Muskelschicht der Glandula mucosa sind von ähnlichem Typ wie an der Skelettmuskulatur der Biene : Zarte und im allgemeinen wenig gegliederte Endkörper an den Muskelfasern (Abb. $38,43)$.

Sehr eigenartig ist die Verbindung der nervösen Endapparate der oberflächlichen Schicht mit dem Zentralnervensystem. Während die grösseren Äste der oberflächlichen Schleimdrïsennerven die gewohnte Struktur parallel verlaufender 


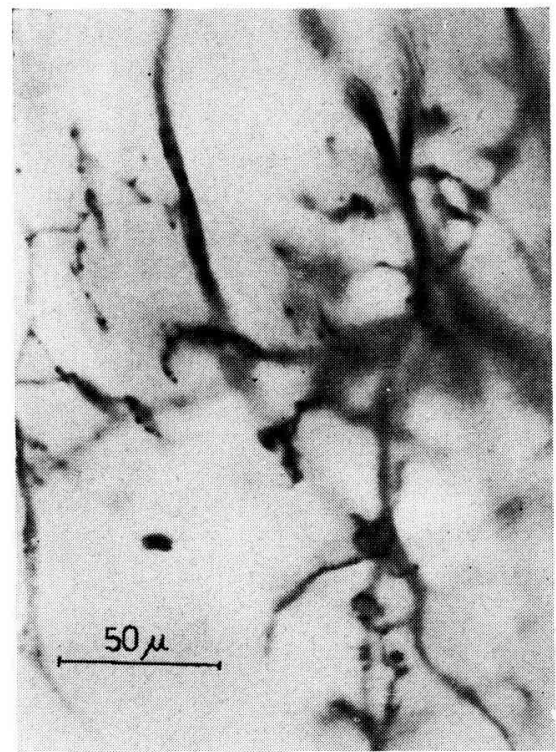

Abb. 43. - Motorische Endigungen in der oberflächlichen Muskelschicht der Schleimdrüse. FIG. 43.- Terminaison motrice sur la couche musculaire superficielle de la glande à mucus.

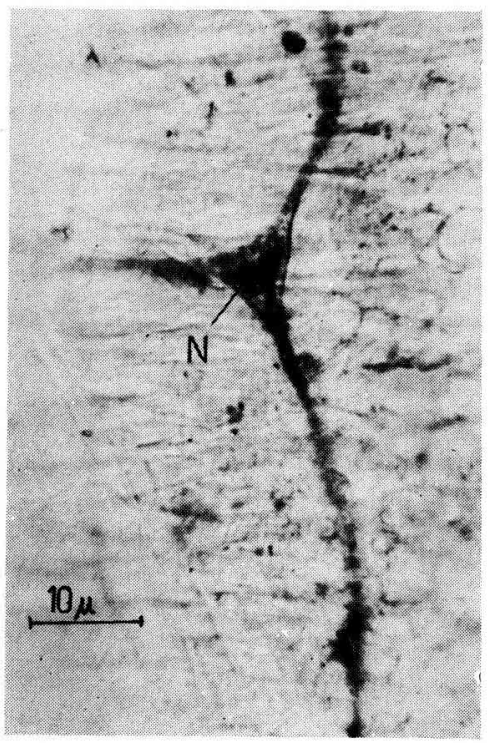

Abb. 44. - Zelle an Verzweigungsstelle eines Nerven. N Nucleus (Schleimdrüse, Oberfläche). FIc. 44. - Cellule au point de bifurcation d'un nerf. N, noyau, (Glande à mucus, surface). 
Fibrillenbündel zeigen, sind am Aufbau der kleineren terminalen Äste Nervenzellen wesentlich beteiligt. An der Kuppe der Schleimdrüsen sind die multipolaren

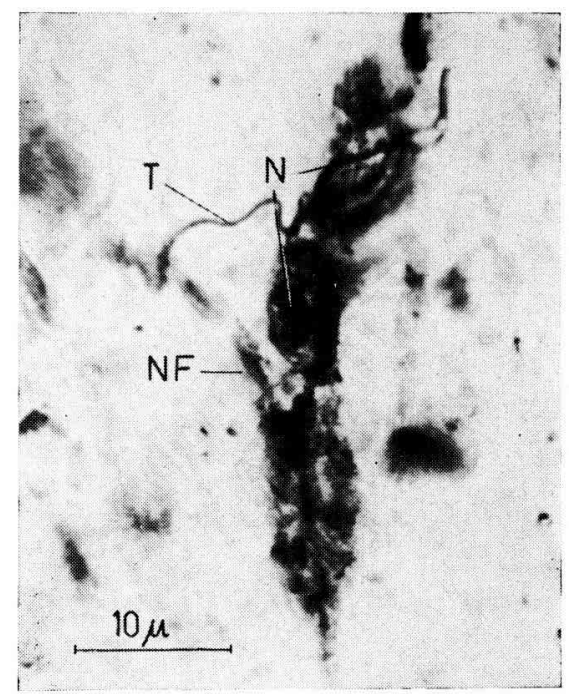

Abb. 45. - Kette von Ganglienzellen an Teilungsstelle eines Nerven (NF) $N$ Nucleus T Trachee. Schleimdrüse, Oberfläche.

FIG. 45. - Chaine de cellules ganglionnaires au point de ramification d'un nerf (NF) $N$, noyau - $T$, trachée, glande à mucus, surface.

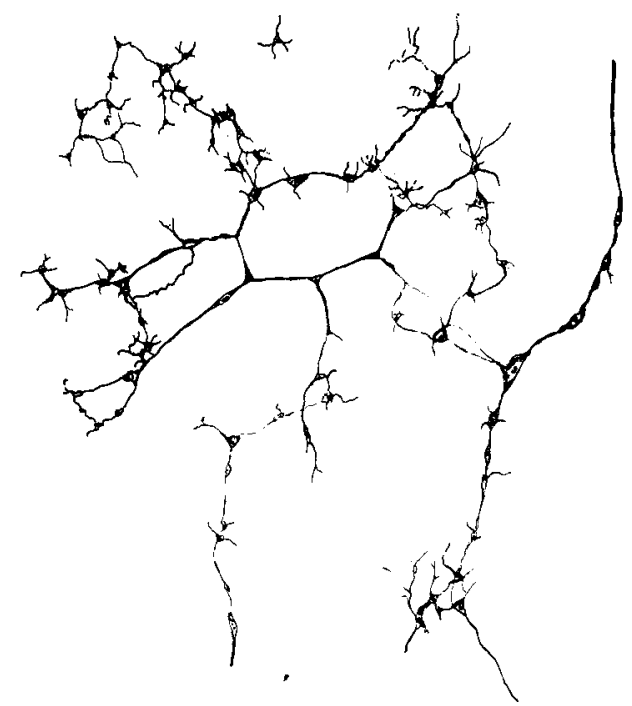

Abb. 46. -.- Plexus an der Schleimdrïsenkuppe (etwas vereinfachte Zeichnung).

FIG. 46. - Plexus sur la cupule de la glande à mucus (dessin quelque peu simplifié)

Nervenzellen mit freien Endigungen, wie erwähnt, durch Verbindung ihrer Fortsätze zu einem terminalen Plexus vereinigt. Ähnliche Plexusbildungen multipolarer Zellen wurden bei der Biene subdermal (S. I5) und bei Blatta in der Hypo- 
dermis und am Darm (MEXER I955) gefunden. Auch die "Dreieckszellen " an der Verzweigungsstelle eines peripheren Nerven (Abb. 44) wurden bei diesen anderen, soeben genannten Plexusbildungen bei Insekten festgestellt (Abb. I3). Was den Schleimdriisenplexus aber von allen uibrigen bisher beschriebenen Plexusbildungen unterscheidet, ist die zellige Struktur der Nervenbahnen, die diese mit den grösseren Ästen verbinden. Relativ kleine multipolare Nervenzellen reihen sich linear aneinander, wobei sie durch mehr oder weniger starke Reduktion ihrer Fortsätze eine bi- oder tripolare Gestalt annehmen (Abb. 45). Es entstehen auf diese Weise rosenkranzartige Nervenstränge, bei đenen Faser- und Plasma-Abschnitte miteinander abwechseln (Abb. 39, 46). Die Neurofibrillen ziehen durch das Zellplasma hindurch,

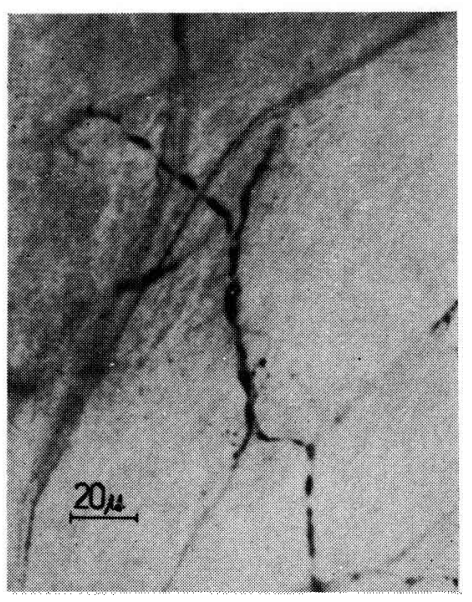

Abb. 47. - "Rosenkranznerv" mil linear aneinandergereihten Ganglienzellen. Schleimdrüse, Oberfläche.

FIG. 47. - "Ner en chapelet" avec cellules ganglionnaires alignées. Glande à mucus, surface.

gewöhnlich unter Auflockerung ihrer Struktur ; die Fortsetzung solcher "Zellketten " bilden nach beiden Richtungen Strecken von ganz normaler fibrillärer Struktur (Abb. 47).

\section{Die motorischen Nerven der tieferen Schicht}

Die innere zirkuläre Muskelschicht der Schleimdriise ist besonders reich innerviert, was vor allem an der kaudalen Hälfte der Drüse mit ihrer kräftigen Muskulatur deutlich wird. Zahlreiche sehr dicke, miteinander durch mannigfache Anastomosen verbundene Nervenäste ziehen in der Muskulatur in apikaler Richtung, wobei sie nach allen Seiten motorische Endapparate an die Muskulatur abgeben (Abb. 48). Diese Endigungen sind von ganz anderer Battart als an irgendeinem anderen Muskel der Biene : Es sind bizarr geformte, derbe Endverzweigungen von beträchtlichen Dimensionen (Abb. 49), deren Spitzen sich parallel der Richtung der Myofibrillen anordnen. Ihre Strukur erscheint im Methylenblau-Präparat wabig-aufgelockert, einzelne kompaktere Streifen innerhalb des Plasmas können als fibrillenartige Strukturen gedeutet werden. An der Abzweigungsstelle dieser "Endbäume " oder an basalen Verzwei- 
gungen sind regelmässig einzelne Zellkerne nachzuweisen, die von einem weniger stark und melit violett gefärbtem Plasma umgeben sind (Abb. 50). Das Plasma dieser peripheren Zellen lässt sich jedoch nur bei geeigneter Färbungsintensität von dem der Endverzweigungen differenzieren; bei Überfärbung ist es von letzterem nicht mehr zu trennen. Es begleitet als "Hüllplasma » die motorischen Endverzweigungen bis zu deren Spitzen — ohne sie allseitig zu umgeben -, entsendet aber auch selbständig Fortsätze zwischen die Muskelfasern. Deshalb und wegen ihres Verhaltens gegenüber einer iiberaus spezifischen Färbemethode erhebt sich die Frage, ob es sich bei diesen Zellen nicht doch eher um nervöse Elemente handelt, die funktionell in den Vorgang der Erregungsïbertragung einbezogen sind, als um blosse Hiillzellen

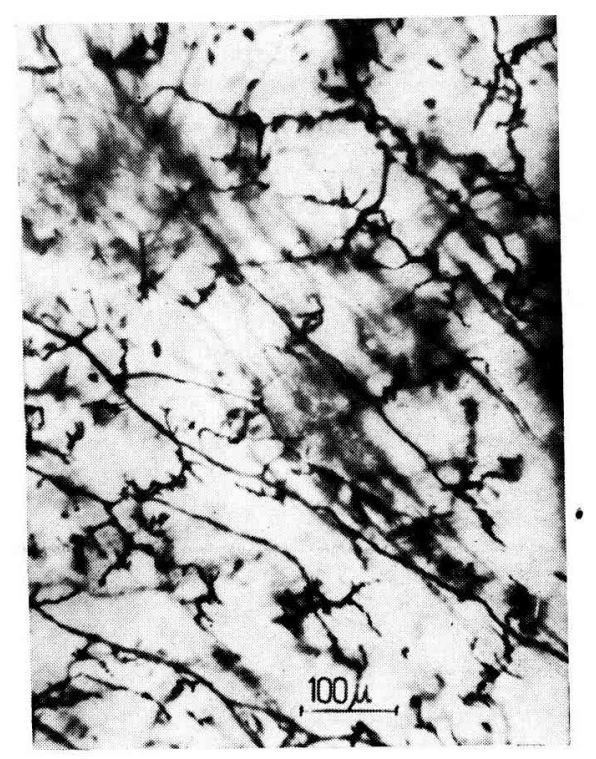

Abb. 48. - Innervation der tiefen Muskelschicht der Schleimdrïse.

FIG. 48. - Innervation de la couche musculaire protonde de la glande à mucus.

des Neurilemms. Vermutlich handelt es sich um eine dem Doyèreschen Hügel analoge Bildung, denn wenn auch die Plasmaanhäufung nicht so gross ist, um die Endkörper allseitig zu umhiullen, so ist doch das typische "Sohlenplasma " und zumindestens ein Kern vorhanden. Bei der Biene ist die Schleimdrüse das einzige Organ, an dem bisher motorische Endigungen dieser Art festgestellt wurden. Aber auf grund dieser Befunde erscheint es doch keineswegs zulässig, alle älteren Angaben über kernhaltige motorische Endplatten bei Insekten als fehlerhafte Deutungen von Varikositäten des endigenden Axons oder von Tracheolen zu erklären (MEYER, I955). MEYER selbst hat an der Muskulatur des Fliegenrüssels mit Silberimprägnation nach SchultzeGros blasse plasmatische Strukturen, welche die motorischen Endigungen einhüllen, dargestellt.

Sowohl das « Sohlenplasma » wie die Endkörper besitzen klar begrenzte Konturen ohne Andeutungen von terminalen Fibrillen. 


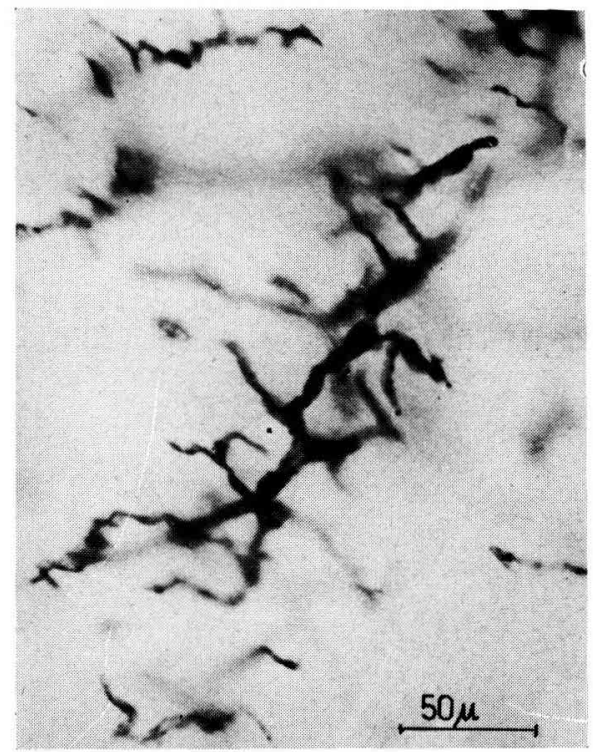

Abb. 49. - Motorische Endapparate aus der tiefen Muskelschicht.

FIG. 49. - Appareil moteur terminal dans la couche musculaire profonde.

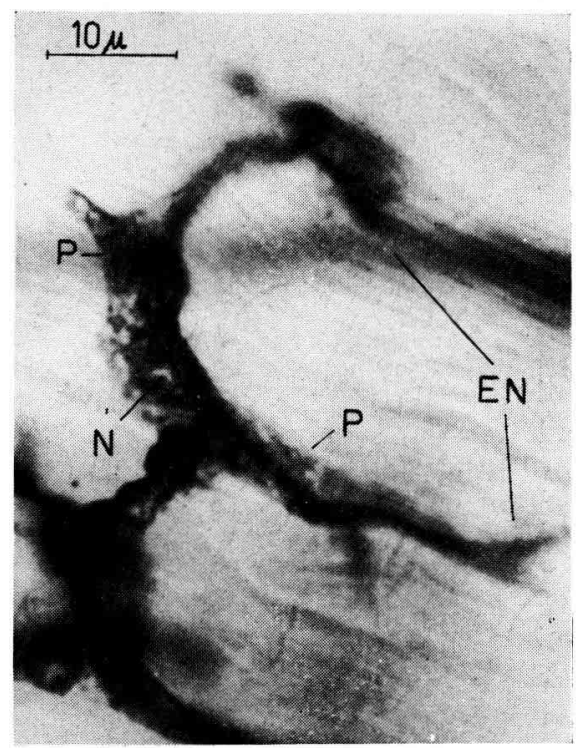

Abb. 5o. - Motorische Endigung mit a akzessorischer Zelle n. EN Endigung der Nervenfaser, $N$ Nucleus, $P$ Plasma der akzessorischen Zelle.

Fig. 5o. - Terminaison motrice avec "cellule accessoire". $E N$, terminaison de la fibre nerveuse $-N$, noyau. $-P$, plasma de la cellule accessoire. 
An den Nerven der Glandula muscosa sind demnach histologisch folgende bemerkenswerte Besonderheiten festzustellen :

I. Zahlreiche Nervenzellen, die sich morphologisch und vermutlich auch funktionell in drei Typen gliedern lassen :

a) Grosse multipolare Zellen, deren Fortsätze an Muskelbündel endigen.

b) Kleine multi-, tri- und bipolare Zellen mit oder ohne frei endigende Fortsätze im Verlauf oberflächlicher, peripherer Nervenäste, durch deren Plasma Fibrillen aus anderen Neuronen hindurchziehen.

c) "Akzessorische "Zellen an den motorischen Endigungen der tiefen Schicht, deren Plasma die Endigungen der efferenten Fasern begleitet, aber auch eigene ganz ähnlich geformte Endigungen an Muskelbündeln bildet.

2. Ungewöhnlicher Plasmareichtum der grossen und plump verzweigten motorischen Endkörper der tiefen (zirkılären) Muskelschicht.

$\mathrm{Zu}$ dieser Strukturform nervösen Gewebes giht es bisher kaum analoge Beispiele unter den Arthropoden. Das teilweise Fehlen der im Nervensystem höherer Tiere allgemeinen Trennung von Zellkörper und leitendem Element (Neurofibrillen) - bei den unipolaren Ganglienzellen der Arthropoden, wo die Fbirillen ohne in den Zellkörper einzutreten, vom Neuriten zum Dentriten ziehen (HANsTröm I928), am weitesten vollzogen - lässt diesen Organisationstyp als sehr ursprünglich erscheinen. Im subdermalen Plexus am Abdomen der Honigbiene ziehen zwar auch verschiedentlich Fibrillen eines anderen Neurons durch das Plasma einer Nervenzelle, aber ein Aufbau von Nervenbahnen durch perlschnurartiges Aneinanderreihen von Nervenzellen wie am apikalen Pol der Schleimdrüsen, wurde nicht beobachtet. Dieser Strukturtyp erinnert etwas an das Nervenstrangsystem z. B. der Echinodermen, in dem ebenfalls Zell- und Fibrillensystem nicht voneinander gesondert sind.

\section{D. - DIE ERREGUNG DER SCHIEIMDRÜSENMUSKUI.ATUR}

Bei Diskussion der funktionellen Bedeutung dieser Besonderheiten muss an die beträchtlichen Unterschiede in der Leitungsgeschwindigkeit zwischen Leitungsbahnen durch ein Axon oder durch eine Zellkette erinnert werden. Die Leitungsgeschwindigkeit in einem motorischen Nerven von Homarus z. B. beträgt $600-1000 \mathrm{~cm} /$ $\mathrm{sec}$, in der Glanglienkette von Lumbricus hingegen nur $60 \mathrm{~cm} / \mathrm{sec}$. (BUDDENBRock, I 953). Synapsen und endoplasmatischer Fibrillenverlauf haben also eine wesentliche Herabsetzung der Leitungsgeschwindigkeit zur Folge.

Unter der Annahme, dass die Erhöhung des plasmatischen Anteils des nervösen Apparates der Schleimdrüsen gegenüber den Leitungselementen zu der übrigen Muskulatur ebenfalls zu einer Herabsetzung der Leitungsgeschwindigkeit führt, lässt sich eine plausible Erklärung für die Verzögerung der Entleerung der Schleimdrüsen und damit für den regulären Ablauf der Ejakulation finden. Denn man muss dann annehmen, dass die Erregungsleitung zur Muskulatur der Glandula mucosa ausgesprochen " langsam " verläuft. Da weiter vor allem die nervösen Endkörper im basalen Abschnitt der Drüse in der beschriebenen Weise vergröbert sind, wird die Kontraktionswelle am apikalen Pol beginnen und kaudad fortschreiten.

Diese Vorstellung setzt allerdings voraus, dass die motorischen Endapparate in der Muskulatur der Vesicula seminalis anders strukturiert sind als an der Schleimdrüse, da dort die Kontraktion früher beginnen muss. Leider konnte diese Frage 
bisher noch nicht geklärt werden, da der voluminöse Bindegewebsmantel um die Vesicula seminalis einer vitalen Nervenfärbung grosse Schwierigkeiten entgegensetzt. Jedenfalls erfolgt die Innervation des Musculus tensor gland. muc. (der durch seine Kontraktion das Ausströmen des Spermas ermöglicht) nicht nach Art der Schleimdrïsen, sondern in derselben Weise wie bei der Skelettmuskulatur : Ein Ast des 9. Segmentnerven verzweigt sich mit ungewöhnlich zahlreichen, feinen Endkörpern an den Fasern des Muskels.

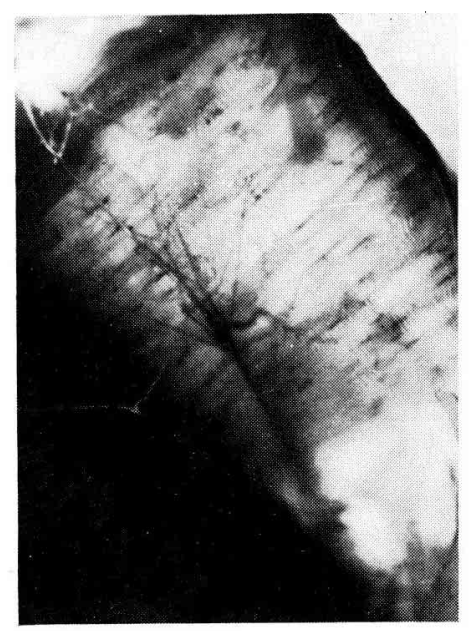

Abb. 5I. - Intersegmentalmuskulatur an Abdomen des ô, mit Verzweigung des Segmentnerven und molorischen Endigungen zwischen Muskelfasern. Vergr. $65 \times$.

FIG. 5. - Musculature inlersegmentaire de l'abdomen du màle avec nert segmentaire ramifié et terminaison motrice entre les fibres musculaires. Grossissement $65 \times$.

E. - DIE HIIISAPPARATE DER COPULA

\section{Die Intersegmentalmuskulatur}

Wie schon erwähnt, tritt als erste Phase der Eversion eine simultane und maximale tonische Kontraktion der abdominalen Skelettmuskulatur ein. Diese Muskulatur ist beim Drohn um ein Vielfaches stärker entwickelt als bei der Königin oder bei der Arbeitsbiene. Die Innervation erfolgt durch die zugehörigen motorischen Segmentnerven (Abb. 5r).

\section{Das genitale Sinnesfeld des $\sigma^{x}$}

An den terminalem Sterniten des $\sigma^{x}$ findet sich eine auffällige Anhäufung von Sinnesborsten, die in Abschnitt III als spezifische Differenzierung des Hautnervensystems dargestellt wurde. Aus der Struktur des peripheren Nervensystems an diesen Stellen, die durch Plexusbildung und Einschaltung multipolarer, assoziativer Nervenzellen gekennzeichnet ist, kann geschlossen werden, dass dieses Sinnesorgan nicht nur zur Reizaufnahme, sondern auch zur Bildung ganz spezifischer Erregungen befähigt ist. Das “ genitale Sinnesfeld » ist eine Besonderheit des $\sigma$, bei Arbeitsbienen 
und Königinnen ist das subdermale Nervensystem an den letzten Sterniten in keiner Weise anders entwickelt als an den übrigen. Die Beziehung dieses Sinnesorgans zum Kopulationsvorgang ist wohl nicht in Zweifel zu ziehen.

Eis ist nicht ohne Interesse darauf hinzuweisen, dass der Musc. tensor gland. muc. von einem andern Ast desselben 9. Segmentnerven versorgt wird, der auch die rezeptorischen Fasern aus dem genitalen sinnesfeld aufnnimmt.

\section{V. - DER NFRVÖSE, APPARAT UND DIF AUSLÖSUNG DER EJAKULATION}

Bei reifen $\sigma^{x} \sigma^{x}$ und hoher Temperatur geniigt manchmal schon ein leichtes Anfassen, um den Fndophallus zur Ausstiilpung und die Ejjakulation in Gang zu bringen. Stärkere Reize — Druck auf das Abdomen, Chloroformnarkose oder Dekapitierung - führen fast regelmüssig zu demselben Effekt. Bei der heute schon routinemässig durchgeführten kïnstlichen Besamung der $q$ wird das Sperma immer auf die Weise gewonne11, dass man die $\sigma^{x}$ durch Chloroformnarkose und nachfolgenden Druck auf das Abdomen zur Ejaktulation veranlasst.

Brshop (I920) fand es bei seinen Untersuchungen über die Anatomie der Fortpflanzungsorgane sehr schwierig, die Organe des $\sigma^{x}$ in situ zu Gesicht zu bekommen. Selbst bei äusserst vorsichtiger Präparierung wird eine Ejakulation - bei invertiertem Endophallus- ausgelöst. Dabei kontrahiert sich häufig die Muskulatur an der Schleimdriusenbasis zuerst, der Schleim wird in die Drüsenkuppe gepresst und nach Ruptur deren Wand in die Leibeshöhle entleert. Selbst die Injektion von Fixierungsmitteln vor der Präparierung führte zı dieser Reaktion und erst die Injektion von kalter gesättigter Pikrinsäure in den Thorax schuf die Möglichkeit, die Fortpflanzungsorgane reifer Drohnen ungestört zu untersuchen.

Andererseits gelingt es nur schwer, Sperma durch blossen 1)ruck aus völlig inaktiven $\sigma^{x} \sigma^{x} \mathrm{zu}$ gewinnen. Eher zerplatzt eine Intersegmentalmembran, als dass der Endophallus zur Umstuilpung gebracht wird.

Den Ablauf der sich mit grosser Präzision und erstaunlicher Kraft vollziehenden Ejakulation unter den Bedingungen der natürlichen Copula müssen wir uns in folgender Weise vorstellen (Abb 52) :

I. Schon der Flug an sich steigert die Erregbarkeit des $\sigma^{x}$ (Woyke). Zentrale Impulse, ausgelöst durch den Paarungstrieb, die sich während der Paarungsspiele noch verstärken, setzen die Erregungsschwelle der motorischen Zentren in den Abdominalganglien herab (es ist bekannt, dass auch bei unspezifischen Irritationen des Zentralnervensystems, z. B. bei der Chloroformnarkose, ganz genau dieselbe Reaktion eintritt wie bei der natürlichen Copula).

2. In diesem Stadium fïhrt eine taktile Reizung der Tasthaare des genitalen Sinnesfeldes auf reflektorischem Wege zu einer simultanen "Entladung " sämtlicher motorischer Zentren der abdominalen Ganglienkette und in der Folge zu einer maximalen tonischen Kontraktur der gesamten abdominalen Muskulatur.

Spricht man den taktilen Sinnesorganen um das Phallotrema nicht jede funktionelle Bedeutung ab, dann muss sich der $\sigma^{x}$ bei der Copula in einer Weise an die fliegende $O$ festklammern, dass die Rezeptoren des genitalen Sinnesfeldes mit dem 
Körper der $\sigma^{*}$ in Berïhrung kommen. Diese Stellung kann aber nur so sein, dass sich der $\sigma^{\top}$ iiber der $Q$ befindet.

Über die Initialstadien der Bienencopula liegen widersprechende Angaben vor (LECOMTE, I958). Es ist deshalb viel darïber diskutiert worden, in welcher Stellung sich die beiden Tiere zueinander befinden (FyG, I95I). Da sich der voll evertierte Endophallus mit seiner Spitze nach oben und vorne umbiegt, und die Chitinplatten in kranialer Richtung weisen - in derselben Lage werden sie später in der Stachelkammer der 9 gefunden -, hatte man folgerichtig den Schluss gezogen, der $ð$ müsse

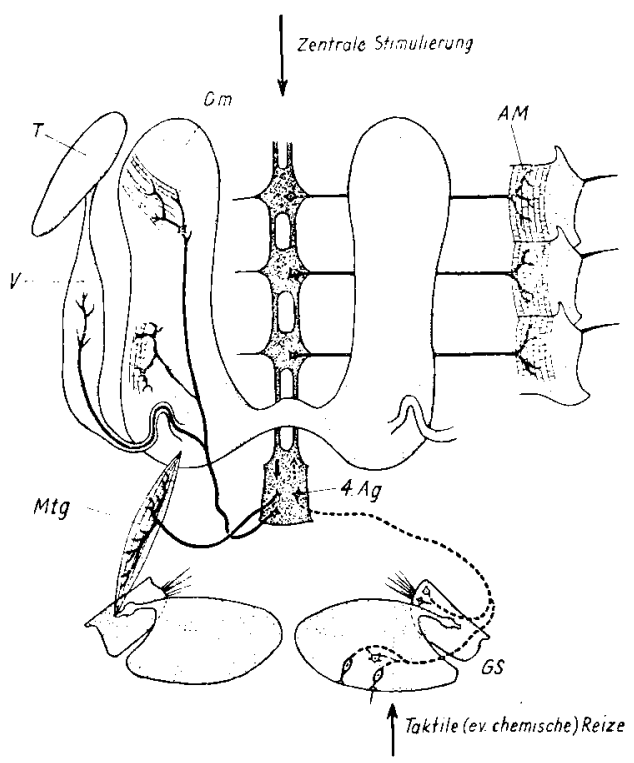

Abb. 52. - Inneriationsschema der männlichen Fortplanztungsorgane. Ausgezogene Linien : Eflerente Nerven ; punkierte Linien; afferente Nerien. 1.11 dbioninalmuskulatur. t. Ig t. Ablominalganglion, Gm Glandula mucosa, (iS genilales Sinnesfeld, Mig Musculus lensor glandulae mucosea, T Testis, V Vesicula seminalis.

Fig. 52. - Schéma de l'innervation des organes refroducleurs males. Lignes pleines : nerfs efférents; lignes pointillées: nerfs afférents. AM, musculature abdominale $-4 \mathrm{Ag}$, to ganglion abdominal $-\mathrm{Gm}$, glande àmucus - GS, champs sensoriel génital - Mtg, muscle tenseur de la glamile à mucus - T, testicule -$V$, vésicule seminale.

sich während der Copula unter der $q$ befinden. Die Feststellung, dass die Chitinplatten vor ihrer Eversion aus dem Endophallus herausgeschoben werden (WoykE u. RUTTNER, I959) entkräftete dieses Argument und die Frage stand dann wieder vö1lig offen. Das Vorhandensein des aedeagalen Sinnesfeldes ist nun ein Indiz dafür, dass die Copulationsstellung der Biene ähnlich der bei anderen Hymenopteren beobachteten (Vespa Schulz-I,ANGNER I954) ist, sich der $\sigma^{x}$ also iiber der $Q$ befindet.

3. Durch Kontraktion der Parameralmuslkulatur (zwischen Deckplattenapodem und Lamina parameralis) werden die Deckplatten türfligelartig aufgerichtet und das Phallotrema geöffnet. Aus dieser Offnung wird unter dem intra-abdominellen Druck der Endophallus herausgepresst.

4. Derselbe Impuls führt zum Auspressen des Sperma : Kontraktion des Musc. tensor gland. muc. und der Muskulatur des Vas deferens. 
5. Entleerung des Schleims durch die - verzögerte - Kontraktion der Schleimdrüsenmuskulatur.

Die Schlussphase der Copula - Bildung des "Begattungszeichens " durch Abschälung der Chitinplatten des Bulbus vom membranösen Endophallus und Trennung des Pärchens - vollzieht sich rein passiv, durch Fortwirken des Druckes im Inneren des Endophallus.

\section{ZUSAMMENFASSUNG}

I. Mit einer modifizierten vitalen Methylenblau-Methode lässt sich an erwachsenen Bienen $\left(F O, * ;, \sigma^{*}\right)$ eine sehr selektive Färbung des peripheren Nervensystem erzielen, die nach geeigneter Fixierung lange haltbar ist.

2. Uberall am Integument des Abdomens sind Haar- und Membransensillen sowie - vorwiegend an unbehaarten Stellen - multipolare Zellen mit freien Endigungen vorhanden. Die Haarsensillen treten in 2 Typen ( mit einer oder mit mehreren Sinnesnervenzellen) auf, die sich voneinander auch durch den Bau des Haates unterscheiden. Polyneuronale Haarsensillen sind in grösserer Zahl nur an den Sterniten der Arbeiterinnen vorhanden, der Königin fehlen sie ganz. Bei den Membransensillen handelt es sich vorwiegend tum freiliegende, durch eine plane Membran verschlossene Poren, in deren Zentrum der Sinneskörper einer Sinnesnervenzelle endigt; sie ähneln im Bautyp den dünnwandigen Kegelsensillen und werden als Sensilla basiplana bezeichnet.

3. Die Neuriten der Sinnesnervenzellen bilden ein subdermales Geflecht, an dem assoziative, multipolare Nervenzellen wesentlich beteiligt sind. Zwischen den Nervenzellen und -fasern bestehen plasmatische und synaptische Verbindungen. Im gesamten kann dieser Plexus als segmental angeordnetes Hautnervensystem mit sensibler Funktion aufgefasst werden, das aber einen gänzlich anderen Aufbaul aufweist als das von TONNER (I936) beschriebene und seither nicht wieder bestätigte "Hautnervensystem der Arthropoden 》. Am reichsten ist das Hautnervensystem bei der Königin ausgebildet. Bei Bombus ist die Struktur des subdermalen Plexus ganz ähnlich wie bei Apis, während bei Vespa die Neuriten der Sinnesnervenzellen ohne assoziative Verbindungen zentripetad ziehen.

4. Beim Drohnen wird ein der Aufnahme taktiler und chemischer Reize dienendes " genitales Sinnesfeld " beschrieben, das aus einem zellreichen Plexus unter der Deckplatte (Aedeagal-Sklerit) und einem Ganglion an der Paramere besteht; beide sind mit zahlreichen Haar - und Membransensillen in Verbindung .Eine Duftdruise an der Lamina parameralis ist nicht vorhanden.

Auch bei anderen Hymenopteren sind die Sklerite des Ectophallus als rezeptorische Organe ausgebildet.

5. An der Analplatte des Proctiger der Biene sind neben Haarsensillen zahlreiche Sensillen mit dünner Wand (Chemorezeptoren ?) und ein gut entwickelter subdermaler Plexus vorhanden.

Die Funktion der Analplatte als Verschluss der Analöffnung wird beschrieben.

6. Die Glandula mucosa besitzt einen überaus reich entwickelten nervösen Apparat : 
a) Oberflächlicher Plexus mit zahlreichen Ganglienzellen, die rosenkranzartig in periphere Nervenbahnen eingelagert sind (Nervenstrangsystem) oder mit multipolaren Fortsätzen an Muskelfasern endigen.

b) Plasmareiche, verzweigte motorische Endigungen in der tiefen Muskelschicht, mit akzessorischen Zellen. Diese Art von Endigungen unterscheidet sich weitgehend von allen anderen motorischen Endkörpern an der Skelett- oder viszeralen Muskulatur der Biene. Die funktionelle Bedeutung dieser Struktureigentuimlichkeit wird in einer Herabsetzung der Leitungsgeschwingkeit vermutet. Die Tatsache, dass der Schleim immer erst nach dem Sperma ejakuliert wird, kann durch diese Erregungsverzögerung erklärt werden.

7. Der reich innervierte Musculus tensor glandulae mucosae, zwischen caudalem Schleimdrüsenpol und Aedeagal-Apodeme, führt durch seine Kontraktion zu einer Streckung des Vas deferens und zur Ruptur dessen Verschlussmembran ; das Sperma erhält dadurch freien Abfluss.

8. Aus Lage und Bau der rezeptorischen Organe um das Phallotrema sowie des Schleimdriisen-Plexus werden Vorstellungen iiber die Funktion des männlichen Genitalapparates entwickelt. Es ergibt sich dabei die zwangsläufige Folgerung, dass sich bei Einleitung der Copula der Drohn über der Königin befinden muss, so wie dies bei anderen Hymenopteren der Fall ist.

Reç pour publication en juillet 196il.

\section{RÉSSUMÉ}

STUCTURE ET FONCTION IU SYSTEME NHRVEUX P'ÉRIPHÉRIQUL: DES ORGANES REPROIUUCTHURS DU MÂLE D'A BEILIL

Tout comme dans les autres manifestations de sa vie sociale (butinage, etc.) l'Abeille fait preuve dans son comportement sexucl d'un très haut degré de spécialisation. La copulation a lieu obligatoirement en vol; le mâle livre en une seule fois la totalité de sa réserve de spermé; la reine reçoit au cours de copulations répétées et qui, en partie au moins, ont lieu très rapidement les unes après les autres, une très grande quantité de sperne qui est déposéce tout d'abord dans les oviductes et, seulement ensuite, parvient dans la spermathèque. En corrélation avec ces particularités on assiste à une forte modification des organes copulateurs du mâle ; à la place de l'ectophallus généralement réduit, on trouve un endophallus puissant et complirfué ; les glandes à mucus sont très fortement développées. Le processus de la copulation suppose l'existence d'un système nerveux périphérique très développé au niveau des organes génitaux pour permettre leur déclenchement et leur coordination.

Le but des présentes recherches est la mise en évidence de ce système nerveux périphérique et l'explication de sa structure histologique. l'organisation segmentaire et l'innervation des organes génitaux féminins a été traitée d'autre part (RUTTNER, 1961).

Io Méthode : Chez l'abeille adulte on peut obtenir une coloration vitale très sélcctive du système nerveux périphérique au moyen d'une méthode modifiéc utilisant le bleu de méthylène. On introduit dans la cuticule du thorax par une petite ouverture pratiquée au moyen d'aiguilles aiguisées quelques cristaux de bleu de méthylène. Le colorant se dissout très rapidement dans l'hémolymphe et se trouve transporté dans les différentes parties du corps. Ia sélectivité et la sécurité de la coloration sont améliorées par l'addition à l'hémolymphe d'une solution tampon et de substances réductrices (ScHABADASCII, I930). La méthode la plus favorable pour l'organisme doit être déterminée empiriquement dans chaque cas particulier; chez la reine les meilleurs résultats ont été obtenus avec le tampon phosphaté de SörenSEN (pH 6,0) et chez le mâle avec une solution de miel ì $20 \mathrm{p}$. Ioo $(\mathrm{pH} 4,5)$.

Les préparations colorées se conservent longtemps, après fixation au molybdate d'ammonium, déshydratation rapide et montage au terpinéol ou dans un milieu neutre tel que lc Caedax.

$2^{\circ}$ Les sensilles à la surface du corps. Une part ie importante des poils de l'abdomen est innervée (fig. 3 , 6). Il existe deux types différents de ces sensilles trichoïdes et elles se distinguent les unes des autres aussi bien par la structure du poil que par l'innervation (sensilles mononeurales avec une cellule nerveuse sensorielle bipolaire et sensilles polyneurales avec quatre cellules nerveuses réunies en un corps terminal commun (fig. 5). 
Entre les sensilles trichoïdes se trouvent en nombre variable des sensilles membraneuses sur la membrane desquelles aboutit la fibre distale périphérique d'une cellule nerveuse sensorielle bipolaire. Cette membrane ferme de façon plane un pore circulaire de la cuticule (Sensilla basiplana (fig. 5,8 ).

Sur les parties glabres du corps on trouve des cellules multipolaires avec extrémité libre (fig. 9). $3^{\circ}$ Le systeme nerveux subdermique de l'abdomen. Les neurites des cellules nerveuses sensorielles forment un entrelacement qui contient également des cellules nerveuses multipolaires associatives.

Entre les cellules nerveuses et les fibres on peut mettre en évidence des liaisons plasmatiques et synaptiques (fig. Io, I6). Le plexus subdermique est en liaison par les nerfs segmentaires avec les ganglions abdominaux correspondants.

Entre reine et ouvrière il existe dans la conformation du système nerveux subdermique des différences dont la signification fonctionnelle n'est pas encore éclaircie. Chez la reine le plexus subdermique est plus richement développé; d'autre part il lui manque les sensilles trichoïdes polyneurales qui. sont présentes chez les ouvrières.

Le plexus est toujours particulièrement développé autour des stigmates.

Chẽ Bombus le système nerveux subdermique de l'abdomen est bâti de la même façon que chez Apis alors que chez les mâles de Vespa aucune formation de plexus n'a pu être mise en évidence. Du point de vue fonctionnel le système nerveux subdermique peut être considéré comme une différenciation périphérique des voies réceptrices. Un système nerveux périphérique ne dépendant pas d'organes réccpteurs tel que Tonnkr l'a décrit en $193^{6}$ chez différents Arthropodes n'a été trouvé, ni chez les Hyménoptères étudiés ni chez les Crustacés marins, pas plus par nous que par d'autres auteurs.

$4^{\circ}$ Le champ sensoriel de l'appareil génital mâle. Dans les sclérites terminaux de l'abdomen du mâle, à la face ventrale, aux alentours de l'ouvcrture génitale, le sytème nerveux subdermique est différencié d'une façon particulière : les valves péniales (sclérite aedeagal) de chaque côté des phallotrèmes portent de très nombreuses et de très fortes sensilles trichoïdes dont les cellules nerveuses sensorielles sont rassemblées par d'abondantes fibres d'association et des cellules nerveuses en un plexus subdermique, dense par endroits (fig. 18,25 ).

A la pointe des Lamina par.umeralis se trouve un petit ganglion avec des cellules nerveuses bi et multipolaires dont les fibres distales innervent les longs poils sensoriels réunis en "pinceau ", des paramères (fig. 26, 27). Il s'agit d'une façon indiscutable d'un organe sensoriel visiblement destiné à percevoir les excitations tactiles et non pas d'un organe odorant (GoFTze et ScInidr, I94I).

Les sclérites puissamment développés de l'ectophallus de Bombus et Vespa possèdent également de nombreuses sensilles tricoïdes avec un plexus subdermique (fig. 28,29 ). Ils doivent, en conséquence, être cux aussi considérés comme des organes récepteurs. Chez Bombus on trouve d'autre part sur ces sclérites des parties membraneuses spéciales qui sont garnies d'une façon très dense de sensilles membrancuses et de sensilles trichoïdes à poils courts. D'après leur structure et leur pilosité on peut conclure cue les paramères fonctionnent aussi comme organes sensoriels chez d'autres Hyménoptères. $5^{\circ}$ Sur le proctigère de l'Abeille, segment terminal yui porte l'anus, on a décrit une plaque sclérifiée (placiue anale) qui, au repos, ferme totalement l'anus (fig. 30 ). Cette plaque est, elle aussi, pourvue de nombreuse sensilles trichoïdes et de délicates sensilles basiconiques dont les cellules nerveuses sensorielles sont en rapport avec un plexus subdermique (fig. $3 \mathrm{I}$ ).

$6^{\circ}$ Parni les organes du tractus génital du mâle, seules les grandes glandes à mucus et les vésicules séminales sont innervées; clles le sont par des nerfis très puissants du ro segment abdominal. Une branche de ce nerf se dirige ì travers la musculature vers la vésicule séminale en suivant le canal déférent (fig. 35,36 ) ; ses ramifications terminales n'ont toutefois pas pu être mises en évidence à cause de l'épaisse enveloppe conjonctive de la vésicule. Les autres branches du nerf du to segment se ramifient ì la surface ct dans la musculature de la glande à mucus.

La structure de la glande à mucus avec son mécanisme de fermeture si particulier et son épithélium glandulaire a été décrite par BISIIOP (r920) (fig. 3.3, 34, 37). La contraction de la musculature de la glande à mucus se produit souts forme d'une onde progressive qui prend naissance au pôle apical de la glande. Ire mucus contenu à l'intérieur de la glande ne peut cependant être évacué que lorsqu'une soupape musculaire s'ouvre et qu'une membrane de fermeture du canal éjaculateur se déchire.

Les glandes à mucus possèdent un appareil nerveux d'une structure particulière dans lequel on peut distinguer deux couches nettement différentes du point de vue histologique.

a) Plexus superficiel avec nombreuses cellules nerveuses multipolaires à terminaisons libres ou à terminaisons situées dans la couche musculaire superficielle et qui sont bâties de la même façon que les terminaisons motrices de la musculature du squelette (fig. 38,43 ). Le plexus superficiel est particulièrement bien développé sur la cupule de la glande à mucus. Les voies nerveuses de ce plexus sont composées par places de cellules nerveuses rangées en chapelets tandis que les fibrilles pénètrent $\grave{a}$ travers le plasma cellulaire (fig. 44, 47). Ce type de structure du tissu nerveux est considéré comme primitif et il fait songer au cordon nerveux des animaux inférieurs dans lequel, de la même façon, les corps de cellules et les éléments conducteurs ne sont pas séparés.

b) Nerfs moteurs de la couche profonde. La couche musculaire interne circulaire de la glande à mucus est desservie par de nombreuses branches nerveuses disposées de façon plus ou moins parallèles 
et dont surtout les terminaisons entre les faisceaux musculaires sont remarquables. Il s'agit de ramifications terminales grossières, de forme bizarre et de dimensions importantes dont les pointes sont disposées parallèlement à la direction des myofibrilles (fig. 48, 49). Sur ces arborescences terminales on trouve régulièrement des noyaux cellulaires isolés qui possedent toutefois un plasma propre qui, par places suit étroitement les terminaisons nerveuses (fig. 5o). Il semble qu'il s'agisse de formations analogues aux cônes de Doyère et que l'on ne peut observer de cette façon que sur les glandes à mucus ; les éléments cellulaires manquent dans toutes les autres terminaisons motrices de la musculature du squelette ou des viscères de l'Abeille.

$7^{0}$ Les particularités de structure du tissu nerveux des organes génitaux du mâle d'Abeille qui viennent d'être décrites constituent une base pour la compréhension des processus physiologiques au cours de la copulation.

Une insémination efficace de la reine n'a lieu que si le sperme du mâle pénètre en quantité dans les oviductes de la reine. Il faut donc, après éversion de l'endophallus, que du sperme pur soit éjaculé et ensuite seulement le contenu des glandes à mucus qui presse la totalité du sperme hors du canal éjaculateur et du vagin dans les oviductes. Toute perturbation dans l'ordre des phénomènes provoque l'échec de l'insémination.

Le mécanisme qui est à la base de la succession précise des éjaculations de sperme puis de mucus doit être recherché dans un retardement de la conduite de l'excitation jusqu'à la musculature des glandes à mucus. D'une façon très générale il existe des différences sensibles dans la vitesse de l'influx le long des voies nerveuses selon qu'il passe par un axone ou par une chaîne cellulaire. On peut en conclure que les cellules accumulées dans les nerfs de la glande à mucus et que la richesse en plasma des terminaisons motrices conduisent à une baisse de vitesse de propagation de l'influx, de telle sorte que l'impulsion déclenchée par voie reflexe atteint plus tardivement la glande à mucus que le reste de la musculature.

Ensuite, on s'efforce de donner une représentation des processus physiologiques qui conduisent à l'insémination.

I'impulsion centrale, déclenchée par l'instinct d'accouplement et renforcée par le vol et les parades sexuelles, abaissent le seuil d'excitabilité des centres moteurs dans les ganglions abdominaux.

A ce stade, une excitation tactile des poils sensoriels du champ sensoriel génital conduit à une " décharge " simultanée de tous les centres moteurs de la chaîne ganglionnaire abdominale et, en conséquence, à une contraction tonique maximum de toute la musculature abdominale.

L'accumulation de sensilles autour de phallotrème et le développement particulier du plexus subdermique dans cette région est, sans aucun doute, en rapport avec la reproduction. Ces formations manquent totalement chez la reine et chez l'ouvrière. Le champ sensoriel génital est l'organe déclencheur de la copulation. Il en résultel'obligation pour le mâle de se trouversur la reine pendant l'accouplement à propos duquel on possède des observations contradictoires. Ce n'est que dans cette position que les poils sensoriels peuvent entrer en contact avec le corps de la reine.

Par la contraction simultanée de la musculature aedeagale (entre valve péniale et Lamina parameralis, (fig. Ig MP) les valves péniales se lèvent à la manière de battants de porte et le phallotrème s'ouvre. Par cette ouverture se produit sous la forte pression intra-abdominale l'éversion de l'endophallus.

La même impulsion conduit à l'éjaculation du sperme ; par contraction d'un muscle fin et richement innervé et qui se trouve entre le pôle caudal de la glande à mucus et l'extrémité de la valve péniale (muscle tenseur de la glande à mucus), le canal déférent est étendu et le passage élargi. Après rupture de la membrane qui ferme le canal éjaculateur le sperme peut être évacué sous pression.

Alors seulement intervient, par suite du retardement de l'influx la contraction de la musculature de la glande à mucus et, avec elle, l'éjaculation du mucus.

Les voies afférentes et efférentes qui gouvernent tout le mécanisme sont représentées sur la figure 52 de façon schématique.

La phase terminale de la copulation, (formation du signe de fécondation par décollement des plaques chitineuses du bulbe d'avec l'endophallus membraneux et séparation du couple) s'effectue de façon passive par persistance de la pression à l'intérieur de l'endophallus (WoYke et RutTNER, 1958). Le mâle est, à ce moment, déjà sans vie, et, d'ailleurs, dans tout l'endophallus il n'y a ni musculature ni innervation.

\section{SUMMARY}

\section{STRUCTURE AND FUNCTION OF THE PERIPIERAL NERVOUS SYSTEM OF THE DRONE GENITAL APPARATUS}

$I^{0}$ By means of a modified method of methylene blue vital staining the peripheral nervous sys-

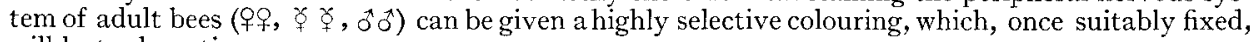
will last a long time.

$2^{\circ}$ All over the integument of the abdomen there are hair and membrane sensilla, and besides 
- mainly in hairless parts - multipolar cells with free ends. 'Two types of hair sensilla occur (with one or with several sensory nerve cells), which also differ in the structure of the hair. Plurineuronal hair sensilla are found in fairly large numbers only in the sternites of worker bees; they are entirely lacking in the queen. Membrane sensilla are, for the most part, exposed pores covered by a flat membrane with the distal process of a sensory nerve cell terminating in their centre. Structurally they resemble the thin-walled peg organs; they are called sensilla basiplana.

$3^{\circ}$ The neurites of the sentry nerve cells form a subdermic plexus in which associatve, multipolar nerve cells have a considerable share. Between nerve cells and nerve fibres there are plasmatic and synaptic connections. As a whole, this plexus can be interpreted as a dermal nervous system arranged segmentally and having a sensory function; its structure, however, is altogethèr different from the "Ilautnervensystem der Arthropoden " described by 'Tonner in I 936 and not corroborated since. 'The dermal nervous systems is most fully developed in the queen. Bombus has a subdermic plexus structurally very similar to that of Apis; in Vespa, on the other and, the neurites of the nervous cells run centripetally without associative connections.

$4^{\circ}$ Drones possess a "genital sense field" which receives tactile and (possibly) chemical stimuli. It is described as a multicellular plexus under the penis valves (aedeagal sclerites) and a ganglion on the parameres; both are connected with numerous hair and membrane sensilla. There is no scent gland on the lamina parameralis.

There are other hymenoptera in which the sclerites of the ectophallus have been developed as receptore organs.

$5^{\circ}$ On the anal plate of the proctiger there are besides hair sensilla a large number of thin-walled sensilla (possibly chemo-receptors) and a well-developed subdermic plexus.

The function of the anal plate as a cover of the anal aperture is described. of :

$6^{\circ}$ The nerve apparatus of the glandula mucosa is very highly developed in the male. It consists

a) a surface plexus with numerous ganglion cells threaded like a string of beads along peripheral nerves, (nerve cord system) or ending with multipolar processes in muscle fibres.

b) motory ends in the deep muscle layer; these are rich in plasma and arboreal, and they have accessory cells. This terminal form differs considerably from all other motory processes in the skeletal and visceral muscular system of the honcybee. It is suggested that this structural peculiarity serves to reduce the speed of transmission. "The fact that invariably mucus is ejected only after the sperm could be explained by this delay of stimulation.

$7^{\circ}$ 'The musculus tensor glantulae mucosae is situated between the pole of the caudal mucous gland and the aedeagal apodeme; as it contracts, the vas deferens is extended and ist covering membrane ruptured giving free egress to the sperm.

$8^{\circ}$ Ideas on the function of the male genital apparatus suggested by the position and structure of the receptor organs round the phallotrema and of the plexus of the mucous gland are discussed. It appears clear beyond all doubt that, as with other hymenoptera, the drone must at the beginning of copulation be above the queen.

\section{BIBLIOGRAPHIE}

Alexandrowicz J. S., I957. Notes on the nervous system in the stomatopoda. V. The various types of sensory nerve cells. Publ. Staz. Napoli, 29, 21,3-225.

Avrrum H., StumpF II., I950. J)as Bienenaure als Analysator für polarisiertes Licht. Z. Naturforsch., 56, ІІ6-І 22 .

Burpexbrock W. V., r953. Verglcichende I'hysiologrie. Band 2 : Nervenphysiologie. Birkhäuser Verlag, Basel - Stuttgart.

Frisci K. v., I949. Die Polarisation des fimmelslichtes als orientierender Faktor bei den Tänzen der Bienen. Experientia 5, 142-148.

Fy: W., I 943. Experimentelle Untersuchungen über den Eilegeakt der Bienenkönigin. Mitt. Schreeiz. Entomol. Ges., XVIII, 493-521.

FYG W., r95r. Ueber die Vorgänge bei der natürlichen Begattung der Bienenkönigin. Schäeiz. Bstg., 74, I $56-17 \mathrm{r}$.

Goetze G., I940. Die leste Bienc. Licdloff, Loth \&o Michaclis, Leipzig.

GoETzE G., SchMidT II., I942. Ein neues I)uftorgan der männlichen Ilonigbiene und seine Bedeutung für die Systematik der Bienenrassen. Zool. Jahrb. (Sy'st.), 75, 337-348.

Hanstroey B., I928. Vergleichende Anatomie des Nervensystens der wirbellosen Tiere. Springer Verlag, Berlin.

JANET Ch., I9I I. Sur l'existence d'un organe chordotonal et d'une vesicule pulsatile antennaires chez l'Abeille et sur la morphologie de la tête de cette espèce. Extr. Compt. Acal. Sci., 152, I Io-I 13.

IIODGson E. S., RoEder K. D., I 955. Electrophysiological analysis of function of primary chemoreceptor unit. Science (Lancaster), 122, 4I 7-, I 8 .

Kirsche W., I 960 . Die Neuronentheorie. Geschichtlicher Ueberblick und heutiger Stand. Münch. med. Wochenschrifl, 102/48, 2 266-2 274 . 
Kuwabara M., Tukeda K., I956. On the hygroreceptor of the honeybee. Phys. Ecol., 7, I-6 (Japan., engl. Resümee)

Lecomte J., 1958. Que savons-nous du comportement des faux bourdons? Ann. Abeille, 1, 31-39.

Lindauer M., Nedel J. O., 1959. Ein Schweresinnesorgan der IIonigbiene. Z. vergl. Physiol., 42, 334-364.

Meyer G. F., r955. Vergleichende Untersuchungen mit der vitalen Methylenblaufärbung am Nervensystem wirbelloser Tiere. Zool. Jahrb. (Anat.), 74, 339-400.

Nedel J. O., I960. Morphologie und Physiologic der Mandibeldrüse einiger Bienen-Arten (Apidae). $Z$. Morph. Ökol. Tiere, 49, I $39-183$.

Power M. E., I948. The thoraco-abdominal nervous system of an adult insect, Drosophila melanogaster. J. comp. Neur., 88.

Rogozina M., I928. Ueber das periphere Nervensystem der Aeschnalarve. Z. Zellorschg., 6, 732-738.

RutTner $1 \%$, 1957 . Die Sexualfunktionen der Honigbienen im Dienste ihrer sozialen Gemeinschaft. Z. vergl. Physiol., 39, $577-600$.

RutTNle F,, I960. Fortpflanzung und Vererbung. In Büdel, A., Herold E., Biene und Bienenzuch. Ehrenwirth Verlag, München.

RutTier F., ro6r. Die Imnervation der Fortpflanzungsorgane der Ionigbiene. Z. Bienenforsch., 5, $253-266$. S̈HABADAsci A., r93o. Untersuchungen zur Methodik der Methylenblaufärbung des vegretativen Nervensystems. Z. Zelliorsch., 10, 221-2.43.

Sciabadascil A, 1930. Zur Theorie und Praxis des Fixierens der Methylenblaufärbung des Nervensystems. Z. Zellforsch., 10, $244^{-2} 53$.

Scineider D., KaIssline K. E., 1957. Der Bau der Antenne des Seidenspinners Bombyx mori L. II. Sensillen, cuticulare Bildungen und innerer Bau. Zool. Jahrb. (Anat.), 76, $223-250$.

SNovgkass R. E., I941. The male genitalia of IIymenoptera. Smiths. Hisc. Coll., 99/14, 1-86.

Snodgrass R. E., I956. Anatomy of the honey bee. Comstock Publ., Ithaca, New-York.

Spatz H., 1952. Nissi und die theoretische Hirnanatomie. Mühch. med. Wochenschrift, 94, I-7.

TonNer F., I933. Lin Beitrag zur Anatomie und Physiologie des peripheren Nervensystems von Astacus fluviatilis. Zool. Jahrb. (Anat.), 53, IоI-I52.

Tonnier F., I936. Das Hautnervensysten der Arthropoden. Lool. Anzeiger, 113, 125-136.

Weblк H., I933. Lehrbuch der Entomologie. G. Fischer Verlag, Jena.

Woyke J., 1955. Effect of flying on the sexual stimulation of drones (polnisch). Pszczelarstwo, 6, I-3.

WOYke J., RUTTNer F., I958. An anatomical study of the mating process in the honeybee. Bee World, $39,3-18$.

ZaNi) E., I95r. Der Bau der Biene. 4. Aullage. E. Ulmer Verlag, Stuttgart. 